\title{
Initial Studies of Pretreatment Methods for Neutralized Cladding Removal Waste (NCRW) Sludge
}

J. L. Swanson

June 1991

Prepared for the U.S. Department of Energy under Contract DE-AC06-76RLO 1830

Pacific Northwest Laboratory Operated for the U.S. Department of Energy by Battelle Memorial Institute 


\title{
DISCLAIMER
}

This report was prepared as an account of work spons.ored by an agency of the United Stayes Government. Neither the United States Government nor any agency

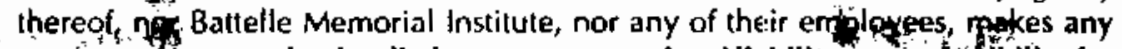
warranty, expressed or implied, or assumes any legal liability or respón sibility for the accuracy, completeness, or usefulness of any iniormation, apparatus, product, or process disclosed, or represents that its use would not infringe privately owned rights. Reference herein to any specific commercial procluct, process, or service by trade name, trademark, manufacturer, or otherwise does not necessarily constitute or imply its endorsernent, recommendation, or favor ng by the United States Government or any agency thereof, or Battelie Memorial Institute. The views and opinions of authors expressed herein do not necessarily state or reflect those of the United States Government or any agency thereof.

\author{
PACIFIC NORTHWEST LABORATORY \\ operated by \\ BATTELLE MEMORIAL INSTITUTE \\ for the \\ UNITED STATES DEPARTMENT OF ENERGY \\ under Contract DE-AC06-76RLO 1830
}

Printed in the United States of America

Available to DOE and DOE contractors from the

Ofifice of Scientific and Technical Information, P.O. Box 62. Oak Ridge, IN 37831; prices available from (615) 576-8401. FTS 6:26-8401.

Availahle to the puhlic from the National Technica! Information Service, U.S. Department of Commerce, 5205 Port Royal Rd., Springfield, VA 22161. 
INITIAL STUDIES OF PRETREATMENT METHODS FOR NEUTRALIZED CLADDING REMOVAL WASTE (NCRW) SLUDGE

J. L. Swanson

June 1991

Prepared for the U.S. Department of Energy under Contract DE-ACO6-76RL0 1830

Pacific Northwest Laboratory

Richland, Washington 99352 
.

-

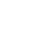




\section{SUMMARY}

Pacific Northwest Laboratory (PNL) is performing conceptual and experimental studies for Westinghouse Hanford Company (WHC) aimed at determining the effectiveness of various pretreatment methods for the neutralized cladding removal waste (NCRW) sludge currently being stored at the Hanford Site of the U.S. Department of Energy (DOE). The objective of such pretreatment methods is to separate the transuranic (TRU) elements and the bulk components of the waste (primarily zirconium, sodium, fluoride, and hydroxide) to a level low enough that the bulk components can be disposed of as low-level waste (LLW), with only a small volume, TRU-containing fraction requiring geologic disposal. This objective is driven primarily by the large cost differential projected between LLW and geologic disposal procedures.

This report contains the results of the first three years $(1987,1988$, and 1989) of the program. These results were earlier reported informaliy in letter reports; they are here compiled in appendix form in this formal report to be more readily available to other workers and the public. The results of work done in 1990 and in following years will be reported in separate formal reports.

Some information was deleted from the original reports because the sources had not been cleared for public release. None of these deletions contained information that was inconsistent with the conclusions, and the conclusions presented in this document have not been changed. With that exception, the reports are presented in essentially the form that they were first written. This was done in the interests of maintaining historical accuracy and of saving time and money.

The first year's work gave results indicating that selective leaching of the TRUs away from the bulk components might be feasible and simpler to perform than separation based on sludge dissolution followed by removal of TRUs by the transuranic extraction (TRUEX) process or by carrier precipitation with lanthanum fluoride. The selective leaching approach was investigated more extensively in the second year but was found to be impractical. In the third year, the effort was centered on the sludge dissolution plus TRUEX solvent 
extraction approach, and very promising results were obtained. Two reports were written that year; the first concentrated on completeness of sludge dissolution and on solvent extraction. The second report focused on issues such as off-gas composition and the properties of residue that did not dissolve in the dissolution step. 


\section{CONTENTS}

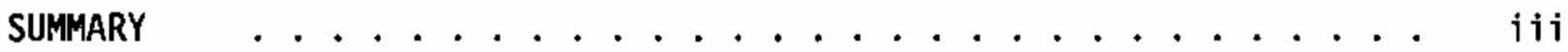

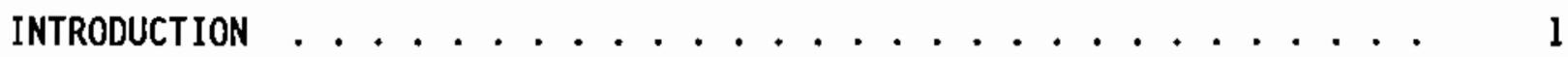

APPENDIX A--LETTER REPORT ON NCRW TRU SEPARATION PROGRESS . . . . A.1

APPENDIX B--SELECTIVE LEACHING OF PU AND AM FROM NCRW SLUOGE . . . . B.1

APPENDIX C--TRUEX PROCESSING OF NCRN SLUDGE, STATUS REPORT . . . . . C.I

APPENDIX D--TRUEX PROCESSING OF NCRW SLUDGE, PROGRESS REPORT . . . . D.I 


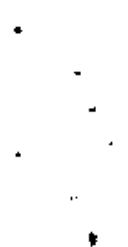




\section{INTRODUCTION}

One of the unique types of radioactive waste currently being stored at Hanford is neutralized cladding removal waste (NCRW) sludge. This sludge contains large amounts of zirconium and sodium compounds, primarily hydroxides and fluorides, with smaller amounts of potassium, nitrite, and other materials. It also contains uranium, the transuranics (TRUs) plutonium and americium, and a mixture of fission products typical of the nonvolatiles present in the irradiated reactor fuel.

This waste arose as a result of the method used to process the Zircaloy clad, metallic uranium fuel elements that were irradiated in $\mathrm{N}$ Reactor at Hanford. That method involved dissolution of the cladding in ammonium fluoride solution followed by a separate dissolution of the uranium in nitric acid. Because the ammonium fluoride solution also attacked the uranium, a portion (generally $-3 \%$ ) of the uranium (and its contained TRUs and fission products) dissolved in the decladding step along with the Zircaloy. Most of the reacted uranium and TRUs were recovered as fluoride precipitates, which were metathesized to hydroxide precipitates before the acid dissolution step. The metathesis was done to lower the amount of fluoride in the dissolved uranium solution.

The spent decladding and metathesis solutions ( $p$ lus the subsequent rinse solutions) were then adjusted for storage in underground, carbon steel-1ined tanks. To protect these tanks against corrosion, this adjustment involved raising the $\mathrm{pH}$ with sodium hydroxide solution and adding nitrite ion (as the sodium salt). These additions led to the precipitation of zirconium hydroxide and sodium fluoride compounds, which then formed a sludge layer in the underground tank. Supernate solution was periodically removed from above the settled sludge and then transferred to other tanks to make room for additional sludge. The NCRW sludge in its current form thus contains only portions of the soluble or partially soluble components that were added (e.g., sodium, fluoride, hydroxide, nitrite) along with all of the insoluble components (e.g., zirconium, plus small fractions of the uranium and TRUs that were not recovered in the decladding and metathesis operations). 
The concentration of TRU elements in this sludge gives an alpha activity of $-10^{3} \mathrm{nCi}$ per gram sludge, which is too high to allow this waste to be disposed of as low-level waste (LLW). Disposal of this waste in a geologic repository would be more costly than disposal as LLW. Thus, an incentive exists to treat this waste to separate the TRUs for the bulk components so that the buik components can be disposed of as LLW (e.g., in a grouted form), with only a small volume, TRU-containing fraction requiring geologic disposal (e.g., in a vitrified form).

To study the feasibility of various methods to accomplish such a separation of the TRUs from the bulk components of NCRW sludge, Westinghouse Hanford Company (WHC) has provided support to Pacific Northwest Laboratory (PNL) ${ }^{\text {(a) }}$ for an experimental program to determine the effectiveness of various methods.

(a) Pacific Northwest Laboratory is operated by Batte1le Memorial Institute for the U.S. Department of Energy under Contract DE-AC06-76RLO 1830. 
APPENDIX A

LETTER REPORT ON NCRW TRU SEPARATION PROGRESS 


\section{A LETTER REPORT FOR WESTINGHOUSE HANFORD COMPANY}

\section{LETTER REPORT ON NCRW TRU SEPARATION PROGRESS}

J. L. Swanson

September 1987

Prepared for

the U.S. Department of Energy

under Contract DE-ACO6-76RLO 1830

Pacific Northwest Laboratory

Richland, Washington 99352 


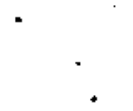

. 
September 30,1987

\author{
Mr. Mark W. Gibson, Staff Engineer \\ Waste Management Systems Engineering \\ 2750E Building, 200E Area \\ Westinghouse Hanford Company \\ Richland, WA 99352 \\ Dear Mark,
}

SUBJECT: RESULTS TO DATE ON SEPARATION OF PU AND Am FROM Zr IN NCRW SLUDGE

This letter contains an abbreviated description of the results that we obtained for you in FY 1987 in the subject area. In some experiments, data collection and analysis are not complete; this letter presents the status as of 9-30-87. We are hopeful that the additional funding expected in FY 1988 will be forthcoming so that we can examine some of the areas in more detail. I feel that we have come quite a long way already, and that there are some very promising areas to pursue in more depth. These areas involve selective leaching of the Pu and Am away from the $\mathrm{Zr}$; this may be feasible using dilute nitric acid alone and can be made even better by the use of certain oxidative conditions.

\title{
SUMMARY
}

Scouting studies were conducted to address several issues regarding potential processing schemes for NCRW sludge, using a composite of waste samples taken from different depths in Tank 105-AW. These issues, and a brief statement of the results to date, are as follows:

1) Completeness of fluoride removal on washing with water. Two water washes at $3.3 \mathrm{~mL} \mathrm{H} 20 / 9$ sludge removed $97 \%$ of the fluoride.

2) Separation of Pu and Am solids from $\mathrm{Zr}$ solids by differences in settling rates. Results of one test indicate this approach is not feasible.

3) Selective leaching of $\mathrm{Pu}$ and Am away from $\mathrm{Zr}$ in the sludge. Leaching with nitric acid alone easily gives near-complete Am leaching, 
but Pu leaching is limited to $-60 \%$; with low concurrent $\mathrm{Zr}$ dissolution, this may give barely adequate selective leaching of TRU elements to meet a $50 \mathrm{nCi} / \mathrm{g}$ target in a final grout waste form. One test indicated that the use of $\mathrm{Ag}$ (II) oxidant at $100^{\circ} \mathrm{C}$ gives sufficiently enhanced Pu leaching; $~ 93 \%$ Pu and $\sim 98 \%$ Am removal accompanied by probably $<15 \% \mathrm{Zr}$ removal was achieved. Other conditions and oxidants (and reductants) tested gave no beneficial effect. Complexants also offer no apparent benefit over simple nitric acid leaching.

4) Complete dissolution of the sludge. Essentially complete dissolution was achieved with $3.2 \mathrm{~mL}$ of $5 \mathrm{M} \mathrm{HNO}_{3}$ per gram of unwashed sludge. Complete dissolution is much more difficult if the sludge is first washed to remove fluoride.

5) Separation of dissolved Pu, Am, and $\mathrm{Zr}$ by TRUEX extraction or by $\mathrm{LaF}_{3}$ precipitation. $\mathrm{Zr}$ tends to extract along with $\mathrm{Pu}$ and $\mathrm{Am}$, so considerable development might be required to develop a suitable TRUEX process. $\mathrm{LaF}_{3}$ does not efficiently carry $\mathrm{Pu}$ and Am from a dissolved sludge solution until the fluoride concentration has been increased by a large amount.

\section{FEED FOR THE STUDY}

The NCRW sludge used in all of our studies to date was a composite of portions of some of the samples taken earlier from Tank 105-AW. Analytical results for these samples were reported in a 2-2-87 letter to L. M. Sasaki of Rockwell Hanford from A. C. Leaf and J. J. McCown of Westinghouse Hanford. The quantities used in our composite, and the Pu and Am concentrations reported for each portion are given in Table 1.

It should be noted that a portion of segment $6 \mathrm{~B}$ was intentionally included in our composite because of its high Am content. I have been told that this segment came from the sludge heel present in the tank before NCRW addition was begun. Thus, $-74 \%$ of the Am and $25 \%$ of the $\mathrm{Pu}$ in our composite came from the tank heel rather than from NCRW. This fact makes the quantitative application 
of our results to other tanks containing NCRW sludge of questionable validity. The processes that look the best with the sludge from Tank 105-AW should be tested on other such sludges.

\section{MAJOR CATIONS IN NCRW SLUDGE COMPOSITE}

Samples of unwashed sludge dissolved nearly-completely in $\sim 5 \mathrm{M} \mathrm{HNO}_{3}$. The undissolved solids remaining were small in quantity and tended to float on the liquid. These solids were not characterized further.

Table 2 contains the results of ICP analyses of solutions obtained by dissolving several portions of the sludge composite used in this work. Sodium and zirconium were the dominant cations found.

\section{TRANSURANIC ELEMENTS IN NCRW SLUDGE COMPOSITE}

Analysis of one solution (NCRN-2) obtained by dissolution of the NCRW sludge composite in $5 \mathrm{M} \mathrm{HNO}_{3}$ by the 325 Building analytical laboratory showed the composite to contain ${ }^{239+240} \mathrm{Pu}$ at a level of $582 \mathrm{nCi} / \mathrm{g}$ sludge and ${ }^{241_{\mathrm{Am}} \text { at a }}$ level of $526 \mathrm{nCi} / \mathrm{g}$. These values are in reasonable agreement with the values of 652 and 449 calculated for the composite from previous analyses (Table 1). In most of our work with the sludge composite, we mounted and did alpha energy analysis (AEA) on the samples ourselves so that we could get the results rapidly. We generally then considered the results in terms of "percent removed" or "percent remajning," relative to the $\mathrm{c} / \mathrm{m}, \mathrm{g}$ sludge value we found in our laboratory in the solution from NCRW-2; those values are $13.7 \times 10^{4} \mathrm{Pu}$ $\mathrm{c} / \mathrm{m}, \mathrm{g}$ sludge and $7.9 \times 10^{4} \mathrm{Am} \mathrm{c} / \mathrm{m}, \mathrm{g}$ sludge.

However, some variability was observed in these values when other portions of the composite were dissolved. In one case (NCRW-6), we found $12.4 \times 10^{4} \mathrm{Pu}$ $\mathrm{c} / \mathrm{m}, \mathrm{g}$ sludge and $8.6 \times 10^{4} \mathrm{Am} \mathrm{c} / \mathrm{m}, \mathrm{g}$ sludge; in another case (NCRW-17) we found $11.8 \times 10^{4} \mathrm{Pu} \mathrm{c} / \mathrm{m}, \mathrm{g}$ sludge and $7.7 \times 10^{4} \mathrm{Am} \mathrm{c} / \mathrm{m}, \mathrm{g}$ sludge. This variation gives an added uncertainty in evaluating the effectiveness of various leach procedures, but this should be of real importance only in cases where leaching approaches completeness. In such cases, the leached solids must be analyzed before the effectiveness of leaching can be accurately given. 


\section{PROCEDURES}

Most experiments used $-3 \mathrm{~g}$ of the NCRW sludge composite contained within glass vials. Washing and leach contacts were generally performed by shaking at room temperature. Contacts at $100^{\circ} \mathrm{C}$ were done by stirring the contents of the vial, which rested in a beaker of boiling water.

Solid/liquid separations were performed by centrifugation and by filtration, using filters having a $0.2-\mu \mathrm{m}$ pore size. Centrifugation was used for bulk separations (e.g., when removing a leach solution from the sludge) and filtration was generaliy used prior to sample dilution for analysis.

Alpha energy analyses and fluoride analyses were performed in our laboratory. Fluoride was determined with a specific ion electrode in a matrix containing a complexing agent to minimize interference from metal ions. Spike recovery methods were used to correct for such interference by metal ions; such corrections were seldom substantial. Cation concentrations were measured on the 325 Building shielded ICP.

\section{FLUORIDE REMOVAL FROM SLUDGE BY WATER WASHING}

The fluoride content of the NCRW sludge could be lowered to low levels by washing with water at room temperature. Results of experiments investigating this aspect of the study are summarized in Table 3.

At wash volumes tested below $3.3 \mathrm{~mL} / \mathrm{g}$ sludge, the concentration of fluoride found in the wash solution was constant at $-0.63 \underline{M}$. This constancy indicates that a sparingly-soluble fluoride salt is present in sufficient quantity that it is not completely dissolved by these amounts of water. This salt is thought to be NaF.

In two of the se experiments (NCRW-1 and NCRW-5), the water-washed sludge was subjected to acid leaching and to alkaline metathesis in an effort to ensure that all fluoride was released from solids so it could be analyzed. The amount of fluoride remaining in the sludge after water washing was $-6 \%$ of the total in NCRW-1 and $-3 \%$ in NCRW-5. Based on the dramatic decrease in fluoride concentrations between the second water wash and the acid leach in NCRW-5, it does not appear likely that significantly more fluoride would have been removed by an additional wash. 
The agreement between the total fluoride found $(-0.0466 \mathrm{~g} / \mathrm{g}$ sludge) in NCRW-1 and NCRW-5 is exceptionat. However, other values do not agree quite as well; $0.0459 \mathrm{~g} \mathrm{~F}^{-} / \mathrm{g}$ sludge was found in water washes in NCRW-10 and $0.039 \mathrm{~g} \mathrm{~F}^{-} / \mathrm{g}$ sludge was found in an experiment (NCRW-17) when the sludge was dissolved in 4 $\underline{\mathrm{MNO}} \mathrm{H}_{3}$. Even at that, the overall agreement of all these data is thought to be quite good.

The fluoride contents listed above, and the zirconium contents given in Table 2 yield values of the fluoride-to-zirconium mole ratio in the NCRW sludge composite ranging from 2.9 to 3.8 .

\section{SEPARATION OF PU AND AM SOLIDS FROM Zr SOLIDS BY SETTLING}

A simple experiment was done to assess the feasibility of separating Pu and Am solids from $\mathrm{Zr}$ solids by differences in settling rate. A sludge/water suspension was shaken, allowed to settle for 10 minutes, and the top $~ 35 \%$ of the mixture was removed for analysis. This top portion was found to contain $36 \%$ of the $\mathrm{Pu}, 30 \%$ of the Am, $34 \%$ of the $\mathrm{Zr}, 31 \%$ of the $\mathrm{Fe}$, and $36 \%$ of the $\mathrm{Na}$. These results demonstrate that little, if any, separation occurred in the experiment and indicate that there is very little chance of successfully separating $\mathrm{Pu}$ and Am solids by differences in settling rate.

\section{SELECTIVE LEACHING OF PU AND Am USING HNO 3 ALONE}

Portions of the NCRW sludge composite that had been washed to remove the bulk of the fluoride were contacted with different concentrations (and amounts) of nitric acid and the amounts of $\mathrm{Am}, \mathrm{Pu}$, and $\mathrm{Zr}$ that dissolved were determined. Results are shown in Figure 1, where the amounts found in filtrates of the solutions (relative to those found in the NCRW-2 complete dissolution experiment) are plotted as a function of the ratio of moles $\mathrm{HNO}_{3}$ added-to-moles $\mathrm{Zr}$ in the sludge (also based on that found in NCRW-2).

The Am leach data were quite scattered, but also quite high ( $-90 \%$ Am leached on the average). Pu leaching increased with the $\mathrm{HNO}_{3}$-to- $\mathrm{Zr}$ ratio up to -5 , $\mathrm{HNO}_{3} / \mathrm{Zr}$, and then leveled off (at $-60 \%$ Pu leached). At a $\mathrm{HNO}_{3}$-to- $\mathrm{Zr}$ ratio of $\sim 3$, optimum separation of $\mathrm{Pu}$ from $\mathrm{Zr}$ was achieved at $\sim 50 \% \mathrm{Pu}$ leached and $-5 \%$ Zr leached. 
These data indicate that both the $\mathrm{Pu}$ and the $\mathrm{Zr}$ are present as more than one species, having different ease of dissolution characteristics. Among the many possible reasons for this is an aging effect; many solids become more difficult to dissoive as they age over time. In this regard, it should be mentioned that the leach data collected now should not provide the sole basis for a process to be implemented many years in the future. Additional studies should be done later to see if aging effects are indeed important.

These data demonstrate that adequate selective leaching of $\mathrm{Pu}$ and Am away from the $\mathrm{Zr}$ may indeed be possible using $\mathrm{HNO}_{3}$ alone. Dissolution of $60 \%$ of the $\mathrm{Pu}$, $100 \%$ of the $\mathrm{Am}$, and $0 \%$ of the $\mathrm{Zr}$, results that may be approachable according to the data of Figure 1 , would leave $-230 \mathrm{nCi} / \mathrm{initial}^{\mathrm{g}}$ sludge associated with the $\mathrm{Zr}$ fraction. This value would meet the target of $243 \mathrm{nCi} / \mathrm{g}$ required to give $50 \mathrm{nCi} / \mathrm{g}$ in grout, based on a likely grout formulation.

It would, of course, be highly desirable to increase the selective leaching of $\mathrm{Pu}$ from $\mathrm{Zr}$ so that some degree of processing flexibility would be available. Attempts to accomplish this by the use of oxidizing agents and by the use of complexants will be discussed in subsequent sections. The likely difficulty in accomplishing this is partially illustrated by the note on Figure 1 regarding the $5 \mathrm{M} \mathrm{HNO}_{3}$ leach case; that is, a $\mathrm{HNO}_{3}-\mathrm{HF}$ step following two $5 \mathrm{M} \mathrm{HNO}_{3}$ Teaches dissolved $28 \%$ of the $\mathrm{Pu}$ and $12 \%$ of the $\mathrm{Zr}$. This indicates that an appreciable portion of the $\mathrm{Pu}$ is indeed quite difficult to dissolve in $\mathrm{HNO}_{3}$ alone.

More detailed (but still not complete) results from a key acid leaching experiment (NCRW-15) are given in Table 4. There the quantities found in various stages of the leach and dissolution processes, relative to those found in complete dissolution experiment NCRW-2, are tabulated. The sludge sample

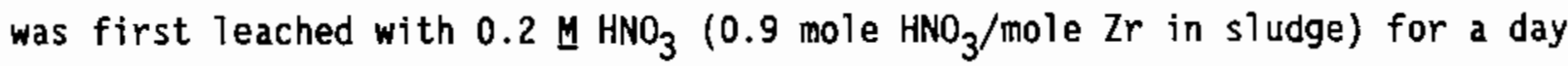
at room temperature and then the added $\mathrm{HNO}_{3}$ concentration was increased to $0.4 \mathrm{M}$. This solution was sampled after another day at room temperature and then again a day later. The mixture was then stirred for 2 hours at $100^{\circ} \mathrm{C}$ and was then sampled as soon as possible and again after shaking for another day at room temperature. The centrate and the suspended solids it contained were removed, mixed, and sampled for analysis. 
A second leach was then performed with $0.4 \mathrm{M} \mathrm{HNO}_{3}$, first at room temperature for a day, and then at $100^{\circ} \mathrm{C}$ for 2 hours. Various additions to this solution were then made in an effort to completely dissolve the sludge so that material balance measurements could be made.

Key points of the data from this acid leaching experiments include:

1) Leaching was no more extensive after 2 days at room temperature than it was after 1 day.

2) Leaching at $100^{\circ} \mathrm{C}$ gave a significant improvement over Teaching at room temperature, in the first leach solution at least. This phenomenon should be investigated more fully before a definite conclusion is drawn, however.

3) Centrifugation was effective in settling only part of the solids. It is important to note that the presence of 1 ight, floaty solids in our experiments with this NCRW sludge composite was the rule, rather than the exception. Some of these solids tended to remain on the surface of the solutions, even after centrifugation. In that regard, some such solids would have been removed with the water washes that preceded the leach contracts; however, tests indicated that those solids contained little, if any, Pu or Am. The problem of difficultly separable solids could be very important on the scale required for process implementation.

4) The second $0.4 \mathrm{MHNO}$ leach solution was much less effective in removing Pu than was the first. It brought the total Pu removed up to near the $60 \%$ level that seems to be the maximum achievable by acid leaching (Figure 1).

5) The addition of fluoride to the second leach solution gave a marked increase in $\mathrm{Pu}$ leaching. However, it is likely that it also gave a marked increase in $\mathrm{Zr}$ dissolution so that selective leaching was not improved. The use of fluoride in leaching will be discussed more in the section on the use of complexants.

6) More Am was found on leaching this sample of the composite than had been found in any of the samples that were completely dissolved; the 
total amount in this sample was $\geq 138 \%$ of that found in complete dissolution experiment NCRW-2. This is a good illustration of the need to dissolve the residue left after leaching in order to give an accurate determination of the amount leached. Perhaps the sample used in NCRW-15 contained an abnormally high portion of the high Am sludge segment (6B) that was included in the composite (or, perhaps, all of the Am did not dissolve in the complete dissolution experiments).

\section{SELECTIVE LEACHING USING OXIDANTS AND REDUCTANTS}

Several oxidants and reductants were tested (in nitric acid solution) in an effort to improve the selective leaching of $\mathrm{Pu}$ from $\mathrm{Zr}$ with washed NCRW sludge. One oxidant, permanganate, was also tested in bicarbonate solution. In only one case (silver-catalyzed persulfate oxidation in nitric acid solution) did there appear to be an appreciable effect. The results of these tests are summarized in Figure 2, where the percentages of $\mathrm{Pu}$ leaching (and, in some cases, $\mathrm{Zr}$ leaching) are plotted as a function of the ratio of moles $\mathrm{HNO}_{3}$ added-to-moles $\mathrm{Zr}$ in the sludge. The lines on Figure 2 represent the results obtained in the absence of oxidant or reductant (Figure 1); an enhanced selective leaching is indicated by a $\mathrm{Pu}$ value above the line while the corresponding $\mathrm{Zr}$ value remains at (or near) the 1 ine.

Solutions that gave essentially no increased $\mathrm{Pu}$ leaching were: $0.07 \mathrm{M}$ HAN in $0.2 \underline{\mathrm{M}} \mathrm{HNO}_{3}, 0.03 \mathrm{M} \mathrm{KMnO}{ }_{4}$ in $0.2 \underline{\mathrm{M}} \mathrm{HNO}_{3}, 0.012 \mathrm{M} \mathrm{Ce}$ (IV) in $0.3 \mathrm{MNO}_{3}, \sim 0.2 \underline{\mathrm{M}}$ $\mathrm{H}_{2} \mathrm{O}_{2}$ in $0.4 \mathrm{M} \mathrm{HNO} \mathrm{H}_{3}$ (at $100^{\circ} \mathrm{C}$ ), and $0.02 \mathrm{M} \mathrm{Ce}$ (IV) in $0.56 \mathrm{M} \mathrm{HNO}_{3}$. However, with $0.02 \underline{\mathrm{Mg}}+0.1 \underline{\mathrm{M} \mathrm{S}} \mathrm{O}_{8}=$ in $0.4 \underline{\mathrm{M}} \mathrm{HNO}_{3}$, a significant improvement was achieved; $-57 \%$ Pu leaching compared to $-40 \%$ Pu leaching expected for $\mathrm{HNO}_{3}$ alone at that $\mathrm{HNO}_{3}$-to- $\mathrm{Zr}$ ratio. As expected, $\mathrm{Zr}$ leaching was not affected by the oxidant; $\sim 3 \%$ of the $\mathrm{Zr}$ was found in the silver persulfate solution, in agreement with the amount leached into $\mathrm{HNO}_{3}$ alone.

The silver persulfate experiment (NCRW-20) was more extensive, and a] so more promising, than indicated by the initial leach results shown in Figure 2. A second leach with fresh silver nitrate/potassium persulfate was also performed, and the leached solids were then rinsed with $0.2 \mathrm{M} \mathrm{HNO}_{3}$ before being dissolved in $5 \underline{\mathrm{M} \mathrm{HNO}} 3+0.7 \underline{\mathrm{MNH}} \mathrm{H}_{4} \mathrm{~F}$. The currently available results from this 
experiment are summarized in Table 5; the results are presented both as the percentages of the amounts found in complete dissolution experiment NCRW-2 and as percentages of the total amounts found in this experiment (the total amounts of $\mathrm{Pu}$ and $\mathrm{Am}$ found here were $87 \%$ and $103 \%$, respectively, of the amounts found in NCRW-2).

The key result of this experiment is that the two silver/persulfate leaches (plus a rinse) removed all but $\sim 7 \%$ of the Pu and $\sim 2 \%$ of the Am from the sludge. Zirconium data are still incomplete, but those that are available indicate that probably $<15 \%$ accompanied the leach and rinse solution. These results are very promising indeed.

The second silver/persulfate leach solution removed small, but significant, additional increments of $\mathrm{Pu}$ and $\mathrm{Am}$ even though a second heating of the first solution had not given increased leaching. This suggests that all of the persulfate may have been consumed in the first heating of the first leach solution. This possibility should be addressed in process optimization tests before a silver/persulfate process is actually defined.

Another potentially important factor is that more $\mathrm{Zr}$ dissolved in the second leach than in the first leach even though the conditions were the same. The reason for this is not known.

It may also be important to note that the (remixed) centrate samples contained essentially the same amounts of $\mathrm{Pu}, \mathrm{Am}$, and $\mathrm{Zr}$ as the corresponding filtrates, which is in contrast to the behavior observed in nitric acid leaching (Table 4). This may mean that solid/liquid separations are more efficient after silver/persulfate digestions, which would be a second beneficial result of such a treatment.

The success of silver/persulfate in improving the selective leaching of $P u$ from $\mathrm{Zr}$ in NCRW sludge prompted testing of another procedure involving $\mathrm{Ag}$ (II) as oxidant. Because $\mathrm{Ag}$ (II) has a limited lifetime in aqueous solutions, especially at low acidities as must be used in this application to minimize $\mathrm{Zr}$ dissolution, an experiment (NCRW-23) was done in which the sludge was leached with $-0.1 \mathrm{M} \mathrm{AgNO}_{3}$ in (initially) $0.2 \mathrm{M} \mathrm{HNO}_{3}$ (1.7 mole $\mathrm{HNO}_{3}$ added/mole $\mathrm{Zr}$ in sludge) in the anode compartment of an electrolytic cell, so that Ag(II) was 
continuously regenerated. This experiment was run for two hours (at room temperature); however, color observations indicated that 1 ittle, if any, $\mathrm{Ag}$ (II) was maintained in solution for the first half-hour.

The results of the electrolytic leaching experiment are not included in Figure 2 because the final $\mathrm{HNO}_{3}$-to-Zr ration is not known; this is because the acid content of the anode compartment evidently increased during the course of the run due to partial diffusion of more-concentrated acid from the cathode compartment and/or to the electrolytic production of some acid in the anode compartment. However, the relative amounts of $\mathrm{Pu}(40 \%)$ and $\mathrm{Zr}(9 \%)$ found in the leach solution are comparable to those found for simple $\mathrm{HNO}_{3}$ leaching at -3.3 mole $\mathrm{HNO}_{3}$ per mole $\mathrm{Zr}$ (Figure 1); this indicates that $\mathrm{Ag}$ (II) had no beneficial effect on the selective leaching of $\mathrm{Pu}$ from $\mathrm{Zr}$ in this experiment. The reason that $\mathrm{Ag}$ (II) did not affect $\mathrm{Pu}$ leaching in this experiment, as it did in the silver/persulfate experiment, is presumed to be due to the lower temperature of this experiment.

The total quantities of $\mathrm{Pu}, \mathrm{Am}$, and $\mathrm{Zr}$ found in this leach solution centrate, a rinse, and in the dissolved solids amounted to $96 \%, 126 \%$, and $88 \%$, respectively, of the amounts found in complete dissolution experiment NCRW-2. This is another instance of a higher-than-expected An content, as was found in a nitric acid leach experiment (Table 4), but not in the silver/persulfate Teach experiment (Table 5).

One likely undesirable effect of using an oxidant such as $\mathrm{Ag}$ (II) to enhance the selective leaching of $\mathrm{Pu}$ is that fission product ruthenium contained in NCRW sludge will almost certainly volatilize as $\mathrm{RuO}_{4}$, which would need to be trapped in some way. The radionuclide release aspect of this problem becomes less severe the longer the waste is stored before processing; ${ }^{106} \mathrm{Ru}$ has a half-life of 1 year, so $99.9 \%$ of it will decay in 10 years.

\section{SELECTIVE LEACHING USING COMPLEXANTS}

Several complexants were also tested in an effort to improve the selective leaching of Pu from $\mathrm{Zr}$ with washed NCRW sludge, but none gave any improvement over what could be achieved with dilute $\mathrm{HNO}_{3}$ alone. These results are summarized in Table 6. 
Neither carbonate nor bicarbonate solution gave $>1 \% \mathrm{Pu}$ dissolution. With CMPO-saturated nitric acid, the extent of Pu dissolution was the same as with nitric acid alone. More Pu was dissolved with DTPA, but the Pu:Zr separation factor was comparable to that obtainable with nitric acid solutions. This was al so the case with $0.1 \mathrm{M} \mathrm{F}+\mathrm{HNO}_{3}$.

The DTPA system was investigated further by performing a second DTPA leach on the same sludge. Only $1 \%$ more $\mathrm{Pu}$ was leached during an overnight contact at room temperature with the fresh solution. This was increased to $10 \%$ by contacting for 2 hours at $100^{\circ} \mathrm{C}$, but the solution then also contained $5 \%$ of the Zr. Thus, DTPA-leaching does not appear to provide a practical approach. The selection of DTPA as the chelating agent to be tested was based on the recommendation of $\mathrm{J}$. L. Ryan of PNL, who performed a brief review of the possible applicability of chelating agents for the selective leaching of $\mathrm{Pu}$ and Am from $\mathrm{Zr}$ in NCRW sludge. This review led to the conclusion that the best (thermodynamic) chance of success was with highly multidentate chelators (such as DTPA) in which greater stearic hindrance might be expected in coordinating a given large number of 1 igand sites to $\mathrm{Zr}$ than in coordinating the same number of sites to $\mathrm{Am}$ or $\mathrm{Pu}$, thus increasing the likelihood of the desired selective leaching.

\section{COMPLETE DISSOLUTION OF SLUDGE IN HNO}

If the TRU elements could not be selectively leached from the $\mathrm{Zr}$ in NCRW sludge, it might be necessary to dissolve the sludge so that the separation could then be accomplished (e.g., by TRUEX extraction of $\mathrm{LaF}_{3}$ scavenging). The results of one experiment (NCRW-6) addressing this matter are summarized in Table 7. It is seen that $3.5 \mathrm{~mL}$ of $3 \mathrm{M} \mathrm{HNO}_{3}$ per gram of sludge did not give complete dissolution, but that $3.8 \mathrm{~mL}$ of $5 \underline{\mathrm{M} \mathrm{HNO}} \mathrm{H}_{3}$ per gram of sludge did give essentially complete dissolution. Other data (Table 2) indicate that $3.2 \mathrm{~mL}$ of $5 \mathrm{HNO}_{3}$ per gram of sludge is sufficient.

These results were obtained with unwashed sludge, so that appreciable fluoride ion was present. Fluoride (or possibly another complexant) appears to be necessary to achieve complete dissolution, as indicated by the low $\mathrm{Zr}$ dissolution observed in the absence of fluoride (Figure 1). 


\section{SEPARATION OF DISSOLVED PU, AM, AND Zr BY TRUEX EXTRACTION}

A few tests were performed to scout the applicability of extracting Pu and Am away from $\mathrm{Zr}$ in a solution obtained by dissolving NCRW sludge. It was found that the concentration of fluoride was not high enough to completely suppress Zr extraction, so that a good separation as not achieved; $65 \%$ of the $\mathrm{Zr}$ in a solution obtained by dissolving washed sludge extracted along with the $\mathrm{Pu}$ and Am, and $40 \%$ of the $\mathrm{Zr}$ in a solution obtained by dissolving unwashed sludge extracted along with the Pu and Am. Initial efforts to lower the extraction of $\mathrm{Zr}$ by complexing it with oxalate resulted in precipitate formation, which is not desirable. It appears that considerable development work might be required to develop this process.

\section{SEPARATION OF DISSOLVED PU, AM, AND Zr BY LaF 3 CARRYING}

Another method that was examined to separate $\mathrm{Pu}$ and $\mathrm{Am}$ from $\mathrm{Zr}$ in a solution obtained by dissolving NCRW sludge is the carrying of $\mathrm{Pu}$ and Am on a $\mathrm{LaF}_{3}$ precipitate. It was found that this separation is workable, but only if an appreciable amount of fluoride is added to the dissolved sludge solution. Results of a series of experiments investigating this potential process are shown in Table 8. At the $\mathrm{HNO}_{3}$ and sludge component concentrations tested, complete carrying of the $\mathrm{Pu}$ and Am was not obtained until the fluoride concentration had reached $-1.5 \underline{M}$, which corresponds to a fluoride-to-Zr ratio of -18. This is thought to be a severe drawback to a procedure like this for process application.

To repeat, we hope to be able to continue this interesting work. I'd also like to take this opportunity to thank you and Dean Kurath for your helpfut and supportive attitude during the work thus far.

Sincerely yours,

John L. Swanson

Senior Research Scientist

Chemical Process Development Section

$J L S: 1 \mathrm{~m}$ 
TABLE 1. Make-up of NCRW Sludge Composite Used in Study

\begin{tabular}{|c|c|c|c|}
\hline Sample & Grams Used (a) & $\frac{\mathrm{NCi} / \mathrm{g} \text { in }}{\mathrm{Pu}}$ & $\frac{\text { Sample }}{\text { Am }}$ \\
\hline $105 \mathrm{AW}$ Seg $2 \mathrm{~A}$ & 21.2 & 410 & 28 \\
\hline $105 \mathrm{AW} \operatorname{Seg} 3 \mathrm{~A}$ & 20.0 & 1000 & 430 \\
\hline $105 \mathrm{AW}$ Seg $4 \mathrm{~A}$ & 18.8 & 380 & 83 \\
\hline $105 \mathrm{Aw}$ Seg $5 \mathrm{~A}$ & 22.3 & 610 & 42 \\
\hline $105 \mathrm{AW}$ Seg $6 \mathrm{~B}$ & 18.7 & 880 & 1800 \\
\hline $\begin{array}{l}\text { Calculated for } \\
\text { Composite }\end{array}$ & 101 & 652 & 449 \\
\hline
\end{tabular}

a) Sludge wet to a flowing paste (no free-standing liquid).

b) Values reported by Leaf and McCown on 2-2-07. 
TABLE 2. Major Cations in NCRW Sludge Composite ${ }^{(a)}$ g. element/g sludge

\begin{tabular}{|c|c|c|c|}
\hline \multirow[b]{2}{*}{ Element } & \\
\hline & NCRW-2 ${ }^{(b)}$ & NCRW-6 & NCRW-17 ${ }^{(d)}$ \\
\hline $\mathrm{Na}$ & 0.0972 & 0.0828 & 0.0938 \\
\hline $\mathrm{Zr}$ & 0.0646 & 0.0612 & 0.0634 \\
\hline U & 0.0122 & 0.0109 & 0.0120 \\
\hline$k$ & 0.0079 & 0.0072 & 0.0079 \\
\hline $\mathrm{Fe}$ & 0.0034 & 0.0030 & 0.0031 \\
\hline Si & 0.0032 & & \\
\hline A1 & 0.0029 & 0.0025 & 0.0026 \\
\hline$M n$ & 0.0021 & 0.0019 & 0.0019 \\
\hline $\mathrm{Cr}$ & 0.0014 & 0.0013 & 0.0013 \\
\hline $\mathrm{Ca}$ & 0.0013 & 0.0011 & 0.0009 \\
\hline $\mathrm{Mg}$ & $4.8 \times 10^{-4}$ & $3.1 \times 10^{-4}$ & $2.6 \times 10^{-4}$ \\
\hline La & $3.5 \times 10^{-4}$ & $3.1 \times 10^{-4}$ & $3.3 \times 10^{-4}$ \\
\hline
\end{tabular}

\footnotetext{
a) By ICP analysis of dissolved sludge solutions. Elements that were detected in lower concentrations were $\mathrm{B}, \mathrm{Ba}, \mathrm{Nd}, \mathrm{Ni}, \mathrm{Sr}$, and $\mathrm{Ti}$.

b) Added $3.2 \mathrm{~mL} 5.4 \mathrm{M} \mathrm{HNO}_{3} / \mathrm{g}$ sludge.

c) Added $5.0 \mathrm{~mL} 5.0 \mathrm{M} \mathrm{HNO}_{3} / \mathrm{g}$ sludge.

d) Added $3.5 \mathrm{~mL} \mathrm{HNO} 37 \mathrm{~g}$ sludge; obtained $4.1 \mathrm{~mL} / \mathrm{g}$ sludge.
} 
TABLE 3. Washing of Fluoride 0ut of NCRW Sludge

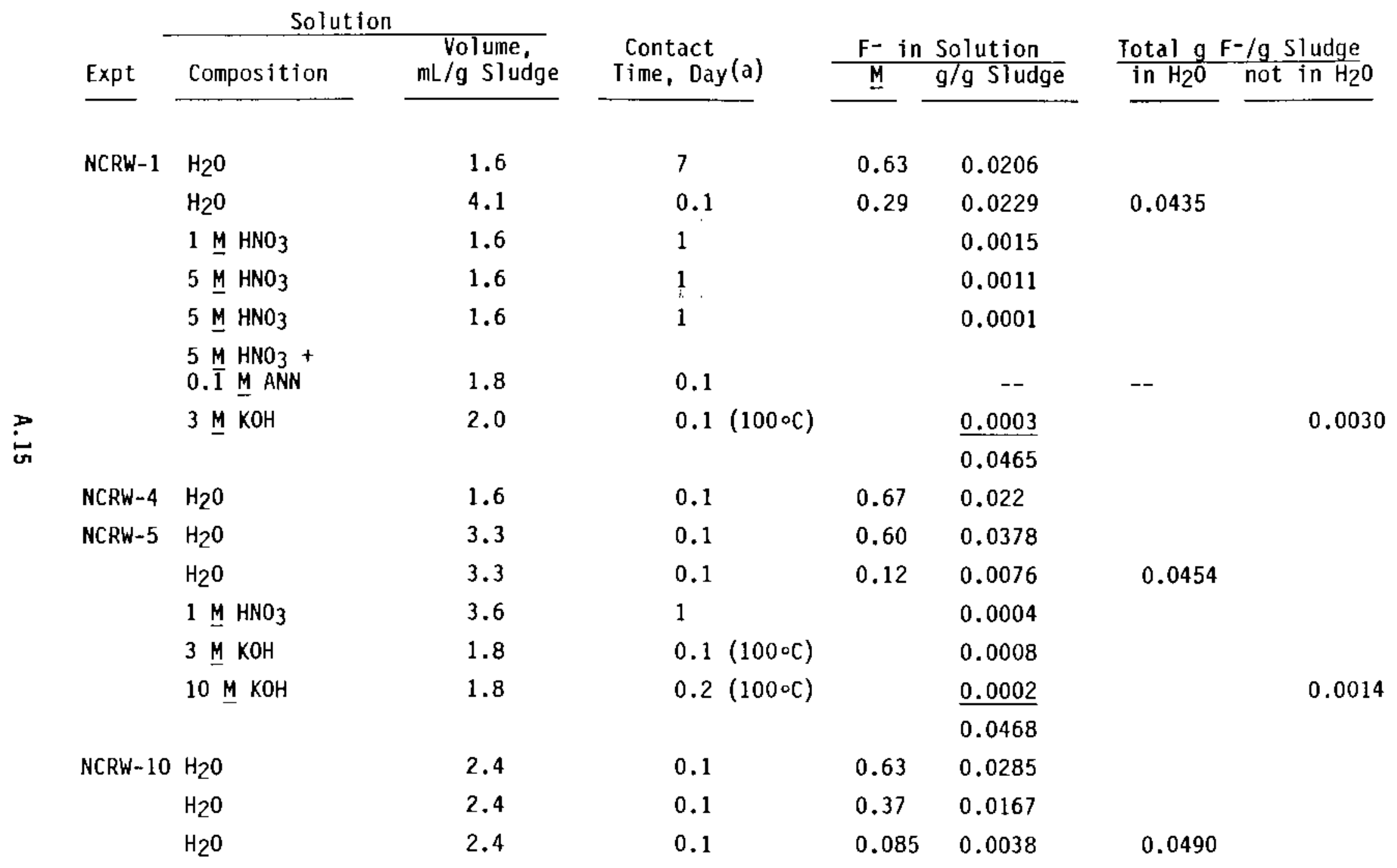

a) At room temperature unless otherwise noted. 
TABLE 4. Results of a Nitric Acid Leach Test (NCRW-15)

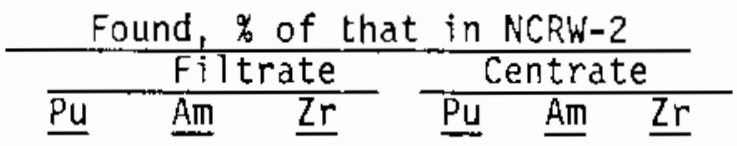

First leach solution

\begin{tabular}{llrrrrrr}
\hline $3.24 \mathrm{~mL} / \mathrm{g} 0.2 \mathrm{M} \mathrm{HNO}_{3}, 1$ day & 17 & 82 & 0.02 & & & \\
$.3 .24 \mathrm{~mL} / \mathrm{g} 0.4 \mathrm{M} \mathrm{HNO}_{3}, 1$ day & 31 & 85 & 3.4 & & & \\
$+1 \mathrm{day}$ at room temp. & 33 & 81 & 3.4 & & & \\
$+2 \mathrm{hr}$ at $100^{\circ} \mathrm{C}$ & 49 & 117 & & & & \\
+1 day at room temp. & 40 & 104 & 2.2 & 52 & 121 & 4.4
\end{tabular}

Second Solution

$\begin{array}{lllll}.3 .38 \mathrm{~mL} / \mathrm{g} 0.4 \mathrm{M} \mathrm{HNO}_{3}, 1 \text { day } & 5 & 12 & 4.4 \\ +2 \mathrm{hr} \text { at } 100^{\circ} \mathrm{C} & & & & \\ +2 \mathrm{hr} \text { at room temp. } & & 7 & 12 & 4.4\end{array}$

- Add $\mathrm{NH}_{4} \mathrm{~F}$ to $0.1 \mathrm{M}$

+1 day at room temp. $\quad 24 \quad 14$

$+2 \mathrm{hr}$ at $100^{\circ}$

$+2 \mathrm{hr}$ at room temp. $\quad 30 \quad 24$

- Adjust to $6 \mathrm{M} \mathrm{HNO}_{3}+0.7$ $\begin{array}{llll}M N_{4} F+1 & \text { day at room } & 27 & 14\end{array}$ temp.

- Adjust to $4 \mathrm{MHNO}_{3}+$ $0.6 \mathrm{M} \mathrm{H}_{4} \mathrm{~F}+0.2 \mathrm{M}$ Oxalate $+2 \overline{h r}$ at room tëmp. $24 \quad 13$ $28 \quad 15$

Third Solution

$.3 .11 \mathrm{~mL} / \mathrm{g} 1 \mathrm{M}$ oxalic acid, $2 \mathrm{hr}$ at room temp.

(Some solids remain) 
TABLE 5. Results of Silver/Persulfate Leach Experiment (NCRW 20)

\section{Solution}

First Leach Solution(a)

- After 2 hr at $100 \circ \mathrm{C}$

- +3 days at room temp.

- +2 hr at $100 \circ \mathrm{C}$

Second Leach Solution(a)

- After $2 \mathrm{hr}$ at $100^{\circ} \mathrm{C}$

- +6 hr at $100 \circ \mathrm{C}$

- +3 weeks at room temp.

Rinse (b)

Dissolved Residual Solid(c)

Total Found
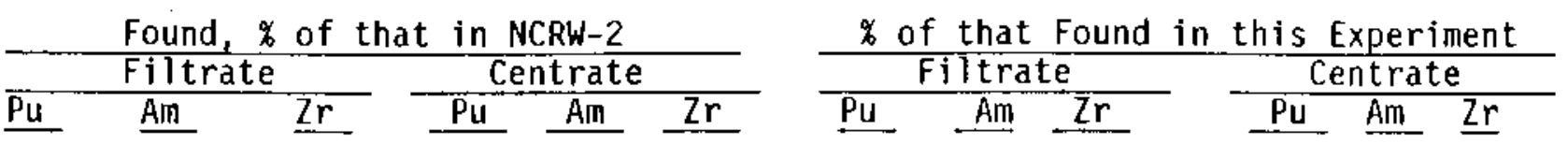

$\begin{array}{ll}62 & 86 \\ 53 & 81 \\ 57 & 82\end{array}$

3

$$
\begin{aligned}
& 86 \\
& 81 \\
& 82
\end{aligned}
$$

59

843

$\begin{array}{ll}71 & 84 \\ 61 & 79 \\ 66 & 80\end{array}$

68

82

$\begin{array}{ll}13 & 11 \\ 13 & 11 \\ 19 & 14\end{array}$

8

14

$19 \quad 14$

$\begin{array}{ll}15 & 11 \\ 15 & 11 \\ 22 & 13\end{array}$

22

13

33

33

62

\begin{tabular}{rr}
6 & 2 \\
\hline 87 & 103
\end{tabular}

(a) $0.02 \mathrm{M} \mathrm{AgNO}_{3}+0.1 \mathrm{M} \mathrm{K}_{2} \mathrm{~S}_{2} \mathrm{O}_{8}+0.4 \mathrm{M} \mathrm{HNO}_{3}(2.1$ mole HNO $3 /$ mole $\mathrm{Zr}$ ).

(b) $0.02 \mathrm{M} \mathrm{HNO}_{3}$.

(c) $5 \underline{\mathrm{M}} \mathrm{H} \overline{\mathrm{N}} \mathrm{O}_{3}+0.7 \underline{\mathrm{MHF}}$. 
TABLE 6. Results of Attempts to Enhance Pu Leaching with Complexants

\begin{tabular}{|c|c|c|c|}
\hline \multirow[b]{2}{*}{ Expt } & \multirow[b]{2}{*}{ Complexant Solution } & \multicolumn{2}{|c|}{$\%$ Found in solution $(a, b)$} \\
\hline & & $\mathrm{Pu}$ & $\mathrm{Zr}$ \\
\hline$N C R W-4$ & $0.5 \mathrm{M} \mathrm{Na}{ }_{2} \mathrm{CO}_{3}$ & 0.1 & (c) \\
\hline NCRW-9 & $0.5 \underline{\mathrm{M} \mathrm{NaHCO}} 3$ & 0.2 & (c) \\
\hline NCRW-11 & $\begin{array}{l}\text { CMPO-saturated } \\
0.2 \mathrm{M} \mathrm{HNO}_{3}\end{array}$ & $15(d)$ & (c) \\
\hline NCRW-14 & $0.05 \underline{M} \operatorname{DTPA}(c \quad p H=8)$ & 20 & 1.4 \\
\hline & $0.1 \underline{\mathrm{MF}}+0.4 \underline{\mathrm{M}} \mathrm{HNO}_{3}$ & 39 & 19 \\
\hline
\end{tabular}

(a) Relative to the amounts found in NCRW-2.
(b) $\geq 1$ day leaching at room temperature.
(c) Not determined.
(d) No different than found in absence of CMPO. 
TABLE 7. Quantities Dissolved from Unwashed Sludge by

Different Amounts of Nitric Acid (Experiment NCRH-6)

Found in Solution, $g / g$ STudge

\begin{tabular}{|c|c|c|c|c|}
\hline Element & $\begin{array}{l}3.1 \mathrm{~mL} 1 \mathrm{M} \mathrm{HNO}_{3} \\
\text { per g STudge }\end{array}$ & $\begin{array}{r}3.5 \mathrm{~mL} 3 \mathrm{MNO}_{3} \mathrm{HNO}^{\text {per g }} \mathrm{S}_{\text {Iudgè }} \\
\end{array}$ & $\begin{array}{l}3.8 \mathrm{~mL} 5 \mathrm{M} \mathrm{HNO}_{3} \\
\text { perg STudge }\end{array}$ & $\begin{array}{l}5.0 \mathrm{~mL} 5 \mathrm{M} \mathrm{HNO}_{3} \\
\text { per g sTudge }\end{array}$ \\
\hline $\mathrm{Na}$ & 0.061 & 0.070 & 0.080 & 0.083 \\
\hline $\mathrm{Zr}$ & 0.0016 & 0.051 & 0.060 & 0.061 \\
\hline U & 0.0078 & 0.0094 & 0.010 & 0.011 \\
\hline$k$ & 0.0051 & 0.0064 & 0.0071 & 0.0072 \\
\hline $\mathrm{Fe}$ & $3.1 \times 10^{-4}$ & 0.0025 & 0.0029 & 0.0030 \\
\hline A T & $3.1 \times 10^{-4}$ & 0.0020 & 0.0024 & 0.0025 \\
\hline Mn & 0.0016 & 0.0016 & 0.0018 & 0.0019 \\
\hline $\mathrm{Cr}$ & $3.1 \times 10^{-4}$ & 0.0010 & 0.0012 & 0.0013 \\
\hline $\mathrm{Ca}$ & $4.9 \times 10^{-4}$ & $7.8 \times 10^{-4}$ & 0.0010 & 0.0011 \\
\hline La & $2.1 \times 10^{-5}$ & $2.6 \times 10^{-4}$ & $3.1 \times 10^{-4}$ & $3.1 \times 10^{-4}$ \\
\hline \multicolumn{5}{|c|}{ Found in Solution, $(\mathrm{c} / \mathrm{m}, \mathrm{g}$ sludge $) \times 10^{-4}$} \\
\hline $\mathrm{Pu}$ & 0.6 & 10.3 & 12.1 & 12.4 \\
\hline Am & 2.3 & 7.3 & 8.9 & 8.6 \\
\hline
\end{tabular}


TABLE 8. Separation of Dissolved $\mathrm{Pu}, \mathrm{Am}$, and $\mathrm{Zr}$ by $\mathrm{LaF}_{3}$ Carrying

Procedure: -Dissolve unwashed sludge in $\mathrm{HNO}_{3}$ to give a solution (NCRW-17) containing $4 \mathrm{M} \mathrm{HNO}_{3}+0.5 \mathrm{M} \mathrm{F}+0.17 \mathrm{M} \mathrm{Zr}+0.024 \mathrm{M} \mathrm{Al}+$ $0.013 \underline{\mathrm{M} e}+\overline{0} .009 \underline{\mathrm{M}} \mathrm{Ca}$.

- DiTute nearly 2-fold with water, add $\mathrm{RE}\left(\mathrm{NO}_{3}\right)_{3}$, then add $\mathrm{NH}_{4} \mathrm{~F}$ to complete ditution to 2-fold. Final $\mathrm{RE}\left(\mathrm{NO}_{3}\right)_{3}=0.01 \underline{\mathrm{M}}$ added.

- Stir 1 hr at room temperature, filter, and analyze.

$[F], \underline{M}$

\begin{tabular}{|c|c|}
\hline Added & Total \\
\hline 0.00 & 0.25 \\
\hline 0.45 & 0.70 \\
\hline 0.65 & 0.90 \\
\hline 0.85 & 1.10 \\
\hline 1.05 & 1.30 \\
\hline 1.45 & 1.70 \\
\hline
\end{tabular}

Remaining in Solution, \% of Total

\begin{tabular}{llll}
\hline$\underline{P u}$ & $\frac{\mathrm{Am}}{86}$ & $\underline{\mathrm{Zr}}$ & $\underline{\text { La }}$ \\
98 & 86 & & \\
35 & 51 & & \\
25 & 38 & & \\
15 & 47 & 73 & 0.3 \\
12 & 19 & & \\
0 & 0 & 71 & 0
\end{tabular}




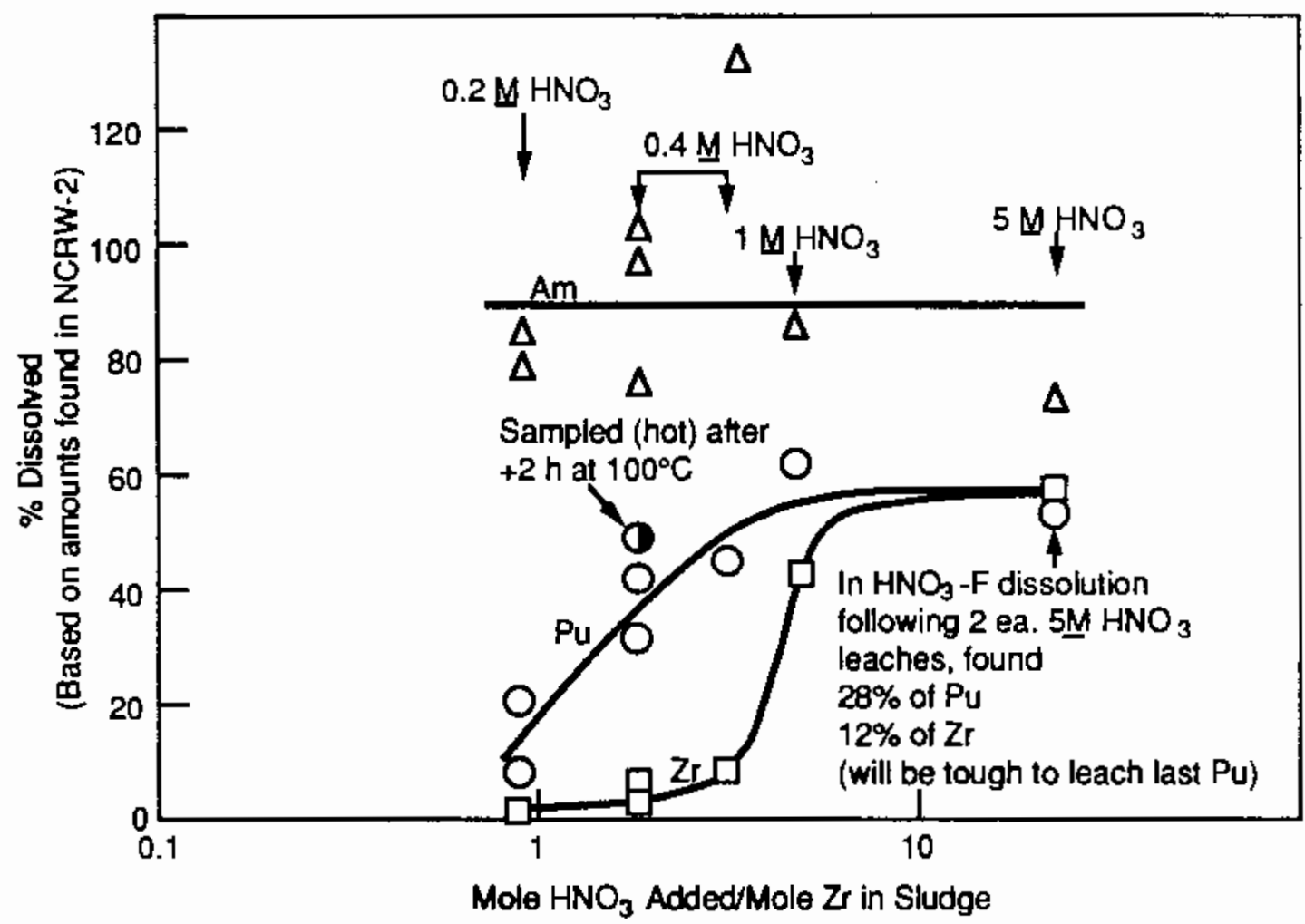

FIGURE 1. Leaching/Dissolution of Water-Washed NCRW Sludge in $\mathrm{HNO}_{3}$ (1 day room temperature) 


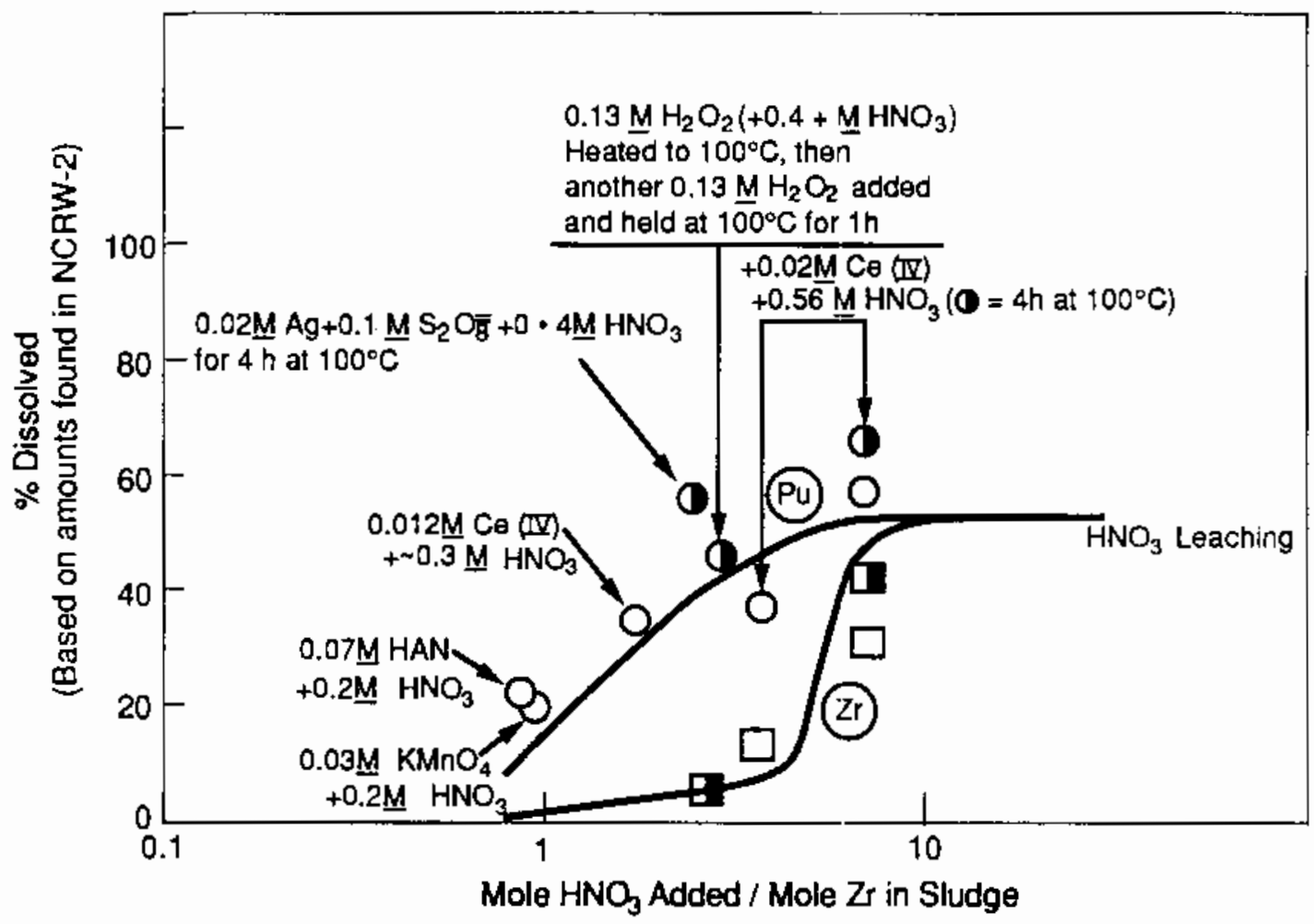

FIGURE 2. Results of Attempts to Improve Selective Leaching of Pu by $\mathrm{HNO}_{3}+$ Oxidant or Reductant 
APPENDIX B

\section{SELECTIVE LEACHING OF PU AND AM FROM NCRW SLUDGE}




\section{A LETTER REPORT FOR WESTINGHOUSE HANFORD COMPANY}

SELECTIVE LEACHING OF PU AND AM FROM NCRW SLUDGE

J. L. Swanson

June 1988

Prepared for

the U.S. Department of Energy

under Contract DE-AC06-76RLO 1830

Pacific Northwest Laboratory

Richland, Washington 99352 


\section{SUMMARY}

Studies have been performed to assess the feasibility of leaching Pu and Am from neutralized cladding removal waste (NCRW) sludge to the extent that the sludge could be converted to a grout containing $\leq 50 \mathrm{nCi}$ of transuranic (TRU) alpha activity per gram of grout, so that it can be disposed of in near surface vaults. Sludge composites of segments taken from both Tank 103-AW and Tank 105-AN in October 1986 were used in these studies.

The studies have emphasized leaching of NCRW sludge by dilute nitric acid, following water-washing to remove fluoride. The results indicate that the desired goal cannot be achieved by this simple process; typically, selective leaching could be achieved only to the extent that a grout could be made that contains $-90 \%$ of the $\mathrm{Zr}$ at a TRU leve] of $\sim 120 \mathrm{nCi} / \mathrm{g}$. Leaching of Pu is more difficult than Teaching of Am.

One experiment employing silver persulfate (in dilute nitric acid) as an oxidant showed significantly enhanced Pu leaching, to the extent that a grout could be made containing $290 \%$ of the $\mathrm{Zr}$ at a TRU level of 40 to $70 \mathrm{nCi} / \mathrm{g}$. Fluoride also assisted in Pu leaching, but the degree of separation from $\mathrm{Zr}$ has not been evaluated.

The TRU levels found in these leach experiments indicate that the untreated NCRW sludges might contain up to $50 \%$ higher concentrations of TRU elements than had been indicated by previous analyses of individual segments of sludge core samples. 


\section{INTRODUCTION}

The neutralized cladding removal waste (NCRW) sludges that are stored in Tanks 103-AW and 105-AW contain higher than anticipated levels of the transuranic (TRU) elements Pu and Am. These higher levels preclude final disposal of these wastes as grout in near surface vaults. This led to the initiation of an experimental program at the Pacific Northwest Laboratory (PNL) to investigate possible means of separating the TRU elements from other sludge components, especially $\mathrm{Zr}$, so that the fraction of this waste that could be disposed as grout in near surface vaults (as opposed to as glass in a geologic repository), would be maximized.

The initial portion of the PNL study (Appendix A) involved scouting studies, with NCRW sludge from 105-AW, of: a) completeness of fluoride removal on washing with water, b) separation of $\mathrm{Pu}$ and Am solids from $\mathrm{Zr}$ solids by differences in settling rates, c) selective leaching of $\mathrm{Pu}$ and $\mathrm{Am}$ away from $2 r, d)$ complete dissolution of the sludge, and e) separation of dissolved $\mathrm{Pu}, \mathrm{Am}$, and $\mathrm{Zr}$ by solvent extraction or by precipitation of $\mathrm{LaF}_{3}$. Those studies indicated that the most promising approach involved selective leaching of the $\mathrm{Pu}$ and $\mathrm{Am}$, after water washing to remove fluoride. The results also indicated that sufficient selective leaching might be attainable using dilute nitric acid alone, especially at an elevated temperature, and that even better selective leaching of Pu could be achieved using certain oxidative conditions. The follow-on work done in FY 1988, which is the subject of this report, addressed only nitric acid leaching because of the simplicity of that approach. 


\section{METHODS AND MATERIALS}

Details of the experimental procedures and results are given in this section.

\section{Procedure}

Most experiments used $-3 \mathrm{~g}$ of a NCRW sludge composite contained within glass vials; plastic vials were used in some of the complete dissolution experiments. Washing and leach contacts were generally performed by shaking at room temperature. Contacts at $100^{\circ} \mathrm{C}$ were done by stirring the contents of the vial, which rested in a beaker of boiling water.

Solid/liquid separations were performed by centrifugation and by filtration, using filters having a $0.2-\mu \mathrm{m}$ pore size. Centrifugation was used for bulk separations (e.g., when removing a leach solution from the sludge) and filtration was generaliy used prior to sample dilution for analysis.

Fluoride was determined with a specific ion electrode in a matrix containing a complexing agent to minimize interference from metal ions. Spike recovery methods were used to correct for such interference by metal ions; such corrections were seldom substantial. Cation concentrations were measured on the 325 Building shielded ICP.

Our in-lab counting data were obtained on an alpha energy analyzer having a counting efficiency of $-11 \%$. In general, duplicate $0.1 \mathrm{~mL}$ portions of 31 fold dilutions of the leach solutions were direct-mounted and counted for 10 minutes.

\section{Composites Used}

Leach experiments were done with three different NCRW sludge composites, one composite of the segments of the 103-AW sludge and two composites of the segments of the 105-AW sludge. The quantities of the segments used in each composite are listed in Table 1 along with the results of earlier analyses of the individual segments. 


\section{Treatment of Alpha Counting Data}

Additional review of our in-lab counting data during the preparation of this report has improved the accuracy of the results over those presented earlier. The approach followed earlier involved summing the Pu and Am peaks of the alpha energy analysis in relatively few channels, and calculating $\%$ leached" values from those numbers plus the total amounts expected in the experiment. This approach was satisfactory for the early scouting work, but was deficient for the more extensive work done recently.

The more rigorous procedure recently adopted to treat the in-lab counting data involves summing the counts in all channels in the range from 5 channels above the ${ }^{241} \mathrm{Am}+{ }^{238} \mathrm{Pu}$ peak to 10 channels below the ${ }^{239+240} \mathrm{Pu}$ peak (this covers the range from $-5.7 \mathrm{MeV}$ to $-4.7 \mathrm{Mev}$ ), to obtain the total (Pu+Am)

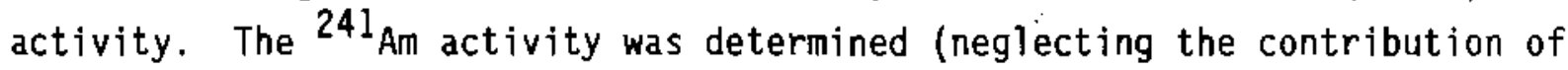
${ }^{238} \mathrm{Pu}$ ) from the activity in its discrete peak plus an estimate of the "tailing" under the ${ }^{239+240} \mathrm{Pu}$ peak, and the Pu activity was then determined by subtracting the Am activity from the total activity. While this procedure is subject to uncertainty in the separate Pu and Am activities, the sum of $P u$ and Am activities (which is the value of primary importance) should be quite accurate. This uncertainty is much greater in experiments involving the composite from Tank 103 - AW, where the ${ }^{238} \mathrm{Pu}$ activity amounted to $\sim 58 \%$ of the

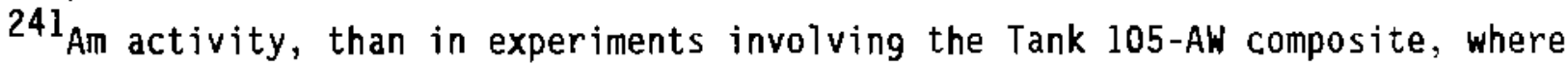
the ${ }^{238} \mathrm{Pu}$ activity amounted to only $-14 \%$ of the ${ }^{241}$ Am activity. These percentages were calculated from the initial sample characterization data, corrected for the additional growth of ${ }^{241}$ Am during the -1 yr interval between those analyses and the current work. For reference, the ${ }^{238}$ pu activity amounted to $-7.5 \%$ of the ${ }^{239} \mathrm{Pu}+{ }^{240} \mathrm{Pu}$ activity in the Tank 103 -AW composite and $\sim 10 \%$ in the 105 -AW composite.

Data obtained by our in-lab counting procedure were compared with those of the 325 Building analytical facility in three instances; the results are compared in Table 2. The agreement was quite good in two of the three samples but only fair in the third case. 


\section{RESULTS AND DISCUSSION}

In addition to the effectiveness of selective leaching of $\mathrm{Pu}$ and Am from Zr, significant results were obtained in the areas of sludge composition and of the behavior of sludge components other than $\mathrm{Pu}$, Am, and $\mathrm{Zr}$ in the leaching process. These results are also included in this section.

\section{Indicated TRU Contents of the NCRW Sludges}

The TRU contents of the NCRW sludge composites used in this work appear to be higher than expected from the analytical results obtained earlier for the individual segments used to prepare the composites. Table 3 summarizes the total quantities of $\mathrm{Pu}$ and $\mathrm{Am}$ found in several of our leach experiments and in two "complete dissolution" experiments; this table also lists the quantities expected based on composite make-ups plus earlier analyses of the individual segments used in the composites, and compares our in-lab counting results with those of the 325 Analytical Lab in the two complete dissolution experiments.

Examination of the data of Table 3 shows that the quantities found by inlab analysis of the leach experiments always exceeded the quantities expected from the earlier analyses of the individual segments, by amounts ranging from $16 \%$ to $46 \%$ in the experiments with 105 -AW sludge and by $49 \%$ in the one $103-\mathrm{AW}$ siudge case.

The quantities found in these leach experiments also exceeded the quantities found initially in our complete dissolution experiments employing 5 $\mathrm{M} \mathrm{HNO}_{3}$. This suggests that dissolution of $\mathrm{Pu}$ and $\mathrm{Am}$ was not really complete in our initial $5 \mathrm{M} \mathrm{HNO}_{3}$ dissolutions; the initial conclusion that $\mathrm{Pu}$ and $\mathrm{Am}$ dissolution was complete was based on the good agreement between the concentrations found in those experiments and the concentrations calculated from the earlier analyses. Very few solids were visually apparent in the complete dissolution experiments involving 105-AW sludge; those that did remain appeared to be dirt or "crud". However, the one 103-AW complete dissolution experiment resulted in a suspension that was quite murky and which likely contained some undissolved sludge components. 
Because of the good agreement between our in-lab analyses and those of the 325 Building analytical facility in analysis of the same solutions (Table 2), it is unlikely that differences in analytical techniques are responsible for our results giving higher TRU concentrations in the sludge samples. Instead, the difference is likely due to more complete dissolution of the TRUcontaining solids in our successive leaching experiments than in the earlier work.

In summary, some unresolved uncertainties remain regarding the real TRU content of the NCRW sludges; additional work will be required to resolve these uncertainties. In discussing our leach results, we will use the quantities found in our in-lab analyses. They are the highest values, so this approach is the conservative one for assessing the applicability of leach processes. Selective Leaching of $\mathrm{Pu}$ And Am From $\mathrm{Zr}$

The highlight results of the extensive leaching experiments are summarized in Table 4. This table lists: 1) the total quantities of Pu and Am found in the experiment, 2) the percentages of $\mathrm{Pu}, \mathrm{Am}$, and $\mathrm{Zr}$ that remain in the solids after each of two leach steps, and 3) Pu and Am contents of a grout that could be prepared after the second leach step.

Partial results of experiments 15 and 20 were contained in Appendix $A$.

Based on consideration of the preliminary results of those two experiments, it was decided that study of the more promising oxidative Teaching approach (experiment 20), in which the TRU content was decreased sufficiently to give a grout containing 40 to $70 \mathrm{nCi} / \mathrm{g}$, should be deferred until it was determined if adequate leaching could be obtained using the simpler $\mathrm{HNO}_{3}$-alone leach approach. Thus, all of the experiments in Table 4 except for \#2O involved leaching with $\mathrm{HNO}_{3}$-alone (following fluoride removal by washing with water).

Early consideration of the data from the 105-AW sludge experiments (15, 24, 27, and 28), using our earlier method of data treatment and the initial TRU contents calculated from the earlier analyses of individual segments, indicated that simple $\mathrm{HNO}_{3}$ leaching of this sludge could indeed provide a worthwhile separation. Those considerations indicated that a grout containing 
$-90 \%$ of the $\mathrm{Zr}$ and $\sim 75 \mathrm{nCi} / \mathrm{g}$ could be achieved (note in Table 4 that the current treatment of the data gives an average of $-120 \mathrm{nCi} / \mathrm{g}$ for these experiments). Even though this indicated result did not meet the target level of $50 \mathrm{nCi} / \mathrm{g}$ in grout, the extents of $\mathrm{Pu}$ and Am leachings ( $50 \%$ and $-90 \%)$ were thought to be promising. If comparable leaching could be obtained with 103-AW sludge, which contains lower TRU levels, it was thought that processing of the combined 105-AW and 103-AW sludges could allow the target TRU level to be attained. (Note that the currentTy indicated TRU content of $120 \mathrm{nCi} / \mathrm{g}$ in grout prepared from leached 105-AN sludge precludes achieving $\leq 50 \mathrm{nCi} / \mathrm{g}$ in grout from the combined sludges unless leaching of 103-AW sludge is highiy efficient and the combined sludge contains more 103-AW sludge than 105-AW sludge).

Accordingly, a composite of the 103-All sludge core sample segments was prepared and tested. The first leach experiment (31) with this composite used the same acid conditions as had been used with the 105-AW sludge composites. This resulted in the dissolution of an excessive amount of $\mathrm{Zr}$ from the 103-AW composite so another experiment (32) was done with half as much acid. This resulted in adequately low $\mathrm{Zr}$ dissolution but the extents of leaching of $\mathrm{Pu}$ and Am were much lower than had been achieved with 105-All sludge. Thus, the projected TRU content of grout made from leached 103-AW sludge was about the same as that from leached 105-AW sludge $(\sim 120 \mathrm{nCi} / \mathrm{g})$.

More detailed results for the experiments summarized in Tabie 4 are contained in Tables 5 through 10, where the conditions used and the results obtained for $\mathrm{Pu}, \mathrm{Am}$, and $\mathrm{Zr}$ are summarized. Each of the steps in the experiments is listed even if no analytical data are available (all samples were alpha-counted initially, but only selected ones have been reanalyzed by the more rigorous data treatment procedure to give the data shown here). A brief listing of some of the highlights of these results is:

1) In experiment 15 (Table 5) it was found that a) very little $\mathrm{Pu}, \mathrm{Am}$, or $\mathrm{Zr}$ are contained in the water washes; b) leaching of $\mathrm{Pu}$ and Am was greater at $100^{\circ} \mathrm{C}$ than at room temperature, while that of $\mathrm{Zr}$ was lower; c) solids are present that do not settle well on centrifugation and that contain appreciable amounts of $\mathrm{Pu}$ and $\mathrm{Zr}$; and d) addition of fluoride to the 
second $0.4 \mathrm{M} \mathrm{HNO}_{3}$ leach solution gave increased $\mathrm{Pu}$ leaching at room temperature and even more increase at $100^{\circ} \mathrm{C}$ ( $\mathrm{Zr}$ leaching was also found to increase substantially at room temperature but the $100^{\circ} \mathrm{C}$ sample was not analyzed for $\mathrm{Zr}$ ).

2) The highlight of experiment 20 (Table 6) was the enhanced leaching of Pu that resulted from oxidation to $\mathrm{Pu}(V I)$ by silver persulfate (at $100^{\circ} \mathrm{C}$ ). Combination of the enhanced leaching plus removal of "floaty" solids gave separation of $\mathrm{Pu}$ and Am from $\mathrm{Zr}$ sufficient to allow grouting of $91 \%$ of the $\mathrm{Zr}$ at a TRU content of on $7 y 36 \mathrm{nCi} / \mathrm{g}$.

3) Experiment 24 (Table 7) was similar to 15, but failed to show improved leaching at $100^{\circ} \mathrm{C}$ in the second leach step. This experiment included a $0.4 \underline{\mathrm{MHNO}}+0.1 \mathrm{M} \mathrm{F}$ leach following the two $0.4 \mathrm{M} \mathrm{HNO}_{3}$ leaches; this was much more effective than the second $0.4 \mathrm{M} \mathrm{HNO}_{3}$ solution in leaching $\mathrm{Pu}$ (no $\mathrm{Zr}$ value was obtained). However, the estimated $\mathrm{nCi} / \mathrm{g}$ in grout was still >100 after this F-containing leach (at room temperature).

4) Experiments 27 and 28 (Tables 8 and 9) used a different, but very similar, composite of 105-AW sludge. The results of these two experiments were in good agreement with the those of experiment 24 .

5) Experiment 32 (Table 10) used a composite of 103-AW sludge and a lower $\mathrm{HNO}_{3}$ concentration $(0.2 \mathrm{M})$ because of the excessive dissolution of $\mathrm{Zr}$ that occurred (in experiment 31) when $0.4 \mathrm{M} \mathrm{HNO}_{3}$ was used. The key result of this experiment was that much lower percentages of Pu and Am were leached from this sludge than from 105-AW sludge. Based on preliminary analytical data, perhaps twice as much $\mathrm{Pu}$ (but about the same amount of Am) was leached in the $0.4 \mathrm{M} \mathrm{HNO}_{3}$ experiment (\#31) with 103-AW sludge; these percentages leached are still well below those observed with 105-AW sludge at comparable conditions. Another important result of experiments 31 and 32 is that solid/liquid separation appeared to be more difficult here than it was in experiments using 105-AW sludge.

It is obvious from the leach test results that there is a multiplicity of TRU (especially Pu) species in the sludges in Tanks 103-AW and 105-AW. Some of the $\mathrm{Pu}$ leaches quite readily but the remainder is rather difficult to 
dissolve, and the fraction that is easily leachable is different between the two tanks. It is also probable that the ease of $\mathrm{Pu}$ leaching varies from one sludge segment to another within a tank, but no data have been obtained to address that point.

\section{Composition of Sludge Composites}

The major metal ion compositions of the sludge composites used in this study, as determined by ICP analyses of "complete dissolution" experiments, are compared in Table 11. The composite sludges from the two tanks are seen to be quite comparable except that the 103-AW sludge composite contains only about $10 \%$ as much $\mathrm{Fe}$ and $\mathrm{Ca}$ and $1 \%$ as much $\mathrm{Mn}$ as the 105-AW sludge composite. It could well be that these differences resulted from differences in the tank heels that were present when NCRW additions were begun rather than from differences in NCRW compositions. The low Fe value in experiment 30 was substantiated by the fact that about half that much Fe was found in the leach steps of experiment 32, which employed the same sludge composite.

The fluoride contents of the three composite samples were comparable: $g$ $\mathrm{F} / \mathrm{g}$ sludge values of $0.045,0.052$, and 0.054 were removed by two water washes at $-3.3 \mathrm{ml} / \mathrm{g}$ sludge from the first composite of 105-AW sludge (experiment 5 ), from the second composite of 105-AN sludge (experiment 27), and from the 103-AW sludge composite (experiment 31), respectively. It is interesting that these fluoride contents are higher than those measured in our normal $5 \mathrm{M} \mathrm{HNO}_{3}$, "complete dissolution" experiments, thus providing additional evidence that dissolution was not really complete in those experiments.

Behavior of Other Sludge Metal. Ions in the $\mathrm{HNO}_{3}$ Leach Process

In only one experiment (15) were enough samples analyzed to obtain a picture of the distribution of other sludge metal ions through the wash, leach, and dissolution cycles. Table 12 contains these results for the major sludge metals, including $\mathrm{Zr}$ for comparison. These distribution results are presented as percentages of the totals found in the experiment, which are also listed and compared with those found in a complete dissolution experiment. Except for AT, good agreement was observed for these elements between the totals found in this leach experiment and the amounts found in the 
complete dissolution experiment. The leach solutions contained $<10 \%$ of the $\mathrm{Zr}$, $\mathrm{Na}$, and $\mathrm{K},<20 \%$ of the $\mathrm{Al},-50 \%$ of the $\mathrm{Fe}$ and $\mathrm{Cr}$, and $-100 \%$ of the $\mathrm{U}$ present in the sludge. These amounts would presumably accompany the leached Am and Pu to disposal in a deep geological repository and the remaining materials would be incorporated in grout for disposal in near surface vaults.

If the leach solutions are neutralized before the next processing step, additional separation of TRU elements from $\mathrm{Na}, \mathrm{K}$, and $\mathrm{Al}$ could be attained (if desired) by separating the resultant precipitate from the supernatant. If a silver persulfate oxidation step is performed and if the Pu and Am fraction is to be vitrified, such a separation might be desired to separate sulfurcontaining saits from the $\mathrm{Pu}$ and An fraction. 


\section{FUTURE WORK INDICATED}

The results discussed above show that simple $\mathrm{HNO}_{3}$ leaching will not leach $\mathrm{Pu}$ and $\mathrm{Am}$ away from $\mathrm{Zr}$ in NCRW sludge sufficiently well that a grout containing most of the $\mathrm{Zr}$ and $\leq 50 \mathrm{nCi} / \mathrm{g}$ of TRU elements can be prepared. It is thus time to emphasize other approaches to the problem, such as:

a) Use of oxidants to improve selective leaching of $\mathrm{Pu}_{\mathrm{u}}$ by converting it to more highty soluble Pu(VI). Our most promising acid leaching result was obtained in one experiment (20) with sijver persulfate and 105-AW sludge, where the TRU content was decreased sufficiently to give a grout containing 40 to $70 \mathrm{nCi} / \mathrm{g}$. This approach should be tried with 103-Aw siudge; if successful there, work on process optimization and evaluation of undesirable side effects should be done.

In addition, oxidative leaching of $\mathrm{Pu}$ in basic solutions should be revisited. We earlier (Appendix $A$ ) did an unsuccessful test with permanganate in bicarbonate solution. We would like to test a stronger oxidant such as ferrate $\left(\mathrm{FeO}_{4}^{\equiv}\right)$ in sodium hydroxide solution, where $\mathrm{Pu}$ (VI) solubility should be ample and $\mathrm{Zr}$ would be insoluble. A subsequent dilute $\mathrm{HNO}_{3}$ leach would probably be required for Am removal.

b) Use of complexants to improve selective leaching. We have increased acid leaching of both $\mathrm{Pu}$ and $\mathrm{Zr}$ (which is undesirable) from 105-AW sludge by adding fluoride, but have not attempted to optimize conditions. Specifically, the effect of temperature on the fluoride-enhanced leaching of $\mathrm{Pu}$ should be evaluated. In addition, scouting studies with other complexants (e.g., phosphate and sulfate) should be done. These studies must involve NCRW sludges from both 103-AW and 105-AW.

c) Assuming that the studies outlined in (a) and (b) indicate that a selective leaching process is feasible, some sludge aging studies should be done to determine if selective leaching will be more difficult in the future. Such studies would compare the ease of sludge leaching before and after storage for several months at an elevated temperature. 
d) Complete dissolution of the sludge followed by separation of Pu and Am from $Z r$. Our initial evaluation (Appendix A) of separation processes such as a TRUEX-type extraction process and a LaF $_{3}$ carrier precipitation process indicated that appreciable optimization work on such processes would be needed.

More work should also be done to determine the conditions that are required for complete dissolution of (at least) TRU-containing sludge solids. This would be necessary to establish the conditions to be used in a process involving complete dissolution, and would also be desirable to resolve the apparent discrepancy between our results and those obtained earlier regarding the total TRU contents of the sludges. 
Table 1. Make Up of Composites Used in Study

\begin{tabular}{|c|c|c|c|c|c|}
\hline \multirow[b]{3}{*}{ Tank } & \multirow[b]{3}{*}{ Segment } & \multicolumn{2}{|c|}{ in segment $\begin{array}{c}n \mathrm{C} i / g \\
\text { in }\end{array}$} & & \\
\hline & & \multirow{2}{*}{$\begin{array}{l}239 \mathrm{Pu}+ \\
240 \mathrm{Pu} \\
\end{array}$} & \multirow{2}{*}{$\begin{array}{l}24 \mathrm{I}_{\mathrm{Am}}+ \\
238_{\mathrm{Pu}}\end{array}$} & \multicolumn{2}{|c|}{ Wt $\%$ in Composite } \\
\hline & & & & Ist Composite & 2nd Composite \\
\hline 105-AW & $\begin{array}{l}2 A \\
3 A \\
4 A \\
5 A \\
6 B\end{array}$ & $\begin{array}{r}410 \\
1000 \\
380 \\
610 \\
880\end{array}$ & $\begin{array}{r}28 \\
430 \\
83 \\
42 \\
1800\end{array}$ & $\begin{array}{l}21.0 \\
19.8 \\
18.6 \\
22.1 \\
18.5\end{array}$ & $\begin{array}{l}19.1 \\
20.1 \\
19.3 \\
22.1 \\
19.4\end{array}$ \\
\hline 103-AN & $\begin{array}{l}3 A \\
4 A \\
5 A \\
6 A \\
7 A \\
8 A \\
8,9 \text { GRNA }\end{array}$ & $\begin{array}{r}370 \\
510 \\
280 \\
640 \\
530 \\
680 \\
39\end{array}$ & $\begin{array}{l}14 \\
17 \\
14 \\
39 \\
56 \\
93 \\
80\end{array}$ & $\begin{array}{l}14.1 \\
13.8 \\
14.5 \\
14.2 \\
14.1 \\
13.8 \\
15.3\end{array}$ & \\
\hline
\end{tabular}

(a) Values obtained in earlier analyses. 
Table 2. Comparison of In-Lab and Analyțical Lab Analyses

\section{$d / m, m L$ Found}

In-Lab Analysis

Sample $\quad \mathrm{Pu} \quad$ Am $\quad$ Total

N21-1-1

N273-4

N301-6
$6.0 \times 10^{3} \quad 3.6 \times 10^{3}$

$8.3 \times 10^{3} \quad 1.2 \times 10^{4}$

$3.2 \times 10^{3} \quad 5.5 \times 10^{2}$
$9.6 \times 10^{3}$

$2.0 \times 10^{4}$

$3.8 \times 10^{3}$
Analytical Lab Analys is
Pu Am Total

$6.0 \times 10^{3} \quad 2.3 \times 10^{3} \quad 8.3 \times 10^{3}$

$5.1 \times 10^{3} \quad 0.9 \times 10^{4} \quad 1.4 \times 10^{4}$

$3.6 \times 10^{3} \quad 7.2 \times 10^{2} \quad 4.3 \times 10^{3}$ 
Table 3. Comparison of TRU Contents of Sludge Composite Samples

\begin{tabular}{|c|c|c|c|c|c|c|c|c|c|c|c|c|}
\hline & & & & $\begin{array}{l}\mathrm{cul} \text { at } \\
\mathrm{g} \mathrm{S}\end{array}$ & & & $1 n-1$ & b An & ysis & 325 & Analy & ical \\
\hline & $\underline{\text { Tank }}$ & Composite & $\underline{\underline{P u}}$ & Am & Iotal & Expt & $\mathrm{Pu}$ & $\mathrm{Am}$ & Iotal & $P \mathbf{P L}_{\text {L }}$ & Am & Iotal \\
\hline & 105 & 1 & 652 & 449 & 1101 & $2^{(b)}$ & 582 & 526 & 1108 & & & \\
\hline & & & & & & (c) & 830 & 500 & 1330 & 834 & 316 & 1150 \\
\hline & & & & & & 15 & 880 & 400 & 1280 & & & \\
\hline & & & & & & 20 & 960 & 650 & 1610 & & & \\
\hline & & & & & & 24 & 810 & 630 & 1440 & & & \\
\hline & 105 & 2 & 658 & 466 & 1124 & 27 & 1000 & 600 & 1600 & & & \\
\hline & & & & & & 28 & 910 & 600 & 1510 & & & \\
\hline & 103 & 1 & 430 & 45 & 475 & $30^{(d)}$ & 400 & 41 & 441 & & & \\
\hline & & & & & & (e) & 370 & 86 & 456 & 400 & 74 & 474 \\
\hline & & & & & & 32 & 620 & 87 & 707 & & & \\
\hline
\end{tabular}

(a) Based on the results of earlier analyses for the contents of the individual segments, plus the quantities of the individual segments in the composites used in this work.

(b) Analysis of a 16-fold dilution of the solution obtained by adding 3.2 $\mathrm{ml} / \mathrm{g}$ of $5.4 \mathrm{M} \mathrm{HNO3.}$

(c) Analysis (months later) of a 5-fold dilution of the original dilution.

(d) Analysis of a 31-fold dilution of the solution obtained by adding 4.2 $\mathrm{ml} / \mathrm{g}$ of $5 \mathrm{M}$ HNO3.

(e) Analysis of a 31-fold dilution of the solution obtained by adding 6.8 $\mathrm{ml} / \mathrm{g}$ of $5 \underline{\mathrm{M}} \mathrm{HNO3}$. 
Table 4. Summary Comparison of Results of Leaching of Water-Washed Sludge

$\begin{array}{rrrrrrrr}\text { Expt } & 15 & 20 & 24 & 27 & 28 & 31 & 32 \\ \text { Tank } & 105 & 105 & 105 & 105 & 105 & 103 & 103\end{array}$

$\mathrm{nC} \mathrm{i} / \mathrm{g}$ Sludge

$\begin{array}{lrrrrrr}\text { Pu } & 880 & 960 & 810 & 1000 & 910 & 620 \\ \text { Am } & 400 & 650 & 630 & 600 & 600 & 87 \\ \text { Tota7 } & 1280 & 1610 & 1440 & 1600 & 1510 & 707\end{array}$

$\%$ Left in S7udge After,
1st 0.2 M $\mathrm{HNO}_{3}$ Leach

$\begin{array}{rr}\mathrm{Pu} & 92 \\ \mathrm{Am} & 67 \\ \mathrm{Zr} & 100\end{array}$

$\%$ Left in Sludge After,
1st 0.4 M $\mathrm{HNO}_{3}$ Leach

$\begin{array}{lllllll}\mathrm{Pu} & 55 & 48 \text { (b) } & 67 & 62 & 66 & \\ \mathrm{Am} & 13 & 18 \text { (b) } & 21 & 23 & 14 & \\ \mathrm{Zr} & 98 & 97^{(b)} & 99 & 99 & 99 & 83\end{array}$

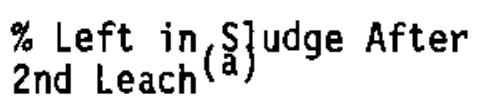

$\begin{array}{lrrllrr}\mathrm{Pu} & 45 & 29(\mathrm{~b}) & 64 & 50 & 52 & -84 \\ \mathrm{Am} & 3 & 5(\mathrm{~b}) & 17 & 14 & 7 & -55 \\ \mathrm{Zr} & 94 & 89(\mathrm{~b}) & 90(\mathrm{c}) & 90(\mathrm{c}) & 92 & 93\end{array}$

$n \mathrm{Ci} / \mathrm{g}$ in Grout $(\mathrm{d})$

$\begin{array}{lrrrrrr}\text { Pu } & 87 & 64 & 118 & 114 & 106 & 115 \\ \text { Am } & 3 & 8 & 24 & 17 & 9 & 11 \\ \text { Total } & 90 & 72^{(e)} & 142 & 131 & 115 & 126\end{array}$

(a) Based on analysis of filtered sample of leach solution $(\sim 3 \mathrm{~mL}$ of solution per gram of sludge), including some leaching at $100^{\circ} \mathrm{C}$.

(b) Silver persulfate present in leach solution.

(c) Value assumed for calculation of $\mathrm{nC} i / g$ in grout.

(d) Based on $243 \mathrm{nCi} / \mathrm{g}$ in sludge giving $50 \mathrm{nCi} / \mathrm{g}$ in grout assuming the quantity of grout is proportional to the percentage of $Z r$ that remains in the sludge.

(e) $36 \mathrm{nCi} / \mathrm{g}$ level attained by combined leach and removal of "floaty" solids. 
Solution

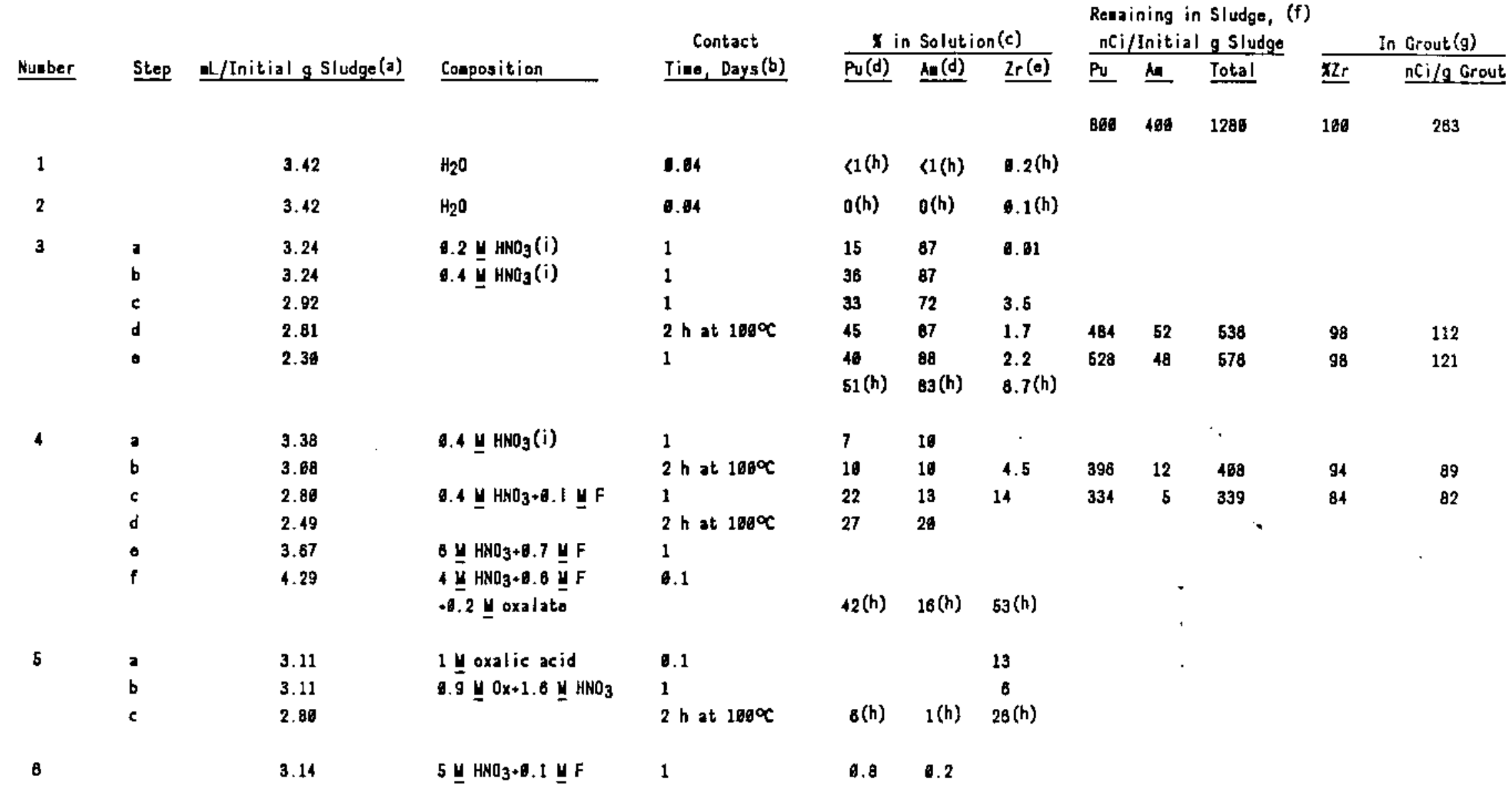

(a) At the beginning of the step.

(b) Days at roon tenperature $\left(-22^{\circ} \mathrm{C}\right)$ unless otherviso indicated.

(c) Based on analysis of 2-p filtrate unless indicated otherwise; seo (h).

(d) Based on the total quantities found in the experiment.

(e) Based on $6.663 \mathrm{~g} \mathrm{Zr} / \mathrm{g}$ initial sludgo; which is representative of the values found in complete dissolution experisents

(f) Including that reacod by preceding leach (if any). Renovais in filtrato are added to provious renoval in filtrate and reaovals in centrato ara added to previous remoral in centrate.

(g) Based on $243 \mathrm{nCi} / \mathrm{g}$ in sludge giving $50 \mathrm{nCi} / \mathrm{g}$ in grout, assuning the quantity of grout is proportional to the percentage of $\mathbf{Z r}$ that reaains in the sludge.

(h) Based on analysis of a portion of the centrate and the 'floaty' solids that accompanied the centrate when it ras reaved.

(i) Resultant pH (after contact) was 3.1 for the $0.2 \mathrm{M} \mathrm{HNO}$ leach, 1.2 for the first 1 y HNO leach (both before and after heating to $1090^{\circ}$ ), and 0.9 for the second $0.4 \mathrm{HNa}$ leach solution. In an earlier experiment (15), $\mathrm{pH}^{\prime} \mathrm{s}$ of consecutivo $3.3 \mathrm{ml} / \mathrm{g}$ water washes were 12.8 and 12.2 . 
Table 6. Detailed Results of Experiatent 20 (0xidative Leaching)

Solution

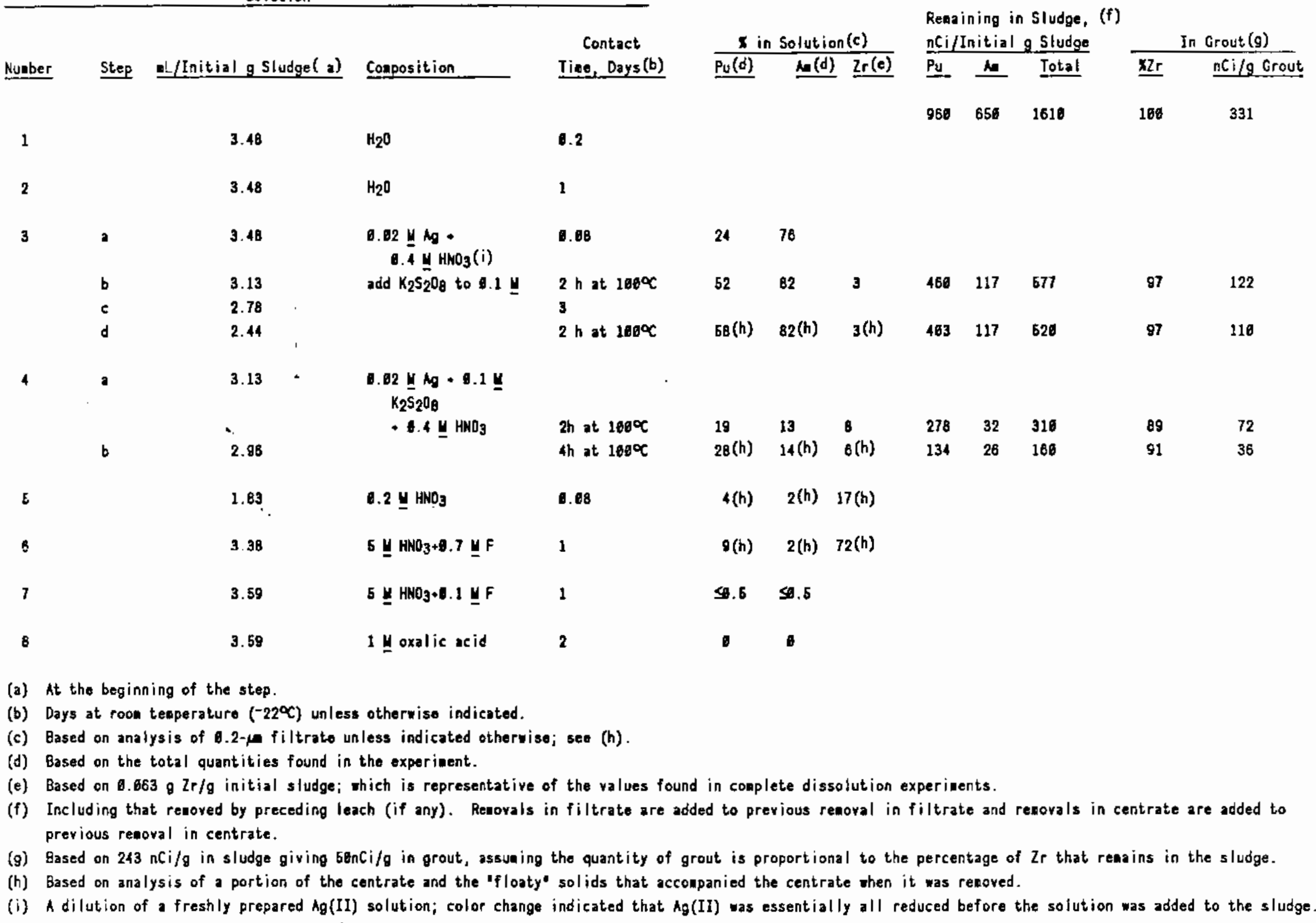


Table 7. Detailed Results of Exporiment 24

Solution

Number Step L/Initial g Sludge (a) Contact

Tine, Days(b) Pu(d) Aa(d) $\underline{\operatorname{Zr}(c)}$

Remaining in sludge, ( $f$ ) $\frac{\text { nCi/Initial g Sludge }}{\text { Pu An }} \stackrel{\text { Intal Grout (g) }}{\text { An }}$

$810 \quad 639 \quad 1440$
2

3

a
c

4

$a$
$b$

5

$\begin{array}{ll}\text { b } & 3.25 \\ \text { c } & 4.92 \\ d & 3.91 \\ & 5.88\end{array}$

6

7

3.32
3.32

3.25
2.54
2.15
1.76

3.25
2.85
2.48

3.25
4.92
3.91
5.88

3.13

3.91
$\mathrm{H}_{2} \mathrm{O}$

$\mathrm{H}_{2} \mathrm{O}$

$0.4 \mathrm{yHC} 3$

$0.4 \pm \mathrm{HNO}_{3}$

$8.4 \underline{\mathrm{HNO}} 3+0.1 \mathrm{UF}$ $5 \mathrm{HNO}+1 \mathrm{H} .1 \mathrm{~F}$

5 y $\mathrm{HNO}_{3}+\mathrm{Q} . \mathrm{Q} \mathrm{Y} F$

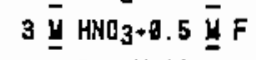

*6. 8 시

1 oxalic acid

$2 \mathrm{HCl}$
9.88

c.

$1244 \quad 75 \quad 3$

1

6

$\begin{array}{lll}33 & 79 & 1 \\ 38(h) & 84(h) & \end{array}$

$543 \quad 132$

675

99

140

i h at $1600 \mathrm{C}$

3

8
$4(h)$

15

3

518

$107 \quad 626$

95(i)

135

1

1

1

$5 \sigma(h)$

$10(\mathrm{~h})$

$-4-1$

$-10$

(a) At the beginning of the step.

(b) Days at roon temperature $\left(-22^{\circ} \mathrm{C}\right)$ unless othorwiso indicated.

(c) Based on analysis of $9.2-\mu$ filtrate unless indicated othervise; seo (h).

(d) Based on the total quantities found in the experiment.

(e) Based on $6.963 \mathrm{~g} \mathrm{Zr} / \mathrm{g}$ initial sludge; thich is representative of the values found in coaplete dissolution experinents.

(f) Including that resoved by proceding leach (if any). Reavals in filtrato are added to previous reasoval in filtrate and removals in centrate aro added to previous renoval in centrata.

(g) Based on $243 \mathrm{nCi} / \mathrm{g}$ in sludga giving $50 n \mathrm{Ci} / \mathrm{g}$ in grout, assuaing the quanticy of grout is proportional to the percentage of $2 \mathrm{r}$ that reasins in the sludge.

(h) Based on analysis of a portion of the centrate and the 'floaty' solids that accoapanied the centrate when it was reaoved.

(i) Value estinted for the purpose of caleulating a value for $\mathrm{nCi} / \mathrm{g}$ in grout. 
Solution

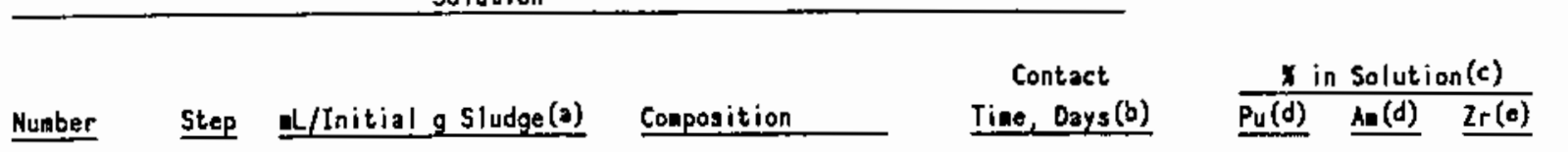

4

a

5

8
3.28

2.45

2.64

2.20

1.90

$3.26-\mathrm{H}_{2} \mathrm{O}$

3.28

2.95

2.84

3.92

3.11
$\mathrm{H}_{2} \mathrm{O}$

$\mathrm{H}_{2} \mathrm{O}$

$0.4 \mathrm{HNO}$

0.1

3

1

$4 \mathrm{~h}$ at $65^{\circ} \mathrm{C}$

2

$4 \mathrm{~h}$ at $100^{\circ} \mathrm{C}$

1

0.4 HNO3

$5 \mathrm{H} \mathrm{HO}_{3}+6.1$ U

1 y oxalic acid

ith at 1690

38 77

5(h) 1 (h)
Contact
Tine, Days (b) $\quad \underline{\text { Pu Solution(c) }}$

Remaining in Sludge, (f)

nCi/Initio g Sludgo

Pu A Total

$\frac{\text { In Grout(g) }}{\underline{\text { xzr }} \quad \text { nCi/g Grout }}$

$1060 \quad 699 \quad 1609$

100

329

B. 6 (h)

$0.1(h)$

2

$33 \quad 69 \quad 2$

45 (h) $89(h)$

$\begin{array}{rr}9 & 9 \\ 12 & 9\end{array}$

19 (h) 11 (h)

$580 \quad 84 \quad 584$

$95(i)$

126

(a) At the beginning of the step.

(b) Days at room teaperature $\left(-22^{\circ} \mathrm{C}\right)$ unless otherwise indicated.

(c) Based on analysis of $0.2-$ e filtrato unless indicated otherwise; see (h)

(d) Based on the total quantities found in the experiment.

(e) Based on $0.063 \mathrm{~g} \mathrm{Zr} / \mathrm{g}$ initial sludge; thich is representative of the values found in cooplete dissolution oxperients.

(f) Including that rewored by preceding leach (if any). Renovals in filtrate aro added to previous removal in filtrate and reaovals in centrate are added to provious removal in centrate.

(g) Based on $243 \mathrm{nCi} / \mathrm{g}$ in sludge giving $5 \mathrm{gnCi} / \mathrm{g}$ in grout, assuming the quantity of grout is proportional to the percentage of $\mathrm{Zr}$ that renains in the s/udge.

(h) Based on analysis of a portion of the centrate and the 'flozty' solids that acconpanied the centrate when it was rearod.

(i) Value estiated for the purpose of calculating a value for $\mathrm{nCi} / \mathrm{g}$ in grout. 
Solution

\begin{tabular}{|c|c|c|c|c|c|c|c|c|c|c|c|c|}
\hline \multirow[b]{2}{*}{ Number } & \multirow[b]{2}{*}{ Step } & \multirow[b]{2}{*}{ L/Initial g Sludge(a) } & \multirow[b]{2}{*}{ Conposition } & \multirow{2}{*}{$\begin{array}{c}\text { Contact } \\
\text { Time, Days (b) }\end{array}$} & \multicolumn{3}{|c|}{ in Solution (c) } & \multicolumn{3}{|c|}{$\begin{array}{l}\text { Resaining in Sludge, ( } f \\
\text { nci/Initial g Sludge }\end{array}$} & \multicolumn{2}{|c|}{ In Grout (g) } \\
\hline & & & & & Pu (d) & 스(d) & $\operatorname{Zr}(\mathrm{e})$ & $\underline{P u}$ & A & Total & $\underline{Z} \mathbf{r}$ & nCi/g Grout \\
\hline & & & & & & & & 910 & 800 & 1510 & 100 & 311 \\
\hline 1 & & 3.27 & $\mathrm{H}_{2} \mathrm{O}$ & 1 & & & & & & & & \\
\hline 2 & & 3.27 & 6.1 y $\mathrm{NaOH}$ & 1 & & & & & & & & \\
\hline \multirow[t]{4}{*}{3} & a & 3.27 & $0.4 \unrhd \mathrm{HNO}_{3}$ & 6.1 & & & & & & & & \\
\hline & b & 2.97 & & 1 & 28 & 66 & 2 & & & & & \\
\hline & c & 2.67 & & $4 \mathrm{~h}$ at $1800^{\circ} \mathrm{C}$ & 34 & 66 & 1 & 601 & 84 & 885 & 99 & 143 \\
\hline & $d$ & 2.38 & & 1 & $14(h)$ & $62(h)$ & 6(h) & & & & & \\
\hline \multirow[t]{3}{*}{4} & 2 & 3.27 & $0.4 \underline{\underline{y}} \mathrm{NNO}_{3}$ & 4 & 8 & Б & 6 & & & & & \\
\hline & b & 2.91 & & 4 h at 10000 & 14 & 7 & 8 & 473 & 42 & 515 & 92 & 115 \\
\hline & $c$ & 2.81 & & 1 & $19(h)$ & $10(h)$ & $16(h)$ & & & & & \\
\hline 5 & & 3.78 & $5 \mathrm{MNO}+0.1 \mathrm{YF}$ & 1 & $32(h)$ & $7(h)$ & & & & & & \\
\hline 8 & & 2.97 & 1 如alic acid & 0.1 & $8(h)$ & $1(h)$ & & & & & & \\
\hline
\end{tabular}

(a) At the beginning of the step.

(b) Days at roou telperature $(-22 \propto)$ unless otherwise indicated.

(c) Based on analysis of 2-fa filtrate unless indicated othorviso; see (h).

(d) Based on the total quantities found in the experisent.

(e) Based on $0.063 \mathrm{~g} 2 \mathrm{r} / \mathrm{g}$ initial sludge; which is representative of the values found in complete dissolution experinents.

(f) Including that renoved by preceding loach (if any). Renovals in filtrato are added to previous removal in filtrate and removals in centrate are added to previous removal in centrate.

(g) Bised on $243 \mathrm{nCi} / \mathrm{g}$ in sludgo giving $59 \mathrm{nCi} / \mathrm{g}$ in grout, assuging the quantity of grout is proportional to the percentage of $\mathrm{Zr}$ that reasins in the sludge

(h) Based on analysis of a portion of the centrate and the 'floaty' solids that accompanied the centrate when it was renoved. 
Solution

\begin{tabular}{|c|c|c|c|c|}
\hline & & -latiol studa(a) & & Contact \\
\hline Number & Step & -L/Initial g Sludge(a) & Conposition & Tiav, Days \\
\hline
\end{tabular}

2

$\begin{array}{ll}\text { a } & 3.26 \\ \text { b } & 2.88 \\ & 2.34\end{array}$

in
5
3.28

3.26

2.34

3.28

3.58

3.54
$\mathrm{H}_{2} \mathrm{O}$

$\mathrm{H}_{2} \mathrm{O}$

$0.2 \underline{\mathrm{HNO}_{3}}$

0.2 ․№3

5 ע $\mathrm{HNO}_{3}+6.1 \mathrm{H}$

1 oxalic acid
Rewoining in Sludge, $(f)$

nCi/Initial g Sludgo

Pu An Totz!

$\frac{\text { In Grout }(g)}{\underline{\text { XZr }} \quad \text { nCi/g Grout }}$

$\begin{array}{llll}829 & 87 & 707 & 198\end{array}$

145

6.68

$2 h$ at $160^{\circ}$

$\begin{array}{lll}B & 33 & 8.3\end{array}$

$570 \quad 58$

628

196

129

28 (h) $52(h) 10(h)$

$2 \mathrm{~h}$ at $180^{\circ}$

-8 (i) -12 (i) 7

Is(h) 17 (h) $15($ h)

$521 \quad 39$

568

93

123

(a) At the beginning of the step.

(b) Days at roon tenperature $\left(-22^{\circ} \mathrm{C}\right)$ unless otherviso indicated.

(c) Based on analysis of 9.2-pe filtrate unless indicated otherwise; seo (h).

(d) Based on the total quantities found in the experinent.

(e) Based on $6.653 \mathrm{~g} \mathrm{zr} / \mathrm{g}$ initial sludge; which is representative of the values found in coaplete dissolution experinents.

(f) Including that reaved by preceding leach (if any). Renovals in filtrate are added to previous removal in filtrate and renovals in centrate are added to previous removal in centrate.

(g) Based on $243 \mathrm{nCi} / \mathrm{g}$ in sludge giving $59 \mathrm{nCi} / \mathrm{g}$ in grout, assuaing the quantity of grout is proportional to the percentago of $\mathrm{Zr}$ that reaains in the sludge.

(h) Based on analysis of a portion of the centrate and the 'floaty" sofids that acconpanied the centrate uhen it was renoved.

(i) Values estinated from early analysis of this and other sapies and subsequent reanlaysis of othe: samples. 
Table 11. Major Metal Ions in Sludge Composites Used

\begin{tabular}{|c|c|c|c|c|c|c|c|c|c|c|c|c|}
\hline \multirow[b]{2}{*}{ Tank } & \multirow[b]{2}{*}{ Composite } & \multirow[b]{2}{*}{ Expt } & \multicolumn{6}{|c|}{ g Metal/g Sludge } & \multirow[b]{2}{*}{$\mathrm{Mn}$} & \multirow[b]{2}{*}{$\mathrm{Cr}$} & \multirow[b]{2}{*}{$\mathrm{Ca}$} & \multirow[b]{2}{*}{ La } \\
\hline & & & $\mathrm{Na}$ & $\mathrm{Zr}$ & U & $K$ & $\mathrm{Fe}$ & Al & & & & \\
\hline \multirow[t]{4}{*}{105} & 1 & 2 & 0.097 & 0.065 & 0.012 & 0.0079 & 0.0034 & 0.0029 & 0.0021 & 0.0014 & 0.0013 & 0.00035 \\
\hline & & 6 & 0.083 & 0.061 & 0.011 & 0.0072 & 0.0030 & 0.0025 & 0.0019 & 0.0013 & 0.0011 & 0.00031 \\
\hline & & 17 & 0.094 & 0.063 & 0.012 & 0.0079 & 0.0031 & 0.0026 & 0.0019 & 0.0013 & 0.0009 & 0.00033 \\
\hline & & Avg & 0.091 & 0.063 & 0.012 & 0.0077 & 0.0032 & 0.0027 & 0.0020 & 0.0013 & 0.0011 & 0.00033 \\
\hline 105 & 2 & 26 & 0.103 & 0.062 & 0.013 & 0.0080 & 0.0037 & 0.0030 & 0.0021 & 0.0014 & 0.0012 & 0.00035 \\
\hline 103 & 1 & 30 & 0.118 & 0.069 & 0.0076 & 0.012 & 0.00038 & 0.0065 & $2 \times 10^{-5}$ & 0.0014 & 0.00012 & 0.00019 \\
\hline
\end{tabular}


Table 12. Behavior of Major Sludge Metal Ions During Washing and Leaching in Experiment 15

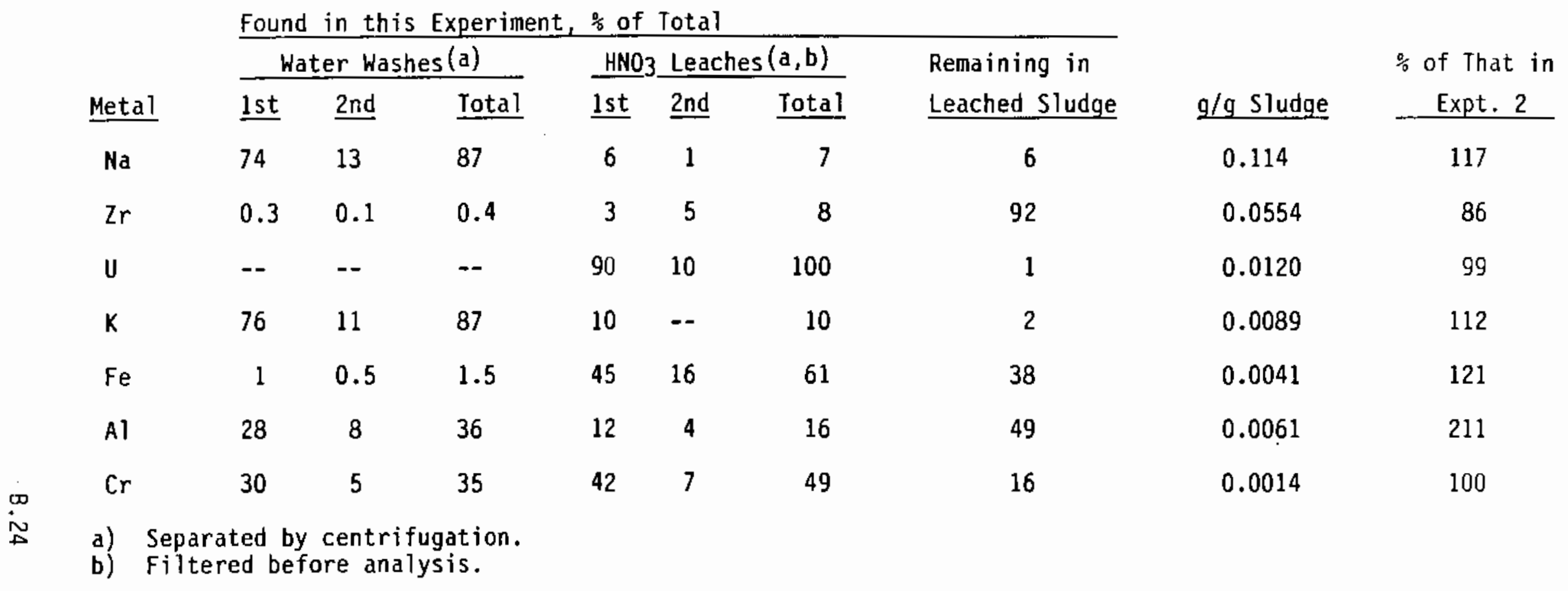




\section{APPENDIX C}

TRUEX PROCESSING OF NCRW SLUDGE, STATUS REPORT 


\section{A LETTER REPORT FOR WESTINGHOUSE HANFORD COMPANY}

TRUEX PROCESSING OF NCRW SLUDGE, STATUS REPORT

J. L. Swanson

June 1989

Prepared for

the U.S. Department of Energy

under Contract DE-ACO6-76RLO 1830

Pacific Northwest Laboratory

Richland, Washington 99352 


\section{SUMMARY}

Separation of the transuranic elements and the inert components of neutralized cladding removal waste (NCRW) sludges by solvent extraction (employing the TRUEX process) following acid dissolution of the sludge is under study. The initial results are very promising; they indicate that the bulk of the sludge can be dissolved in nitric acid (without heating) and that $\mathrm{Pu}$ and $\mathrm{Am}$ can be extracted away from $\mathrm{Zr}$, and other inert components, by appropriate extraction and scrubbing conditions. The extraction raffinate should be suitable for disposal as low-level waste, and the extracted Pu and An can be stripped for disposal as transuranic (TRU) waste (presumably in a glass waste form).

Some problems remain to be completely resolved; a principal one is the establishment of reproducible conditions that avoid the formation of solids in the solvent extraction steps. Also needed is more information in several areas that are important to plant design. Among these are dissolution end point control, properties of residual solids, and offgas compositions. These three areas will be studied in the next stage of this project. 


\section{INTRODUCTION}

The neutralized cladding removal waste (NCRW) sludges that are stored in Tanks 103-AW and 105-AW contain higher than anticipated levels of the transuranic (TRU) elements Pu and Am. These higher levels preclude final disposal of these wastes as grout in near surface vaults. This led to the initiation of an experimental program at the Pacific Northwest Laboratory (PNL) to investigate possible means of separating the TRU elements from other siudge components, especially $\mathrm{Zr}$, so that the fraction of this waste that could be disposed as grout in near surface vaults (as opposed to as glass in a geologic repository), would be maximized.

The initial portion of the PNL study (Appendix A) involved scouting studies, with NCRW sludge from 105-AW, of : a) completeness of fluoride removal on washing with water, b) separation of $\mathrm{Pu}$ and Am solids from $\mathrm{Zr}$ solids by differences in settling rates, c) selective leaching of Pu and Am away from $\mathrm{Zr}, \mathrm{d}$ ) complete dissolution of the sludge, and e) separation of dissolved $\mathrm{Pu}, \mathrm{Am}$, and $\mathrm{Zr}$ by solvent extraction or by precipitation of $\mathrm{LaF}_{3}$. Those studies indicated that the most promising approach involved selective leaching of the $\mathrm{Pu}$ and $\mathrm{Am}$, after water washing to remove fluoride. The results also indicated that sufficient selective leaching might be attainable using dilute nitric acid alone, especially at an elevated temperature, and that even better selective leaching of Pu could be achieved using certain oxidative conditions.

The second portion of the study (Appendix B) investigated more completely the selective leaching of $\mathrm{Pu}$ and Am using dilute nitric acid (following waterwashing to remove fluoride). Oxidants were not used in these tests because of the desire to keep the process simple. Leaching of most of the Pu and Am was achieved, but the extent of removal was not sufficient to allow disposal of the residue as low-level waste; typically, leaching could be achieved only to the extent that a grout could be made that contains $-90 \%$ of the $\mathrm{Zr}$ at a TRU level of $-120 \mathrm{nCi} / \mathrm{g}$.

The third portion of the study, which is the subject of this report, was to center on developing a flowsheet employing the TRUEX solvent extraction 
process on feeds obtained by dissolving the sludges in acid solutions. Two approaches were planned for investigation; the first approach involved water washing to remove fluoride and then dissolving the washed sludge in oxalic acid or in mixed nitric/oxalic acids, while the second approach involved simply dissolving the unwashed sludge in nitric acid and accepting the corrosion problems of acidic fluoride solutions. Some promising results were obtained in the first approach, but the investigation was plagued by poorly understood precipitation processes that gave $\mathrm{Pu}$ - and Am-containing solids. Because of this problem, and because of the growing realization that waterwashing to remove fluoride would be a formidable problem because of solidliquid separation difficulties, the first approach was dropped and the experimental effort was centered on TRUEX solvent extraction following nitric acid dissolution of unwashed sludge. The results of that effort to date are the subject of this report. 


\section{METHODS_AND MATERIALS}

The NCRW sludge samples used in this work were the 103-AW and 105-AW composite samples prepared and described last year (Appendix B). These composites contained portions of each segment (including the heel) of core samples taken from the individual tanks. The composites had dried on standing; they were returned to their original paste-like form by adding water before they were divided out for use here.

The TRUEX solvent $(0.2 \underline{M}$ CMPO $+1.4 \underline{M}$ TBP in NPH) used in this work was provided by Dan Herting of WHC. It had been washed with $0.1 \mathrm{M} \mathrm{Na}_{2} \mathrm{CO}_{3}$ and 0.01 $\underline{\mathrm{MNO}} \mathrm{H}_{3}$ after it was prepared. It was re-washed with dilute carbonate periodically during the course of this work. The HEDPA (1-hydroxyethane-1, 1diphosphonic acid) used in the strip solutions was also provided by Herting.

\section{SLUDGE DISSOLUTION}

The NCRW sludge samples were dissolved (in plastic vials) by first adding water, then stirring to suspend the solids, and then adding $16 \mathrm{MHNO}_{3}$ dropwise while stirring. There was essentially no sign of a reaction occurring (other than a clearing of the solution) except at an intermediate range in the addition, where the solution "fizzed" due to gas evolution (the gas was doubtless $\mathrm{CO}_{2}$ released from carbonate when the $\mathrm{pH}$ became low enough for that release to occur). There was no stable foam formation.

When the chosen reaction period had been completed, the slurry was filtered through a $0.2 \mu \mathrm{m}$ filter (these filtrates provided the feeds for subsequent solvent extraction tests). The residual solids were washed with water and then returned to a plastic vial, where they were dissolved by heating in $-5 \mathrm{M} \mathrm{HNO}_{3}+\sim 0.5 \mathrm{M} \mathrm{HF}$.

\section{SOLVENT EXTRACTION CONTACTS}

The solvent extraction contacts were performed in small glass vials, which were shaken manually for one minute and the centrifuged to effect phase clarification. Organic phase samples were not analyzed directly for TRU and metal ion concentrations; instead, these values were deduced by calculation 
from the concentrations found in the aqueous phases of other contacts and from the phase ratios used in the contacts. These "material balance concentrations" were sometimes based on the initial concentrations, but were usually determined from the concentrations found in subsequent scrub and/or strip contacts (the concentrations in the final stripped organic phase were assumed to be zero in these calculations). This material balance procedure is more uncertain than if each organic phase had been individually stripped for analysis, but it is much more efficient in terms of sample consumption and of manpower and is certainly accurate enough to give distribution coefficient values that are good to one significant figure, which is adequate for the current needs.

\section{ANALYTICAL PROCEDURES}

The concentrations of $\mathrm{Pu}$ and Am were determined by alpha counting on our in-Taboratory counter, using the procedure developed last year for treatment of the counting data (see Appendix B--Treatment of Alpha Counting Data). Due to additional decay of ${ }^{241} \mathrm{Pu}$ to ${ }^{241} \mathrm{Am}$, the ${ }^{238} \mathrm{Pu}$ activity in the Tank 103 - $\mathrm{AW}$

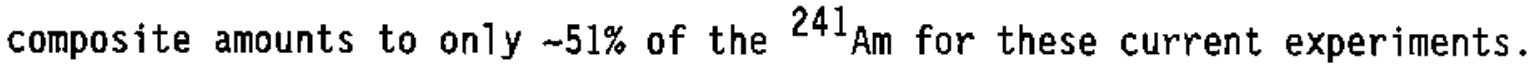

Bulk metal ion concentrations were determined by ICP analysis, using the shielded unit in 325-A Building. Fluoride concentrations were measured in our laboratory, using a specific ion electrode. Organic phase fluoride (and acid) concentrations were determined by adding a small volume of organic to a large volume of water, titrating the acid while stirring the two phases, and then measuring the concentration of fluoride in the aqueous phase.

Acid concentrations were determined in most cases by measuring the amount of $\mathrm{NaOH}$ required to titrate the sample to $\mathrm{pH}=7$ and subtracting from that value the amount of $\mathrm{NaOH}$ required to hydrolyze the concentration (based on the ICP results) of hydrolyzable metal ions (e.g., $\mathrm{Zr}, \mathrm{Al}, \mathrm{Cr}, \mathrm{Fe}$ ) present in the sample. The concentrations determined in this way to be present in the feed solutions and in the extracted aqueous phases are not very precise because the titration curve does not have a very sharp endpoint (see Figure 1), and because the hydrolyzable metal ion correction is reiatively large. However, the values determined to be present in organic solutions and the scrub 


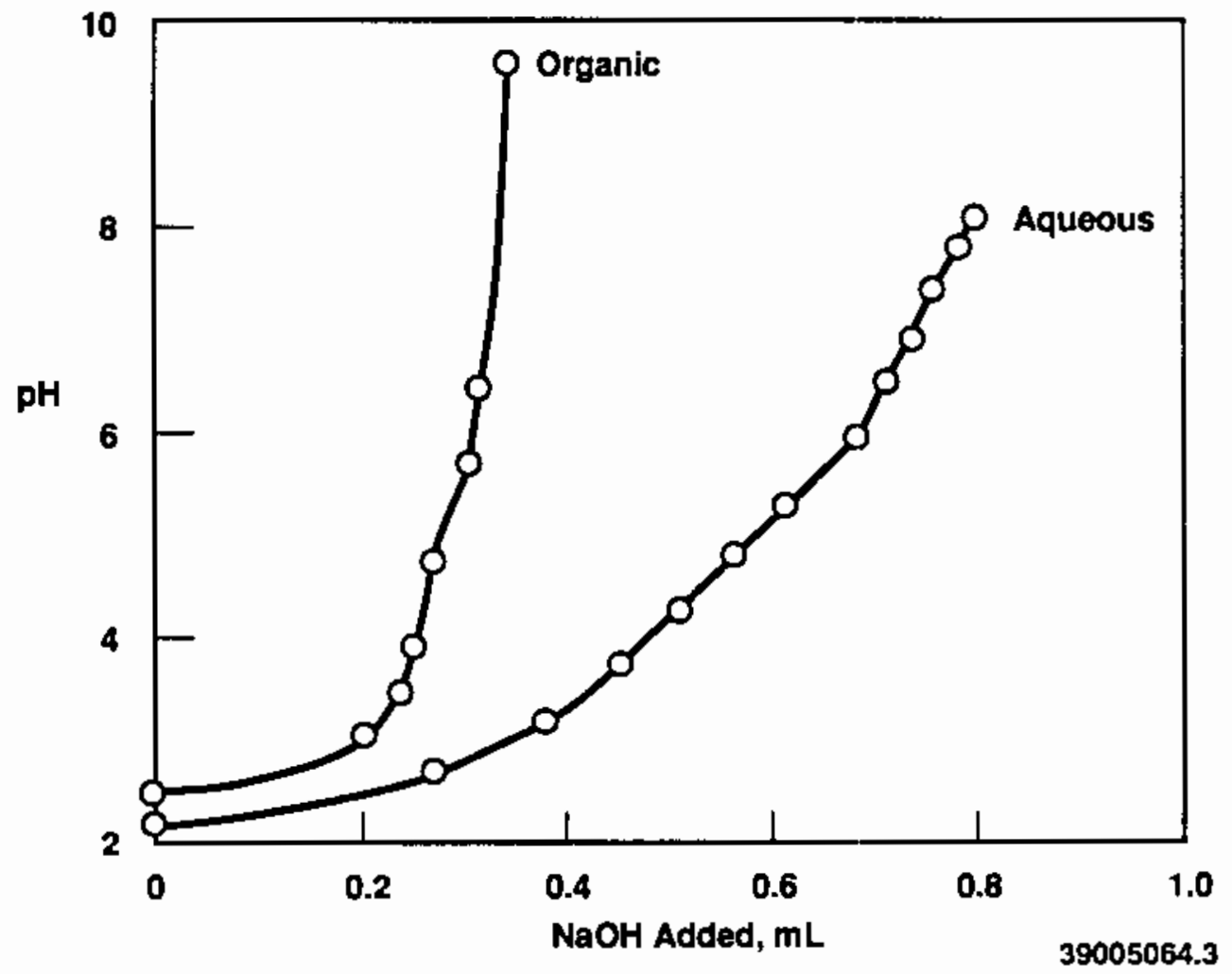

FIGURE 1. Typical Titration Curves for Aqueous and Organic Samples 
solutions should be quite good. The acid concentrations in the HEDPA strip solutions were determined by titrating to $\mathrm{pH}=5$ and subtracting the amount due to the HEPDA itself; these acid concentrations were often relatively imprecise because of the large HEDPA correction.

The hydrolyzable metal ion corrections used in determining acid concentrations were based on two hydroxides per mole of $\mathrm{Zr}$ and three hydroxides per mole of $\mathrm{Al}+\mathrm{Cr}+\mathrm{Fe}$. This implies that the principal zirconium species in solution is $\mathrm{ZrO}^{++}$or $\mathrm{Zr}(\mathrm{OH}) 2^{++}$. The chemistry of zirconium is not well enough known to state this with certainty, which introduces yet another uncertainty into the acid concentration values listed here (especially in the feed and extracted aqueous solutions). 


\section{RESULTS AND DISCUSSION}

A proposed flowsheet for the TRUEX processing of NCRW sludge, which is based on the results of the experimental work and other knowledge, is contained in Figures 2 (the dissolution process) and 3 (the solvent extraction process). These flowsheets will be discussed first and then the experimental detajls and results will be discussed more fully.

\section{PROPOSED FLOWSHEET}

The sludge dissolution flowsheet (Figure 2) includes a primary dissolver, where most of the sludge is dissolved, and a secondary dissolver, where the residual solids from the primary dissolution step are dissolved in stronger acid, with heating (and are then recycled to the primary dissolver). The solids from the primary dissolution step could instead be sent directly to the glass-making process and still greatly $(-10$-fold) reduce the amount of waste glass (over the untreated case), but it is felt that the secondary dissoiution step will be cost-effective. However, periodic removal of these solids directly to glass every tenth batch is included so that tramp solids (dirt, etc.) will not build up excessively; this will result in $\sim 0.5 \%$ of the zirconium in the sludge going to glass. Even that amount could be decreased by adding a filtration step between the secondary and the primary dissolvers (to remove the tramp solids there), but that is not included in this flowsheet. Heating during the primary dissolution step is not required for dissolution of the (bulk of the) sludge, but it may be important to avoiding the formation of interfacial crud in the TRUEX extraction step, and may be included in the process.

The $\mathrm{Zr}$, $\mathrm{Na}$, fluoride, and hydroxide concentrations in the sludge that are shown in Figure 2 were obtained from typical values found in the experiments, using a sludge density of 1.35. The carbonate concentration is an average of the values found in some early work by others.

The solvent extraction flowsheet (Figure 3) is based on results of batch contact experiments with feeds prepared by dissolution of NCRW sludge, and on the flowsheet that has been proposed for use with $C C$ waste. Three stages are 


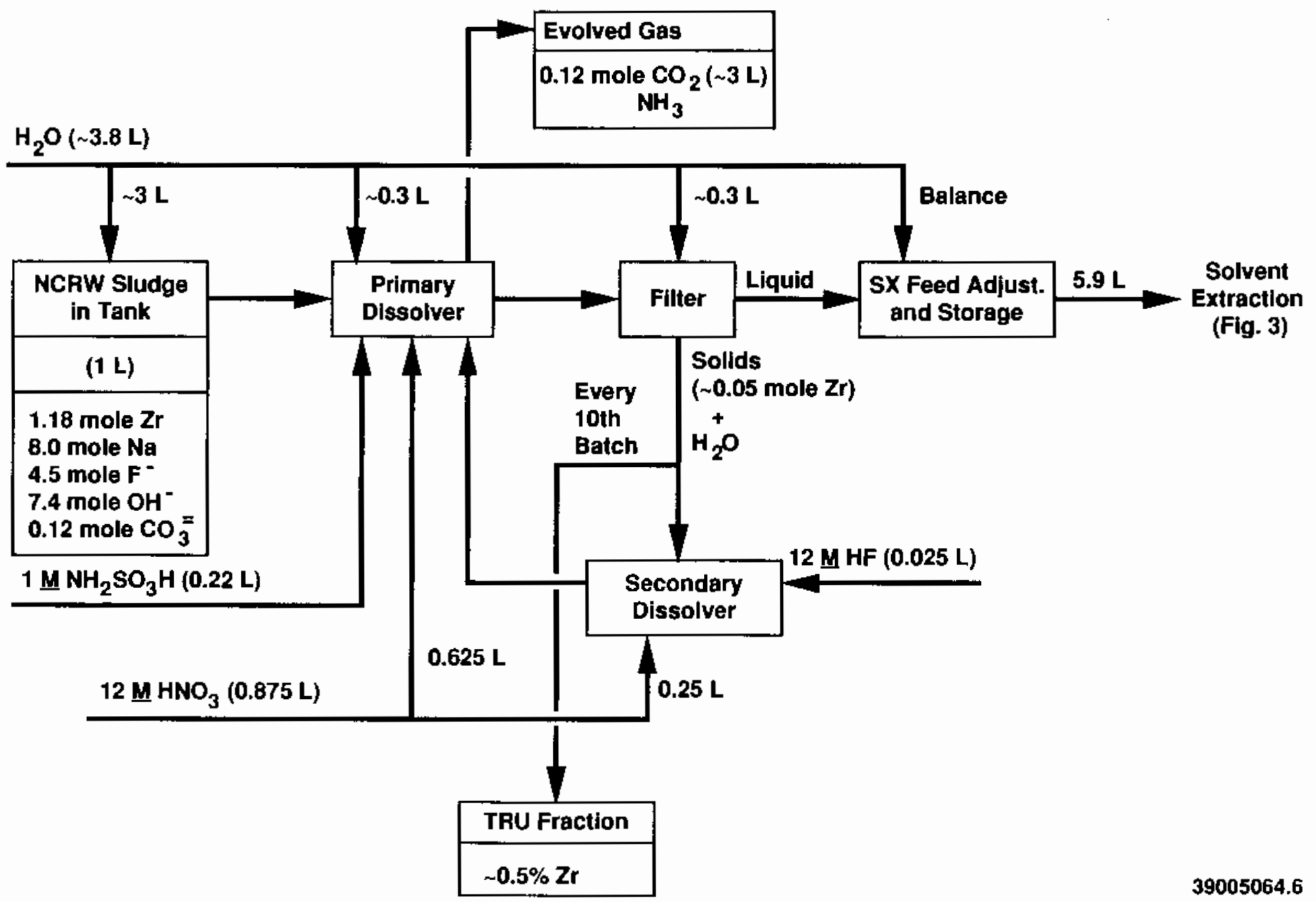

FIGURE 2. Dissolution of NCRW Sludge 


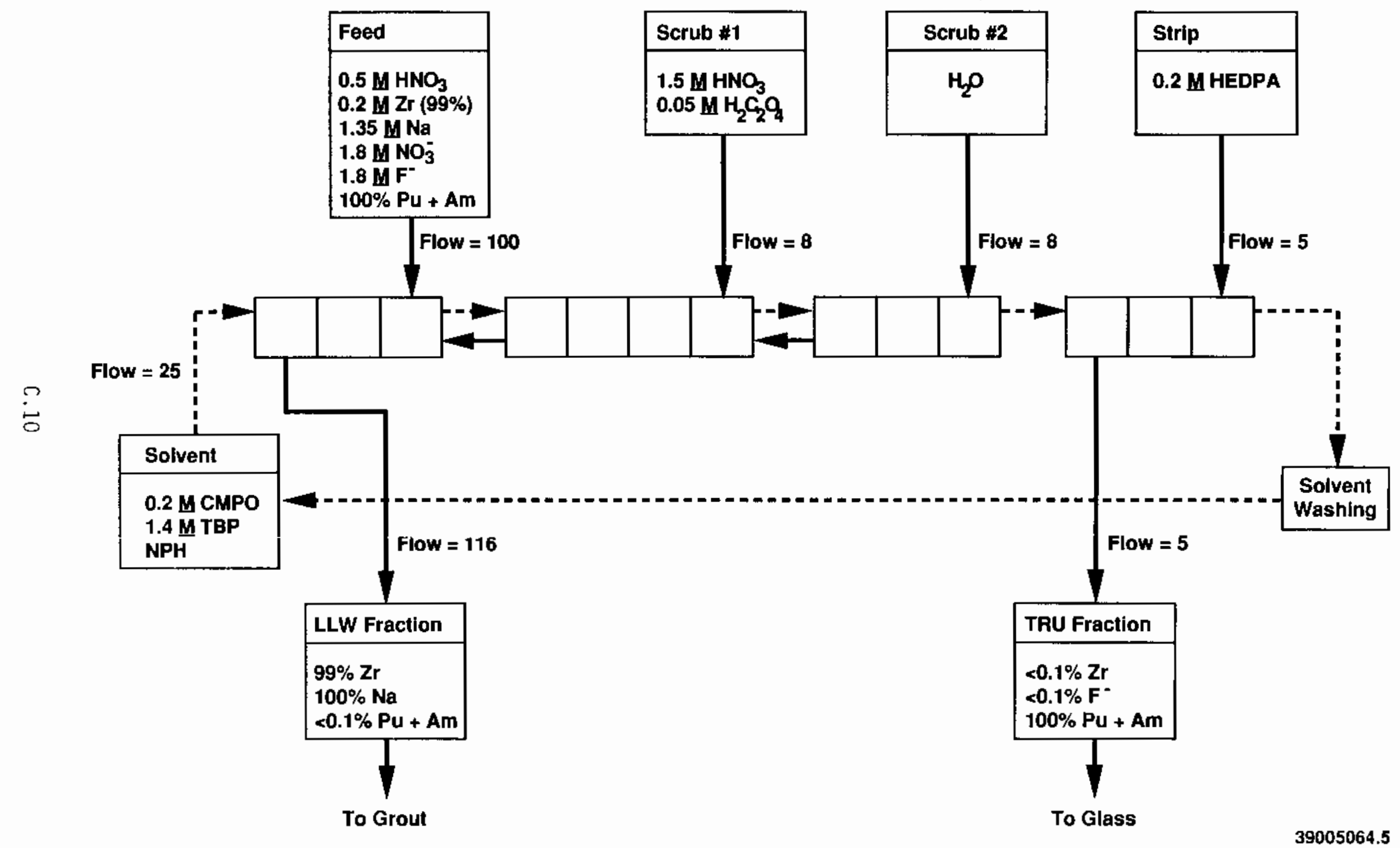

FIGURE 3. TRUEX Processing of Dissolved NCRW Sludge 
included in the extraction bank even though two could well be sufficient. Appreciable extraction (0 0.2 to 0.3 ) of both zirconium and fluoride will occur, but they are removed by scrubbing with a mixture of nitric and oxalic acids (Scrub \#1). Four stages are included in the first scrub section; with the flow ratio listed, this should decrease the amounts of zirconium and fluoride left in the organic phase to $<0.1 \%$ of the total.

This first scrub section should be the subject of more study. It would be desirable to decrease the $\mathrm{HNO}_{3}$ concentration so that less $\mathrm{HNO}_{3}$ would have to be removed in the second scrub section. Of perhaps greater concern is that the addition of oxalate can lead to the formation of precipitates in the raffinate stream. This precipitation occurs slowly, so there appears to be little danger of precipitation within the extraction contactor, but it may be desirable to try to avoid such precipitation completely.

The second scrub section and the strip section are patterned after the CC flowsheet. The water scrub is aimed solely at decreasing the concentration of $\mathrm{HNO}_{3}$ in the organic phase so that stripping will be more efficient in the following section. Minimal effort was given to stripping the extracted metals into HEDPA; stripping was found to be quite efficient.

\section{DETAILEO RESULTS}

In this section are discussed the results obtained on dissolution completeness and feed solution composition and on the results of batch contacts simulating conditions in the extraction, scrubbing, and stripping portions of the TRUEX flowsheet. Gas evolution during sludge dissolution is also discussed.

\section{Sludge Dissolution}

The resuits of the tests done this year on the primary dissolution of NCRW sludge by nitric acid are summarized in Tables 1 and 2 . Table 1 contains listings of the quantities used in the test, the dissolution time and temperature conditions, the percentages of the components that were not in solution at the end of the test, and the total quantities found in both the primary and 
TABLE 1. Summary of Primary Dissolution Condition, Dissolution Completeness, and Total Quantities in Sludge

\begin{tabular}{|c|c|c|c|c|c|}
\hline Expt. \# & 34 & 37 & 46 & 47 & 41 \\
\hline Tank\# & 103 & 103 & .103 & 103 & 105 \\
\hline g sludge & 2.65 & 3.23 & 2.95 & 2.69 & 2. \\
\hline $\mathrm{H}_{2} \mathrm{O}$ added, mL & 14 & 7.2 & 7.2 & 12.1 & 12. \\
\hline $16 \underline{\mathrm{M} \mathrm{HNO}} \mathrm{H}_{3}$ added, $\mathrm{m} 1$ & 1.44 & 1.36 & 1.36 & 1.50 & 1 . \\
\hline Resulting volume, $\mathrm{mL}$ & 17.5 & 10.8 & 10.3 & 15.6 & 15. \\
\hline Diss. time, $h$ & 2 & 4 & 4 & 2 & 5 \\
\hline Diss. temp, ${ }^{\circ} \mathrm{C}$ & $r . t^{(a)}$ & r.t & $100^{\circ(b)}$ & r.t. & $r$ \\
\hline \multicolumn{6}{|l|}{$\%$ Undissolved } \\
\hline $\mathrm{Pu}$ & 18 & 5 & 8 & (c) & 4 \\
\hline Am & 7 & 2 & 2 & (c) & 1 \\
\hline $\mathrm{Zr}$ & 4 & 7 & 45 & (c) & 2 \\
\hline A1 & 28 & 24 & 0 & (c) & 28 \\
\hline $\mathrm{Cr}$ & 29 & 8 & 2 & (c) & 4 \\
\hline $\mathrm{Fe}$ & 15 & 7 & 7 & (c) & 5 \\
\hline $\mathrm{Na}$ & 0 & 0 & 1 & (c) & 0 \\
\hline
\end{tabular}

Total found in sludge, $\mathrm{nCi} / \mathrm{g}$

$\begin{array}{rrrrrr}\mathrm{Pu} & 501 & 432 & 452 & \text { (c) } & 1066 \\ \mathrm{Am} & 90 & 90 & 88 & \text { (c) } & 688\end{array}$

Total found in sludge, $g / g$ sludge

$\begin{array}{llllll}\mathrm{Na} & 0.141 & 0.147 & 0.141 & \text { (c) } & 0.126 \\ \mathrm{Zr} & 0.084 & 0.086 & 0.076 & \text { (c) } & 0.078 \\ \mathrm{~K} & 0.0152 & 0.0155 & 0.0152 & \text { (c) } & 0.0084 \\ \mathrm{Al} & 0.0076 & 0.0075 & 0.0081 & \text { (c) } & 0.0010 \\ \mathrm{Cr} & 0.0022 & 0.0021 & 0.0024 & \text { (c) } & 0.0019 \\ \mathrm{Fe} & 0.00054 & 0.00052 & 0.00055 & \text { (c) } & 0.0048 \\ \mathrm{U} & 0.0096 & 0.0106 & 0.0197 & \text { (c) } & 0.0276\end{array}$

(a) Room temperature $\left(-22^{\circ} \mathrm{C}\right)$.

(b) Digestion at $100^{\circ} \mathrm{C}$ followed acid addition at $22^{\circ} \mathrm{C}$.

(c) Not available because secondary dissolution step was not done. 
IABLE 2. Composition of Filtrates from Primary Dissolutions

\begin{tabular}{|c|c|c|c|c|c|c|c|c|}
\hline \multirow[b]{2}{*}{ Expt. } & \multirow[b]{2}{*}{$\underline{\text { Tank }}$} & \multicolumn{5}{|c|}{ Molarity } & \multicolumn{2}{|c|}{$n C i / m L$} \\
\hline & & $\underline{\mathrm{Na}}$ & $\underline{Z r}$ & Acid & $\mathrm{NO}_{3}^{-(a)}$ & $\mathrm{F}^{-}$ & $\mathrm{Pu}_{\mathrm{u}}$ & Aln \\
\hline 34 & 103 & 0.9 & 0.13 & 0.53 & 1.3 & & 59 & 12 \\
\hline 37 & 103 & 1.6 & 0.22 & 0.38 & 2.0 & 0.84 & 109 & 24 \\
\hline $46^{(b)}$ & 103 & 1.5 & 0.12 & 0.37 & 2.1 & 0.58 & 108 & 22 \\
\hline 47 & 103 & 1.1 & 0.15 & 0.55 & 1.6 & 0.55 & 81 & 11 \\
\hline 41 & 105 & 0.8 & 0.13 & 0.62 & 1.6 & 0.44 & 147 & 90 \\
\hline
\end{tabular}

(a) Based on the amount of $\mathrm{HNO}_{3}$ added.

(b) Digestion at $100^{\circ} \mathrm{C}$; $-45 \%$ of Zr precipitated.

secondary dissolutions. Table 2 lists the compositions of the resulting solutions, which were used as feeds in solvent extraction tests.

In the room temperature dissolution experiments, only 2 to $7 \%$ of the $\mathrm{Zr}$ did not dissolve. However, $45 \%$ of the $\mathrm{Zr}$ was present in the solid phase in the experiment (46) where the solution was digested at $100^{\circ} \mathrm{C}$ following acid addition. It thus appears that some $\mathrm{Zr}$ compound precipitated during the $100^{\circ} \mathrm{C}$ digestion period. It would be interesting to see if such precipitation occurred at a higher acidity.

About one-fourth of the Al did not dissolve in the primary dissolution step at room temperature, but none of the Al remained undissolved in the case that was digested at $100^{\circ} \mathrm{C}$. The $\mathrm{Al}-\mathrm{to}-\mathrm{Zr}$ mole ratios in the room temperature primary dissolution residues were 2.1 and 1.0 in the tests with sludge from 103 -AW and 0.6 in the test with 105-AW sludge.

The portion of $\mathrm{Pu}$ that did not dissolve in the primary dissolution step ranged from 4 to $18 \%$, and the portion of undissolved Am ranged from 1 to $7 \%$. These amounts are more than high enough to give $>100 \mathrm{nCi} / \mathrm{g}$ in the residue. In order to minimize the $\mathrm{Zr}$ (and $\mathrm{A} I$ ) fed to the glass plant, this residue is processed further in the proposed flowsheet. This can be done by dissolving the residue in more concentrated $\mathrm{HNO}_{3}(+\mathrm{HF})$ in a secondary dissolver and processing this material through TRUEX solvent extraction along with the material that dissolved in the primary dissolution. 
The secondary dissolution step was not investigated in detail, but one check of the conditions shown in Figure 2 verified that they would work (most secondary dissolutions were performed solely for analytical reasons and used larger volumes than would be desirable in a process). This test used the residue from Expt. 41, which began with $2.5 \mathrm{~g}$ of the 105 -AW sludge. Nearly all of the residue from the primary dissolution was dissolved within 2 hours at $100^{\circ} \mathrm{C}$ in $1 \mathrm{~mL}$ of $5 \mathrm{M} \mathrm{HNO}{ }_{3}+0.5 \mathrm{MF}$; these conditions correspond to using $\sim 0.4 \mathrm{~L}$ of solution to dissolve the residue from $1 \mathrm{~L}$ of sludge, as opposed to the value of $-0.6 \mathrm{~L}$ of solution per liter of sludge shown in Figure 2. There remained only a trace of undissolved residue, which was brown in color.

\section{Gas Evolution During Dissolution}

Three components of NCRW sludge can lead to gas evolution during sludge handling or dissolution. These components are ammonia, carbonate, and nitrite.

Ammonia may be partially volatilized during transfer, mixing, etc. operations that occur while the slurry is basic. The fraction volatilized would depend on such parameters as time, temperature, degree of mixing, and gas sparge rate (the fraction volatilized would be expected to increase with increases in each of these parameters), and cannot be estimated very quantitatively at this time. However, it is thought to be unlikely that a large fraction of the ammonia would volatilize in the planned steps. Earlier analyses of sludge samples taken in 1986 showed an ammonia concentration of $0.06 \mathrm{M}$ in the 103-AW sludge and $0.09 \mathrm{M}$ in the 105-AW sludge; these concentrations could well be lower now because of gradual volatilization on standing. The ammonia concentrations found in the NCRW sludge in 1986, indicate that less than $1 \%$ of the ammonia charged to PUREX to declad the fuel, was present in the sludge. Is it necessary to be concerned about this small amount of ammonia, especially when the amount released is likely to be a small fraction of that present?

Carbon dioxide will be evolved quantitatively from carbonate when the sludge is acidified for dissolution; because this evolution will not occur until the solution is acidic, it should not affect the ammonia volatilization discussed in the preceding paragraph. To avoid an overly rapid $\mathrm{CO}_{2}$ release, 
which could lead to entrainment of solution out of the dissolver, acid should be added slowly to the well-stirred sludge slurry during the dissolution process. Earlier analyses of samples taken in 1986 showed a carbonate concentration of $0.09 \mathrm{M}$ in the 103-AW sTudge and $0.16 \mathrm{M}$ in the 105-AW siudge in 1986; higher concentrations might exist now due to pickup of $\mathrm{CO}_{2}$ from the air.

The presence of nitrite in the sludge will lead to the evolution of some oxides of nitrogen when the sludge is acidified for dissolution unless a reagent that destroys nitrous acid (e.g., sulfamic acid, hydrazine, hydroxylamine nitrate) is present during acidification. Addition of such a reagent appears to be a prudent step, and sulfamic acid addition has been included in the proposed flowsheet (Figure 2). Sulfamic acid was chosen over hydrazine and hydroxylamine pretty arbitrarily, based on the facts that 1) it reacts rapidly (more so than hydroxylamine) with nitrous acid, 2) it does not reduce $\mathrm{Pu}$ (IV) to $\mathrm{Pu}(\mathrm{III})$, as do hydrazine and hydroxylamine, and 3 ) the presence of its hydrolysis product (sulfate) should pose no problem in grout, even though it does in glass. If the sulfamic acid choice is unpopular, either hydrazine or hydroxylamine could be made to work satisfactorily. Earlier analyses of samples taken in 1986 showed a nitrite concentration of $0.4 \mathrm{M}$ in the 103-AW sludge and $0.02 \underline{M}$ in the 105-AW sludge; the reason for this large variation is unknown.

\section{Extraction Contact Results}

Data obtained when the filtered, dissolved sludge solutions (Table 2) were extracted with TRUEX solvent $(0.2 \underline{\mathrm{M}}$ CMPO $+1.4 \underline{\mathrm{M}}$ TBP in NPH) are summarized in Table 3 . This table gives the volume ratio used in the extraction contact, the concentrations of important components found in both phases, and the distribution coefficients of those components. As was mentioned earlier, the organic phase concentrations (and thus the distribution coefficients) for $\mathrm{Pu}, \mathrm{Am}$, and $\mathrm{Zr}$ are relatively imprecise because they are based on the concentrations found in the aqueous phases of subsequent (or preceding) contacts, and on the volume ratjos used. However, it is very clear from these data that the $\mathrm{Pu}$ and Am distribution coefficient values in the first extraction contacts are in the range 20 to 200 , while the $\mathrm{Zr}$ extraction 
TABLE 3. Results of Extraction Contacts

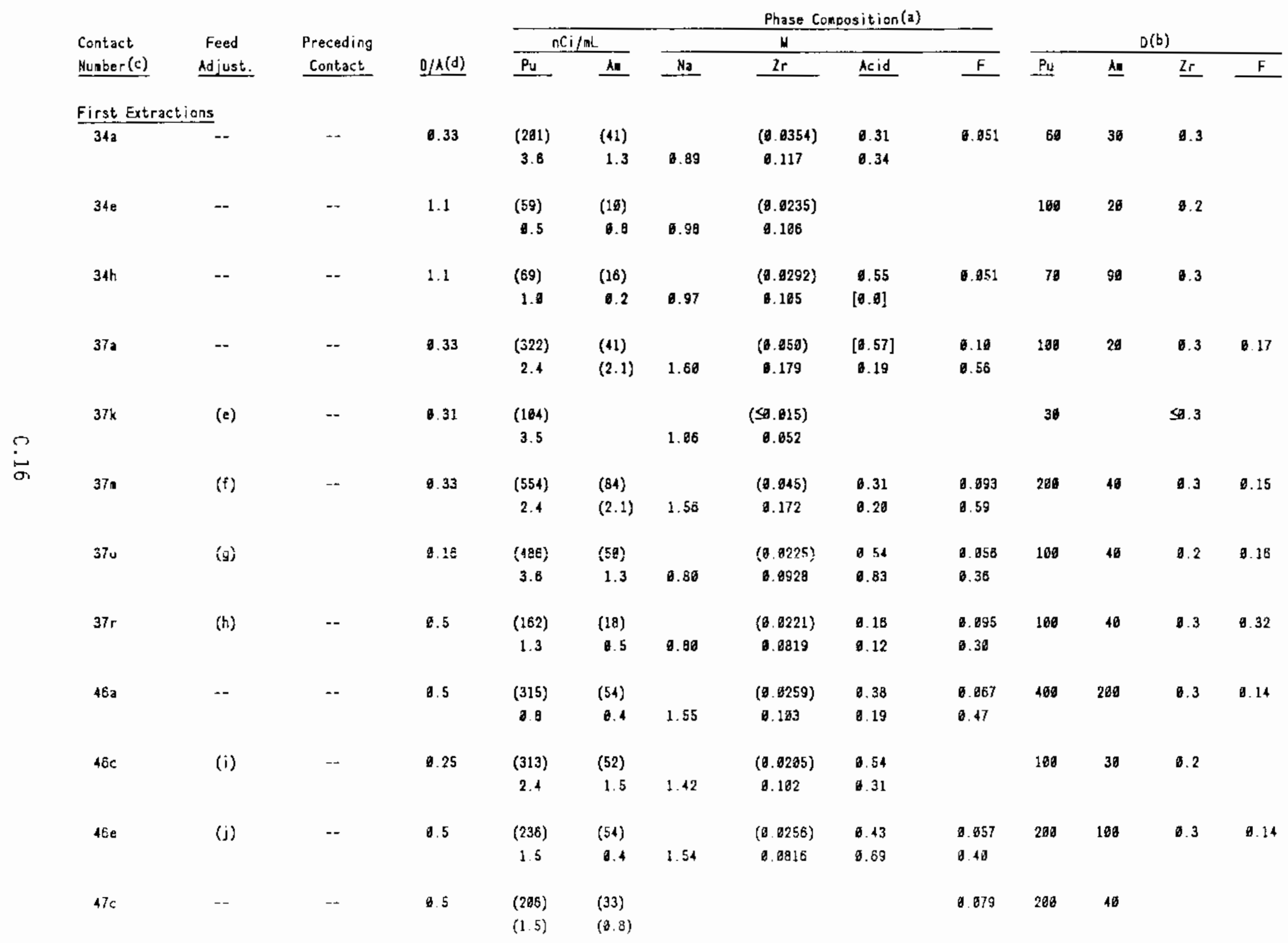


TABLE 3. (contd). Results of Extraction Contacts

\begin{tabular}{|c|c|c|c|c|c|c|c|c|c|c|c|c|c|}
\hline \multirow{3}{*}{$\begin{array}{l}\text { Contact } \\
\text { Number (c) }\end{array}$} & \multirow{3}{*}{$\begin{array}{c}\text { Feed } \\
\text { Adjust. }\end{array}$} & \multirow{3}{*}{$\begin{array}{c}\text { Preceding } \\
\text { Contact } \\
\end{array}$} & \multirow[b]{3}{*}{$\underline{0} / \mathrm{A}(\mathrm{d})$} & \multicolumn{6}{|c|}{ Phase Conposition(a) } & \multirow{2}{*}{\multicolumn{4}{|c|}{$D(b)$}} \\
\hline & & & & \multicolumn{2}{|c|}{$\mathrm{nCi} / \mathrm{mL}$} & \multicolumn{3}{|c|}{$N$} & \multirow[b]{2}{*}{$F$} & & & & \\
\hline & & & & Pu & An & $\mathrm{Na}$ & $\mathrm{Zr}$ & Acid & & $\underline{P_{y}}$ & AN & $\underline{2 r}$ & $F$ \\
\hline & & & & 1.0 & 1.7 & 0.84 & 0.115 & 0.48 & 0.58 & & & & \\
\hline \multicolumn{14}{|c|}{ Second Extractions } \\
\hline \multirow[t]{2}{*}{$34 \mathrm{~d}$} & -- & $34 \mathrm{a}$ & 0.33 & {$[8.1]$} & {$[3.6]$} & & [6.038] & 9.34 & & 9 & 39 & 0.3 & \\
\hline & & & & 0.9 & 0.12 & 9.88 & 0.105 & {$[0.23]$} & & & & & \\
\hline \multirow[t]{2}{*}{$37 \mathrm{~b}$} & $\cdots$ & $37 a$ & ว. 33 & {$[4.9]$} & {$[\geq 5]$} & & {$[9.872]$} & & 6.12 & 6 & $\geq 20$ & B. 5 & 9.16 \\
\hline & & & & 8.8 & $\leq 6.3$ & 1.55 & 0.155 & 0.18 & 0.74 & & & & \\
\hline \multirow[t]{2}{*}{$47 d$} & (k) & $47 \mathrm{c}$ & 0.5 & $(2.9)$ & $(1.7)$ & & & & 0.078 & 230 & $\supseteq 20$ & & 6. 17 \\
\hline & & & & $\leq 0.1$ & $\leq 0.1$ & & & & 0.47 & & & & \\
\hline \multirow[t]{2}{*}{$41 d$} & -- & $41 c$ & 0.5 & {$[2.1]$} & {$[3.4]$} & & {$[0.824]$} & $0.2 B$ & 0.068 & 3100 & 206 & 9.2 & 0. 12 \\
\hline & & & & $\langle\theta .02$ & 0.02 & 9.84 & 0.103 & 6.35 & g. 58 & & & & \\
\hline
\end{tabular}

(a) The upper values of a set are for the organic phase and the lower values are for the aqueous phase. Values enclosed by parentheses or by brackets were obtained froa the concentrations found in subsequent or preceding contacts, and fron the voluas ratios used in those contacts; the values enclosed by parentheses are based on subsequent contacts and those enclosed by brackets aro based on precoding contacts.

(b) Distribution coefficient equals organic phase concentration divided by aqueous phase concentration.

(c) The nuneral portion of the contact nuaber corresponds to the nuaber of the dissolved sludge solution (Table 2) used for feed. The letter portion of the contact nuber indicates the sequence in which the contacts were done.

(d) $0 / A$ denotes the volume of the organic phase divided by the volume of the aqueous phaso.

(e) $H F$ was added to increase the fluoride concentration by 8.6 (a 5 t dilution resulted). This addition resulted in incediate precipitate formation.

(f) $\mathrm{H}_{2} \mathrm{C}_{2} \mathrm{O}_{4}$ was added to $\mathrm{O} .085 \mathrm{M}$ (a 18 dilution resulted).

(g) Diluted $190 x$ while adding $\mathrm{H}_{2} \mathrm{C}_{2} \mathrm{O}_{4}$ to 6.9625 and $\mathrm{HNO}_{3}$ to increase the acidity to $\mathrm{a} .9$

(h) Diluted 100\% wile adding $\mathrm{H}_{2} \mathrm{C}_{2} \mathrm{O}_{4}$ to 0.0025 W.

(i) Diluted 10x while adding $\mathrm{H}_{2} \mathrm{C}_{2} \mathrm{O}_{4}$ to 0.0045 and adding $\mathrm{HNO}_{3}$ to increase the acidity to $0.47 \mathrm{M}$.

(j) Diluted 3.3x whilo adding $\mathrm{H}_{2} \mathrm{C}_{2} \mathrm{O}_{4}$ to $0.016 \mathrm{H}$ and adding $\mathrm{HNO}_{3}$ to increase the acidity to $11 \mathrm{~N}$.

(x) Difuted $1.2 x$ while adding $\mathrm{HNO}_{3}$ to increase the acidity by 19. 
coefficient values were only -0.2. Thus, nearly all of the Pu and Am can be extracted away from the bulk of the $\mathrm{Zr}$ in a few stages of extraction, especially if the organic-to-aqueous phase ratio $(0 / A)$ is low.

Table 3 also contains the results of the few cases where a dissolved sludge solution was extracted a second time with fresh solvent. Lower Pu distribution coefficients were sometimes obtained in these second contacts, whereas the Am and $\mathrm{Zr}$ values were comparable to those obtained in the first extractions. This behavior suggests that a small fraction of the Pu in some feeds was present in a poorly extractable form; this is an undesirable feature, but the fraction was so 10 w $(<2 \%)$ that the waste stream would still have a TRU content low enough to qualify for disposal as low-level waste.

One potentially severe problem observed in these extraction contacts was that solids often formed and collected at the interface as an "interfacial crud" (which was white in color). Such material can have very deleterious effects on the operation of continuous countercurrent solvent extraction equipment, so many tests were made in an effort to find conditions that would avoid such material. Results in this area are summarized in Table 4, even though they appear to be inconclusive. Listed here are the age of the feed at the time of contact, the feed adjustment conditions (if any), the volume of feed used in the test, and the organic-to-aqueous phase ratio (feed compositions are contained in Table 2). The first two dissolved sludge solutions (from Expts. 34 and 37) gave interfacial crud under a wide variety of conditions. When Expt. 46 (the one that was digested at $100^{\circ} \mathrm{C}$ ) gave a solution that did not form crud, it was thought that a digestion step would do away with the problem. Accordingly, Expt. 47 was begun with the intent of investigating the effect of more moderate digestion conditions; however, this solution gave no crud when it was contacted without digestion. This is rather baffling because the composition and conditions of preparation (see Tables 1 and 2) of solution 47 were very similar to those of solution 34 , which did form crud. Solution 4l, which was prepared from 105-AW sludge, was aiso thought at first to not form sludge but a later observation indicates that too small a volume was used in the initial test to give an observable amount. 
Brief attempts to determine the composition of the interfacial crud were not successful. It is interesting to note that the crud was never observed in a contact other than a first extraction contact. The fact that is was not observed in a second extraction suggests that it involves a minor component of the dissolved sludge solution (or a unique, minor species of a major component).

In many of the cases shown in Table 3, the composition of the feed was adjusted before the extraction contact was performed. These adjustments,

TABLE 4. Summary of Interfacial Crud Observations

\begin{tabular}{|c|c|c|c|c|c|}
\hline Contact & $\begin{array}{l}\text { Feed Age }{ }^{(a)} \\
\text { Days }\end{array}$ & $\begin{array}{c}\text { Feed } \\
\text { Adjustment }\end{array}$ & $\begin{array}{c}\text { Feed } \\
\text { Volume, mL }\end{array}$ & $\underline{0 / A^{(b)}}$ & $\begin{array}{c}\text { Crud } \\
\text { Observed? }\end{array}$ \\
\hline $\begin{array}{l}34 a \\
34 e \\
34 h\end{array}$ & $\begin{array}{r}3 \\
16 \\
21\end{array}$ & $\begin{array}{l}\text { None } \\
\text { None } \\
\text { None }\end{array}$ & $\begin{array}{l}3.3 \\
1.0 \\
1.0\end{array}$ & $\begin{array}{l}0.33 \\
1.1 \\
1.1\end{array}$ & $\begin{array}{l}\text { Yes } \\
\text { Yes } \\
\text { Yes }\end{array}$ \\
\hline $\begin{array}{l}37 \mathrm{a} \\
37 \mathrm{k} \\
37 \mathrm{~m} \\
370 \\
37 \mathrm{r}\end{array}$ & $\begin{array}{r}7 \\
10 \\
10 \\
20 \\
20\end{array}$ & $\begin{array}{l}\text { None } \\
(\mathrm{c}) \\
(\mathrm{c}) \\
(\mathrm{c}) \\
(\mathrm{c})\end{array}$ & $\begin{array}{l}3.9 \\
1.0 \\
1.0 \\
2.0 \\
1.0\end{array}$ & $\begin{array}{l}0.33 \\
0.31 \\
0.33 \\
0.16 \\
0.5\end{array}$ & $\begin{array}{l}\text { Yes } \\
\text { Yes } \\
\text { Yes } \\
\text { Yes } \\
\text { Maybe }\end{array}$ \\
\hline $\begin{array}{l}46 a \\
46 c \\
46 e\end{array}$ & $\begin{array}{r}1 \\
4 \\
13\end{array}$ & $\begin{array}{l}\text { None } \\
\text { (c) } \\
\text { (c) }\end{array}$ & $\begin{array}{l}0.5 \\
0.5 \\
3.1\end{array}$ & $\begin{array}{l}0.5 \\
0.25 \\
0.5\end{array}$ & $\begin{array}{l}\text { No } \\
\text { No } \\
\text { No }\end{array}$ \\
\hline $\begin{array}{l}47 a \\
47 b \\
47 c\end{array}$ & $\begin{array}{r}0 \\
24 \\
28\end{array}$ & $\begin{array}{l}\text { None } \\
\text { None } \\
\text { None }\end{array}$ & $\begin{array}{l}0.5 \\
0.5 \\
3.0\end{array}$ & $\begin{array}{l}0.25 \\
0.25 \\
0.50\end{array}$ & $\begin{array}{l}\text { No } \\
\text { No } \\
\text { No }\end{array}$ \\
\hline $\begin{array}{l}41 a \\
41 c \\
41 j \\
41 j \text { (cont) }\end{array}$ & $\begin{array}{r}0 \\
31 \\
32 \\
32\end{array}$ & $\begin{array}{l}\text { None } \\
\text { None } \\
\text { None } \\
\text { None }\end{array}$ & $\begin{array}{l}0.5 \\
3.0 \\
0.5 \\
0.5\end{array}$ & $\begin{array}{l}0.25 \\
0.5 \\
0.25 \\
0.5\end{array}$ & $\begin{array}{l}\text { No } \\
\text { Yes } \\
\text { No } \\
\text { No }\end{array}$ \\
\hline
\end{tabular}

\footnotetext{
(a) Time interval between sludge dissolution plus solution filtration and the extraction contact.

(b) $0 / A$ denotes the volume of the organic phase divided by the volume of the aqueous phase.

(c) Feed adjustment conditions given in Table 3.
} 
which are described in the footnotes of the table, were made for one of two reasons. One reason was to have oxalic acid present in the extraction stage, as it would be if oxalic acid is used in the scrub stream to enhance $\mathrm{Zr}$ scrubbing, and the other reason was to try to find conditions which would avoid interfacial crud formation. As was seen in Table 4, none of the feed adjustment steps were successful in avoiding interfacial crud. The tests involving oxalic acid addition showed that the presence of a low concentration of oxalic acid had no significant effect on the extraction of $\mathrm{Pu}, \mathrm{Am}$, or $\mathrm{Zr}$. However, a precipitate formed in the oxalate-containing aqueous phases on standing; this is a matter of some (slight) concern because it is generally desirable to avoid precipitation in a solvent extraction process. However, because this precipitation would apparently be delayed until after the solution has exited the contactor, it may not be a problem.

\section{Scrub Contact Results}

The data obtained in scrub contacts at various conditions are summarized in Table 5. The majority of these contacts employed a scrub solution composition of $1.5 \mathrm{M} \mathrm{HNO}_{3}+0.05 \mathrm{M} \mathrm{H}_{2} \mathrm{C}_{2} \mathrm{O}_{4}$, as suggested by Horwitz et al (1985) to remove extracted $\mathrm{Zr}$ from the organic phase. This scrub composition was indeed quite effective in removing the $\mathrm{Zr}$, but not the Am and $\mathrm{Pu}$, from the organic phase. Three scrub contacts at $0 / A=3.00$ decreased the organic phase $\mathrm{Zr}$ concentration by $95 \%$ in the $34 j-k$ contacts and by $98 \%$ in the $37 \mathrm{c}-\mathrm{e}$ contacts. Fluoride was also efficiently removed by these scrub contacts; contacts $37 \mathrm{c}$-e removed $95 \%$ of the fluoride that had extracted in contact $37 \mathrm{~b}$ (Table 3).

The fluoride distribution coeffecients measured here are substantially lower than those calculated for hydrofluoric acid (HF) using the Generic TRUEX Model (these calculations were kindly performed by George Vandegrift of Argonne National Laboratory, upon request). This fact, plus the rather close correlation of the zirconium and fluoride distribution coefficients, suggested that a fluoride-containing $\mathrm{Zr}$ species was a major organic phase species. Contacts $46 \mathrm{f}-\mathrm{i}$, where the organic phase was first scrubbed twice with $1.5 \mathrm{M}$ $\mathrm{HNO}_{3}$ alone and then twice with $1.5 \mathrm{M} \mathrm{HNO} 3+\mathrm{H}_{2} \mathrm{C}_{2} \mathrm{Cl}_{4}$, were then done in an effort to gain more insight into this possibility. The results of these 
contacts are consistent with the hypothesis of an extractable, fluoridecontaining $\mathrm{Zr}$ species, but they are not sufficient to demonstrate its correctness.

The low Zr distribution coefficients obtained in contacts $46 j-k$, which were water scrubs following nitric-oxalic acid scrubbing, prompted further investigation into scrubbing with dilute nitric acid alone. Contacts $41 \mathrm{e}-\mathrm{g}$ employed a $0.5 \mathrm{M} \mathrm{HNO}_{3}$ scrub composition, which was markedly less effective than $1.5 \mathrm{M} \mathrm{HNO}_{3}+0.05 \mathrm{M} \mathrm{H}_{2} \mathrm{C}_{2} \mathrm{O}_{4}$ in removing $\mathrm{Zr}$ (and $\mathrm{F}^{-}$) from the organic phase; three contacts at $0 / A=3.00$ decreased the organic phase $\mathrm{Zr}$ concentration by only $65 \%$ and the organic phase fluoride concentration by only $70 \%$. Perhaps the low $\mathrm{Zr}$ distribution coefficient observed in contact $46 \mathrm{j}$ occurred because of the presence of some oxalic acid that had extracted in contact $46 i$.

\section{Strip Contact Results}

Results obtained when organic phases were stripped with 0.2 M HEDPA solutions to transfer the extracted transuranics back to an aqueous phase are summarized in Table 6 . Most of these contacts were done for analytical purposes only, and involved much lower $0 / A$ values than would be desired in a process. The few contacts done at process-desirable $0 / A$ values $(47 \mathrm{e}-\mathrm{f}$ and, to a lesser extent, 37f) showed that stripping was indeed efficient under those conditions. The available data do indicate that complete fluoride stripping would be difficult. This possibility should be examined in more detail in the future. 
TABLE 3. Resuits of Scruis Conlacts

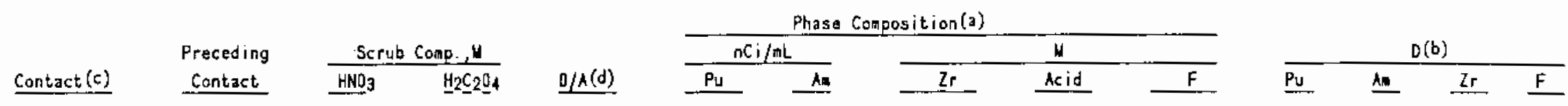

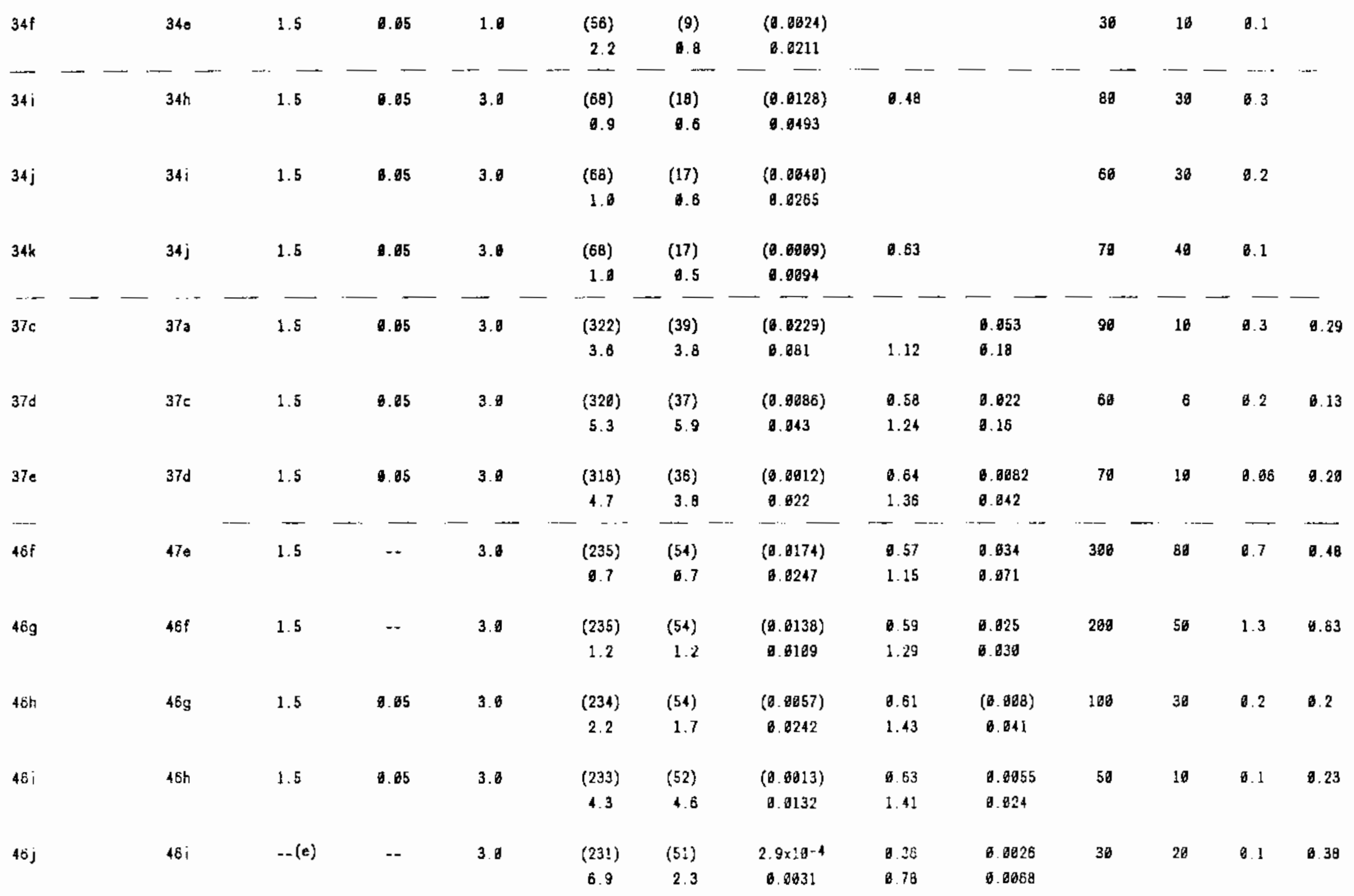


TABLE 5. (contd). Resuits of Scrub Contacts

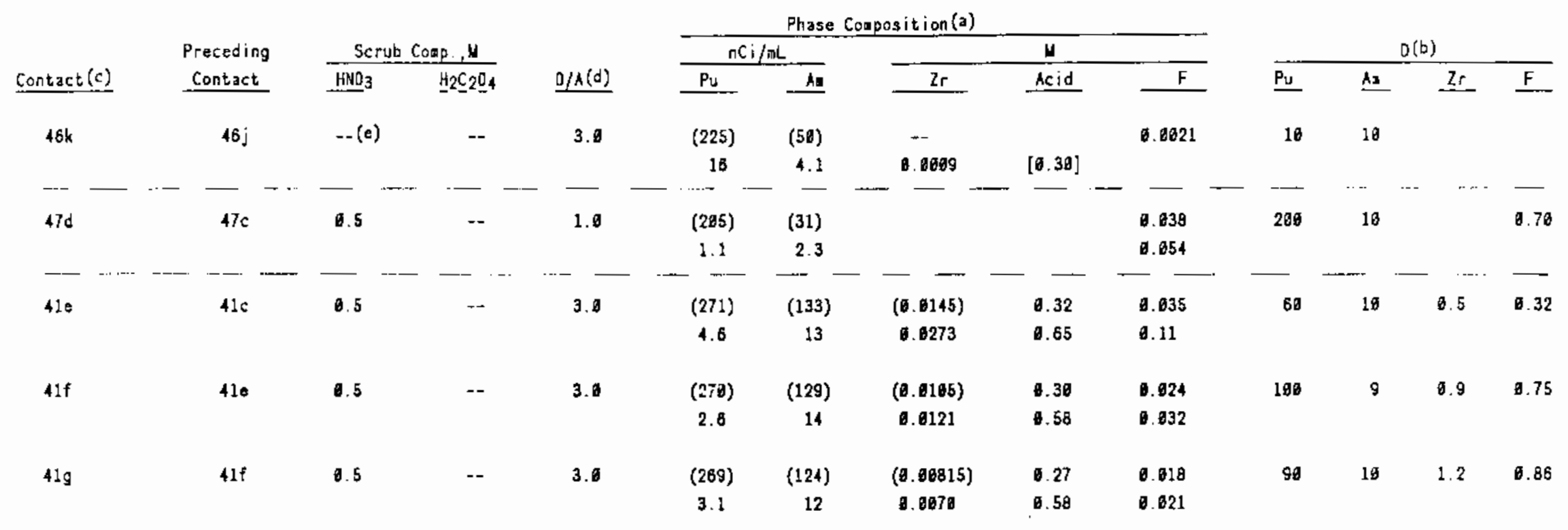

(a) The upper values of a set are for the organic phase and the lower values are for the aqueous phaso. Values enclosed by parentieses ar by brackets were obtained from the concentration found in subsequent or preceding contacts, and fros the voluse ratios used in those contacts; tho ralues enclosed by parentheses are based on subsequent contacts. and those enclosed by brackets aro based on preceding contacts.

(b) Distribution coefficient equals organic phase concentration divided by aqueous phase concentration.

(c) The numeral portion of the contact number corresponds to the number of the dissolved sludge solution (Table 2) used for feed. The letter portion of the contact number indicates the sequence in which the contacts were done.

(d) $0 / A$ denates the volune of the organic phase divided by the rolume of the aqueous phase.

(e) Water used as scrub solution. 
TABLE 6. Results of Sirippirg with 0.2 in HEDPA Solutions

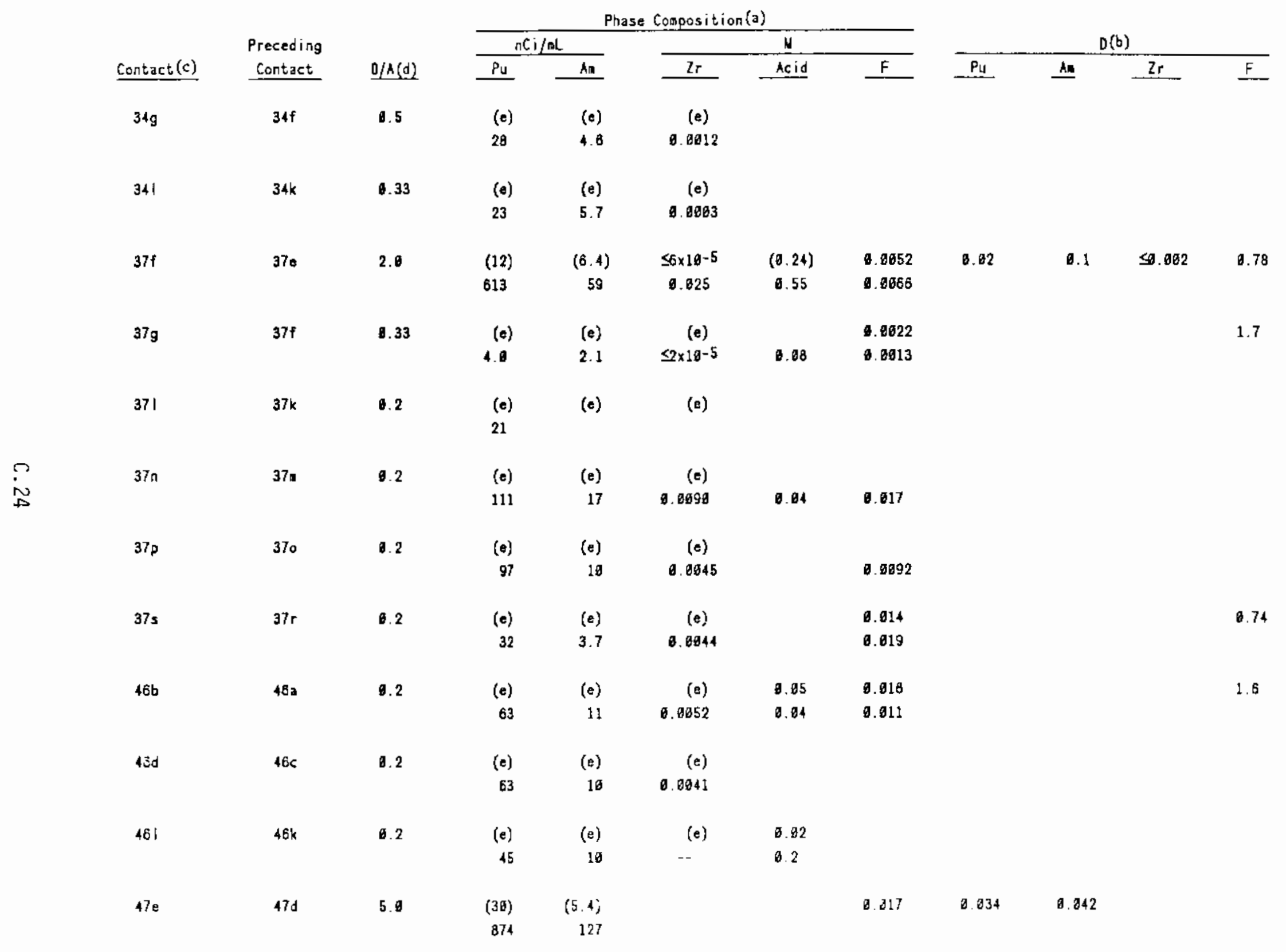


TABLE 6. (contd). Results of Stripping with 0.2 M HEOPA Solutions

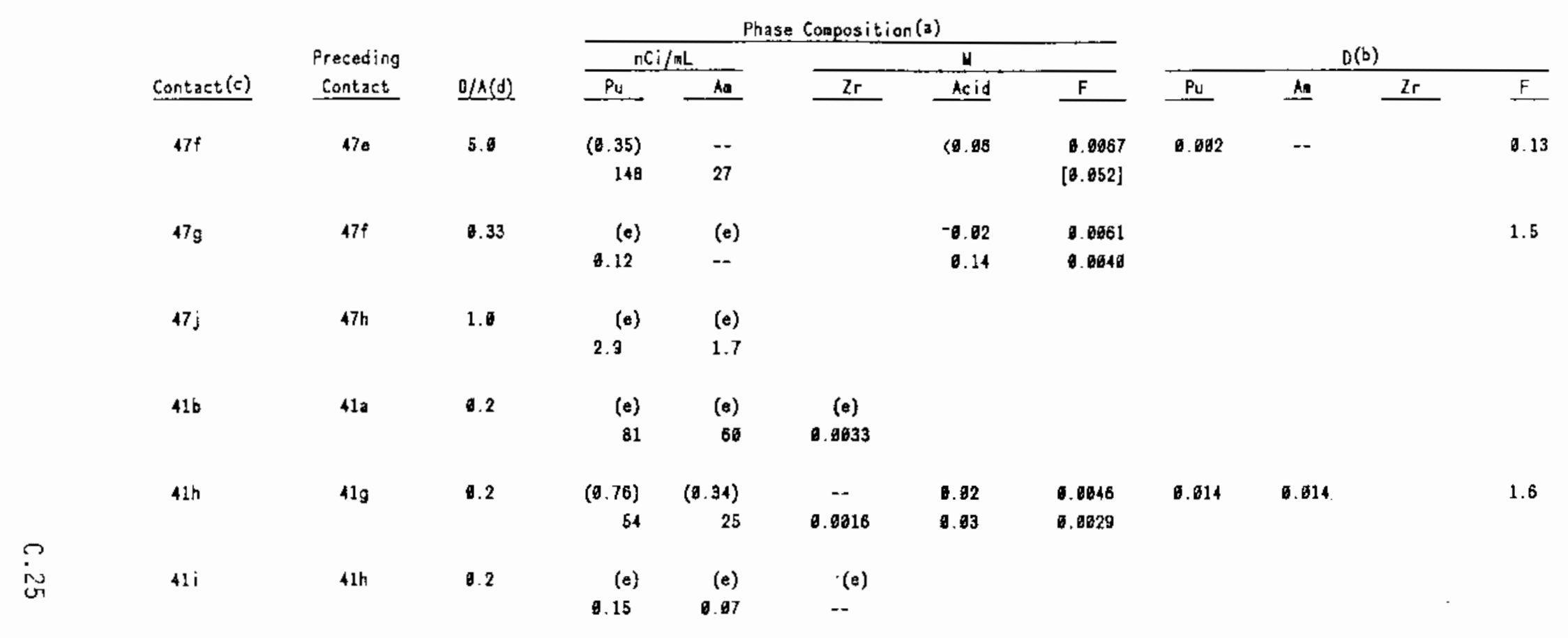

(a) The upper values of a set are for the organic phase and the lover values are for the aqueous phase. Values enclosed by parentheses or by brackets were obtained fro the concentrations found in subsequent or preceding contacts, and from the volume ratios used in those contacts; the values enclosed by parentheses are based on subsequent contacts and those enclosed by brackets aro based on preceding contacts.

(b) Distribution coefficient equals organic phase concentration divided by aqueous phase concentration.

(c) The numeral portion of the contact nuaber corresponds to the number of the dissolved studge solution (Table 2) used for feed. The letter portion of the contact nuaber indicates the sequence in wich the contacts were done.

(d) O/A denotes the volune of the organic phase divided by the roluas of the aqueous phase.

(e) Concentration assumed to be zero, for the purpose of material balance calculations for the preceding contact. 


\section{FUTURE WORK INDICATED}

Although the flowsheet results are quite promising, additional data are needed in many areas. Foremost among these is the need to determine reproducible conditions that avoid the formation of interfacial crud when the dissolved sludge solution is contacted with TRUEX solvent. Such conditions might involve altering the primary dissolution step conditions, or adjusting the composition of the solution after dissolution (or both).

Better definition of the conditions needed in the secondary dissolution step are also desired. For example, it may well not be necessary to heat to $100^{\circ} \mathrm{C}$ in this step, as has been done for convenience in the work reported here.

The use of an alternative (to oxalate) complexant in the scrub solution should also be investigated, to avoid the possibility of precipitation of oxalate compounds in the solvent extraction contractor. Fluoride would appear to be a likely candidate for such a complexant (but it would then have to be scrubbed from the organic).

Also needed is more information in several areas that are important to plant design. Among these are 1) dissolution end point control on a plant scale, 2) properties (anion composition, particle size, etc.) of the residual solids from the dissolution steps, and 3 ) offgas compositions. These areas are to be studied in the next stage of this effort. 


\section{REFERENCES}

Horwitz, E. P., D. G. Kalina, H. Diamond, G. F. Vandegrift, and W. W. Schulz. 1985. "The TRUEX Process-A Process for the Extraction of Transuranic Elements from Nitric Acid Wastes Utilizing Modified PUREX Solvent," Solvent Extraction and Ion Exchange, 3:75-109. 

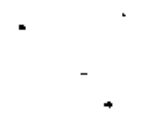

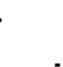


APPENDIX D

TRUEX PROCESSING OF NCRW SLUDGE, PROGRESS REPORT 
A LETTER REPORT FOR WESTINGHOUSE HANFORD COMPANY

TRUEX PROCESSING OF NCRW SLUDGE, PROGRESS REPORT

J. L. Swanson

September 1989

Prepared for

the U.S. Department of Energy

under Contract DE-AC06-76RLO 1830

Pacific Northwest Laboratory

Richland, Washington 99352 


\section{CONTENTS}

SUMMARY

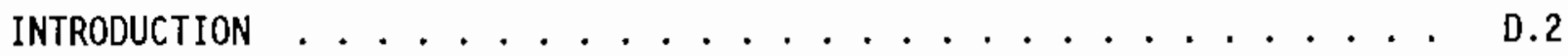

METHODS \& MATERIALS . . . . . . . . . . . . . . . . . D.3

SLUDGE SAMPLES ...................... . . . . . . . . . .

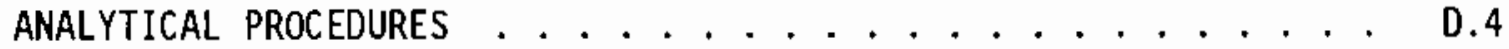

RESULTS AND DISCUSSION . . . . . . . . . . . . . . . . . . . D.5

AMOUNTS OF POTENTIAL GAS-FORMING MATERIAL IN SLUDGES . . . . . . D.5

GAS EVOLUTION OURING DISSOLUTION

pH TITRATION OF SLUDGES . . . . . . . . . . . . . . . . . D.9

SETTLING STUDIES WITH UNDISSOLVED RESIDUES . . . . . . . . . . D.11

FILTRATION TESTS WITH UNDISSOLVED RESIDUES . . . . . . . . . D.15

PARTICLE SIZE DATA ................... D. . . . . . .

SCANNING ELECTION MICROSCOPE RESULTS . . . . . . . . . . . D.19

GAMMA-EMITTING RADIONUCLIDES IN UNDISSOLVED RESIDUES . . . . . $\quad$. .33

NON-METAL - ION COMPONENTS OF UNDISSOLVED RESIDUES . . . . . . . D.35

SOLVENT EXTRACTION STUDIES .................. . . . . . . . . . 


\section{SUMMARY}

This report contains results obtained during the final four months of $F Y$ 1989 on the development of a flowsheet to process neutralized cladding removal waste (NCRW) sludges using the TRUEX process. These results were obtained primarily in areas not addressed in the initial experiments, which were reported earlier (Appendix C).

The off-gas from the dissolution process was found to be predominantiy $\mathrm{CO}_{2}$ and $\mathrm{NO}_{X}$, which result from the presence of carbonates and nitrites in the sludges. Conversion of carbonate to $\mathrm{CO}_{2}$ was quantitative, but only a smail fraction $(\sim 10 \%)$ of the nitrite was released as $\mathrm{NO}_{\mathrm{x}}$ during dissolution. This ${ }^{N O}{ }_{x}$ release was lowered by having sulfamic acid present during dissolution, to react with the nitrite. Sulfate, which is formed in this reaction, did not have an adverse effect on the subsequent extraction of Pu or Am in the TRUEX process.

Properties of the undissolved residues from the sludge dissolution step important to solids removal and to vitrification operations were determined. The contents of sulfate, carbon, fluoride, and chloride in these residues appeared to be low enough to meet vitrification specifications. Particle sizes and compositions were somewhat different in the residues from the sludges in the two NCRW tanks, and were markedly different in the residue from a simulated sludge prepared in the laboratory.

Limited additional study of the TRUEX extraction portion of the process indicated that the tendency to form an interfacial crud (which is undesirabie) is lessened at higher feed acid concentrations.

Data were also obtained in the areas of dissolution end point control and of the content of gamma-emitting radionuclides in the undissolved residues. 


\section{INTRODUCTION}

The preceding report of this work (Appendix C) presented some very promising results of experiments investigating the feasibility of processing neutralized cladding removal waste (NCRW) sludges using the TRUEX process. Those results indicated that the bulk of the sludge can be dissolved in nitric acid (without heating) and that the Pu and Am can be separated from $\mathrm{Zr}$ (and other inert components) by appropriate TRUEX extraction and scrubbing conditions. Work over the subsequent four months, which is described in this report, has emphasized obtaining information in several other areas that are important to plant design. Results are presented here that pertain to dissolution end point control, to the properties and compositions of the residual solids, and to offgas compositions. In most of the areas, the current data are not sufficient to "close the issue", but they are presented now to provide timely assistance to preliminary design efforts. 


\section{METHODS AND MATERIALS}

Details of the sludge samples and the analytical procedures used in this work are contained in this section.

\section{SLUDGE SAMPLES}

Work continued using the same composites as in the earlier work, which were of core samples taken in 1986 and will be referred to hereafter as 103AW (1986 composite) and 105-AW (1986 composite). A (partial) composite of a core sample taken recently from Tank 103-AW was also received and used in some experiments; this sample is referred to as 103-AW (1989 composite). In addition, a simulated sludge sample was prepared for some comparative measurements.

Sludge Sample 103-AW (1989 Composite)

Sample 103-AW (1989 composite) is a composite of segments 6 through 10 of a core sample taken in mid-March of this year. Segments 1 through 3 contajned no solids. Segments 4 and 5 did contain solids, but were not included in this composite because they were needed for other work. (Sample and information were both provided by $R$. L. Weiss of WHC.)

Preparation of Simulated Sludge

One area of study that was recently initiated is an attempt to define conditions whereby a nonradioactive sludge that has properties comparable to actual NCRW sludge (insofar as residual solids are concerned) can be prepared. If successful, this effort will greatly simplify the execution of meaningful large scale tests of solid/liquid separation techniques.

In the first attempt in this area (NCRW-1C), a "CRW solution" containing $0.5 \underline{M}\left(\mathrm{NH}_{4}\right)_{2} \mathrm{ZrF}_{6}$ in $0.9 \mathrm{M} \mathrm{NH}_{4} \mathrm{~F}$, which was prepared several years ago by dissolving Zircaloy in $\mathrm{NH}_{4} \mathrm{~F}+\mathrm{NH}_{4} \mathrm{NO}_{3}$ solution, was spiked with aluminum-and iron-nitrate solutions to match the $A 1-t o-Z r$ ratio $(0.3$ mole per mole) found in 103-AW sludge and the Fe-to-Zr ratio (0.1 mole per mole) found in 105-AW sludge. This mixture was then added (in -12 increments) to a $50 \% \mathrm{NaOH}$ solution containing $10 \mathrm{~mole}$ of $\mathrm{NaOH}$ per mole $\mathrm{Zr}$, while stirring, and the 
sludge was left to age in the resultant solution for -1 month before being used in the studies.

ANALYTICAL PROCEDURES

The procedures described earlier (Appendix C) were used as before, and some new measurements were added.

Nitrite concentrations were measured spectrophotometrically in dilute acid solutions, using the peak at $373 \mathrm{~nm}$. Interference from other colored species was avoided by using the difference in peak height before and after adding hydroxylamine nitrate (which reacts rapidly with nitrous acid) as the measure of the nitrous acid concentration.

Ammonia and fluoride concentrations were determined using specific ion electrodes. Spike recovery measurements were routinely made to assure the absence of matrix effects.

Carbon, sulfate, and gas analyses were performed in PNL's 325 Building Analytical Laboratory, using a carbon analyzer instrument, an ion chromatograph, and a mass spectrometer, respectively.

Particle size analyses were performed by D. B. Bechtold of WHC (Westinghouse Hanford Company), using a Brinkman instrument. Particles were also examined (by J. E. Coleman) using PNL's shielded scanning electron microscope in 325 Building. 


\section{RESULTS AND DISCUSSION}

This section contains the experimental details and results for the experiments in a number of areas. Data were obtained in the areas of: 1) gas evolution during dissolution, 2) properties of the undissolved residues important to solid/liquid separation (e.g., particle sizes, settling rates, filtration tests), 3) fission product and non-metal-ion components of undissolved residues, and 4) solvent extraction.

AMOUNTS OF POTENTIAL GAS-FORMING MATERIALS IN SLUDGES

Data have been obtained on the concentrations of three components of NCRW sludge that can lead to gas evolution during sludge handling or dissolution. These components are ammonia, carbonate, and nitrite.

Ammonia concentrations found recently in both 103-AW (1986 composite) and 105-AW (1986 composite) sludges are more than 10-fold lower than the results reported at that time; the recent results are $-0.003 \mathrm{M}$ with 103 -AW sludge (Expt. NCRW-48) and -0.002 M with 105-AW sludge (Expt. NCRW-43). The more recent 103-AW (1989 composite) sludge sample was found to contain $0.014 \mathrm{M}$ ammonia, which is $\mathbf{- 3 - f o l d}$ lower than the initially-reported value. These results indicate that the sludges are gradually evolving ammonia (as expected), and that the evolution is more rapid from the sludge samples in the laboratory than it is from the tank.

The carbonate concentrations in the sludges were determined by leaching with water and analyzing the leachates for total carbon (TC) and organic carbon (TOC) species, with the difference being taken as carbonate (plus bicarbonate). The results are summarized in Table 1, along with the total carbon concentrations found in dissolved sludge solutions, and with the values found in earljer analyses.

The carbonate concentrations found here in the 1986 composites are generally higher than those found in the earlier analyses, which is not surprising because of the possibility of pickup of $\mathrm{CO}_{2}$ from the air by these highly basic slurries. The carbonate content of the 1989 composite agrees 
TABLE 1. Results of Carbon Analyses on Sludges

\begin{tabular}{|c|c|c|c|c|c|}
\hline \multirow[b]{2}{*}{ Sludge } & \multirow[b]{2}{*}{ Expt } & \multicolumn{4}{|c|}{$\mathrm{mg} \mathrm{C} / \mathrm{g}$ sludge } \\
\hline & & $T \mathrm{TC}$ & $\frac{\text { Water }}{\text { TOC }}$ & $\mathrm{CO}_{2}$ & $\begin{array}{l}\text { TC in Dissolved } \\
\text { Sludge Solm. }\end{array}$ \\
\hline 103-AW & -- & 3.2 & 0.83 & & \\
\hline 103-AW (1989 Comp.) & 50 & & & $0.65^{(a)}$ & \\
\hline 103-AW (1986 Comp.) & 36 & 4.76 & 1.70 & 3.06 & \\
\hline 103-AW (1986 Comp.) & 48 & 9.24 & 3.30 & 5.94 & 3.43 \\
\hline 105-AW (Coroneos) & -- & & 7.1 & 1.43 & \\
\hline 105-AW (1986 Comp.) & 38 & 12.7 & 11.4 & 1.3 & \\
\hline 105-AW (1986 Comp.) & 40 & 12.1 & 5.7 & 6.4 & \\
\hline 105-AW (1986 Comp.) & 42 & & & & 2.83 \\
\hline
\end{tabular}

(a) Based on $\mathrm{CO}_{2}$ evolution value discussed el sewhere.

quite well with that found in the 1986 analyses, which suggests that pickup of $\mathrm{CO}_{2}$ by the sludge in the tank has not progressed in the last three years.

Nitrite concentrations in the sludges were also measured by analyzing (spectrophotometrically) water leachates. A concentration of $0.42 \underline{\mathrm{M}}$ was found in NCRW-48 for 103-AW (1986 composite), and a concentration of $0.18 \underline{M}$ was found in NCRW-43 for 105-AW (1986 composite).

The first gas evolution experiment (discussed el sewhere) gave a value of 0.30 Mitrite in 103-AW (1989 composite), based on the amount of nitrous acid found in the dissolved sludge solution and the amount of $\mathrm{NO}_{x}$ that was evolved during dissolution. The nitrous acid concentration found here in the dissolved sludge solution is appreciably higher than that found in other dissolved sludge solutions (but comparable to that found in water leaches of sludges). This higher level is thought to result from two procedural changes aimed at minimizing decomposition of nitrous acid. These changes were to perform the analysis as soon as possible after the dissolution step and to analyze a sample that had been clarified by centrifugation rather than by (vacuum) filtration. 


\section{GAS EVOLUTION DURING DISSOLUTION}

Two tests have been run to study gas evolution during the dissolution step; both tests used the 103-AW (1989 composite) sludge. These tests were run by adding the acid to a vial containing compacted sludge plus covering water and quickly attaching the vial to a slightly-evacuated $(-3$ in. $\mathrm{Hg})$, argon-filled reservoir fitted with a vacuum gauge. When the dissolution reaction period had been completed, the system was opened at the top of the vial to sweep product gas (and some air) into the reservoir, and the reservoir was then sampled into an evacuated sampler for mass spectrometric analysis. Quantities of gas evolved during dissolution were calculated from the analytical results, the known volumes of the reservoir and the sampler, and the pressures in the sampler and reservoir before and after the sample was taken.

In the first test (NCRW-50), $1.5 \mathrm{~mL}$ of $15.7 \underline{\mathrm{M} \mathrm{HNO}} \mathrm{H}_{3}$ was injected into 7.0 $\mathrm{mL}$ of water covering the compacted sludge (3.0g) and the mixture was stirred for $2 \mathrm{~h}$. Both $\mathrm{CO}_{2}$ and $\mathrm{NO}_{x}$ were found in the gas sample, at a mole ratio of 2.9-to-1. Because the contents of the reservoir were colorless until air was introduced, and they then became reddish-brown, it is assumed that N0 was the predominant $\mathrm{NO}_{x}$ species evolved during dissolution. The quantity of $\mathrm{CO}_{2}$ evolved was $1.6 \times 10^{-4}$ mole; this gives (assuming $100 \%$ conversion of carbonate to $\mathrm{CO}_{2}$ ) a carbonate concentration in the initial sludge of $0.073 \underline{\mathrm{M}}$.

The quantity of $\mathrm{NO}_{x}$ evolved was $5.6 \times 10^{-5}$ mole, which is only $-9 \%$ of the amount of nitrous acid found in the dissolved sludge solution $\sim 0.5 \mathrm{~h}$ after the completion of the dissolution period. Thus, only a small portion of nitrite present in the sludge decomposed to release $\mathrm{NO}_{x}$ to the gas phase. The quantities of nitrous acid and $\mathrm{NO}_{x}$ found in this experiment give a nitrite concentration in the initial sludge of $0.30 \mathrm{M}$.

The second gas evolution test attempted to demonstrate the effectiveness of suifamic acid $\left(\mathrm{NH}_{2} \mathrm{SO}_{3} \mathrm{H}\right)$ in preventing $\mathrm{NO}_{x}$ evolution by destroying nitrous acid

$$
\mathrm{HNO}_{2}+\mathrm{NH}_{2} \mathrm{SO}_{3} \mathrm{H}=\mathrm{H}_{2} \mathrm{SO}_{4}+\mathrm{N}_{2}+\mathrm{H}_{2} \mathrm{O}
$$


before it can decompose

$$
3 \mathrm{HNO}_{2}=\mathrm{HNO}_{3}+2 \mathrm{NO}+\mathrm{H}_{2} \mathrm{O} \text {. }
$$

In this test (NCRW-51), $5.0 \mathrm{~mL}$ of $4.7 \mathrm{M} \mathrm{HNO}_{3}+0.17 \underline{\mathrm{M} \mathrm{NH}} \mathrm{SO}_{3} \mathrm{H}$ was injected into $3.5 \mathrm{~mL}$ of water covering the compacted sludge; a vigorous reaction occurred immediately, with the result that some of the gaseous products were lost before the vial could be attached to the reservoir system. However, the results are still informative.

The concentration of $\mathrm{CO}_{2}$ in the gas sampler was $79 \%$ of that in the preceding experiment, which suggests that no more than $-20 \%$ of the $\mathrm{CO}_{2}$ releasing reaction occurred before the vial could be attached to the reservoir. Contrary to the hoped-for result, $\mathrm{NO}_{\mathrm{X}}$ was present in the gas sample; however, the $\mathrm{NO}_{\mathrm{x}}$-to- $\mathrm{CO}_{2}$ mole ratio was 0.19 compared to 0.35 in the preceding experiment. This indicates that about half as much $\mathrm{NO}_{x}$ was evolved in this experiment with sulfamic acid as was evo'ved in the experiment without sulfamic acid. This is a promising result, even if it is not as good as had been desired. In the absence of sulfamic acid, the nitrous acid that doesn't volatilize in the dissolution step can (partially, at least) volatilize later in other parts of the process; because nitrous acid is extractable by TBP, it will definitely be spread around. This, of course, cannot happen if the nitrous acid is destroyed in the dissolution step by reaction with sulfamic acid (or other appropriate reagent).

It is possible that more complete nitrous acid destruction can be achieved by modifying the procedure; for example, by having the sulfamic acid present in the water before the nitric acid is added. This was not done in NCRW-51 because of the desire to obtain another $\mathrm{C}_{2}$ evolution value, and the feeling that some $\mathrm{CO}_{2}$ would evolve due to acidification with sulfamic acid.

Hydrazine and hydroxylamine nitrate are other reagents that can be used for nitrous acid destruction. These have not yet been examined for the proposed application with NCRW sludge. 


\section{pH TITRATION OF SLUDGES}

Data obtained on adding $\mathrm{HNO}_{3}$ to slurries (containing $-4.5 \mathrm{~mL}$ of added water per gram of sludge) of NCRW sludge are shown in Figure 1. The results obtained with the sludges from the two tanks and from the cold simulation attempt are seen to be similar, but far from identical.

The arrows drawn adjacent to the curves in Figure 1 indicate the points at which gas evolution (presumably $\mathrm{CO}_{2}$ ) was first observed. In both cases, this point was below $\mathrm{pH}=7$ (as expected). This is important to the possibility of gaseous ammonia being swept out of solution by the evolving gases; because the $\mathrm{pH}$ is below 7 before gas evolution commences, ammonia evolution during sludge dissolution should be very slight (because nonvolatile ammonium ion is the dominant ammonia species at such $\mathrm{pH}$ values). It is not known why noticeable gas evolution began at different $\mathrm{pH}$ values with the different sludges. The "gas evolution pH value" with 105-AW sludge was verified in experiment $\mathrm{NCRW}-43$, where $\mathrm{HNO}_{3}$ was added more rapidly and a value of -6.1 was observed, but the value with 103-AW sludge has not been verified. Gas evolution was not observed with the simulated siudge, presumably because of the lack of carbonate formation during the relatively short ( -1 month) period of aging.

The results of these titration curves, plus analyses of the free acid concentrations in the resulting solutions, suggest a way of determining the end point of sludge dissolution in a plant (if appropriate $\mathrm{pH}$ measurements can be made there). The final free acid concentrations (1.23 $\mathrm{M}$ in NCRH-42 and $1.12 \underline{M}$ in NCRW-48) agree very well with those calculated (1.20 $\underline{M}$ and $1.10 \underline{M}$, respectively) based on the arbitrary assumption that neutralization of all of the hydroxide (and carbonate) species in the sludge was just completed by $\mathrm{pH}=1$. For comparison, the calculated free acid molarities based on neutralization being just complete at $\mathrm{pH}=1.5$ were 1.28 and 1.19 and those based on neutralization being just complete at $\mathrm{pH}=0.5$ were 0.82 and 0.84 .

Thus, addition of the appropriate amount of acid after the $\mathrm{pH}$ has reached a value of 1.00 could be used to give the desired solution free acid concentration. This is a desirable objective, but it does not give information regarding the relative concentrations of insoluble sludge 


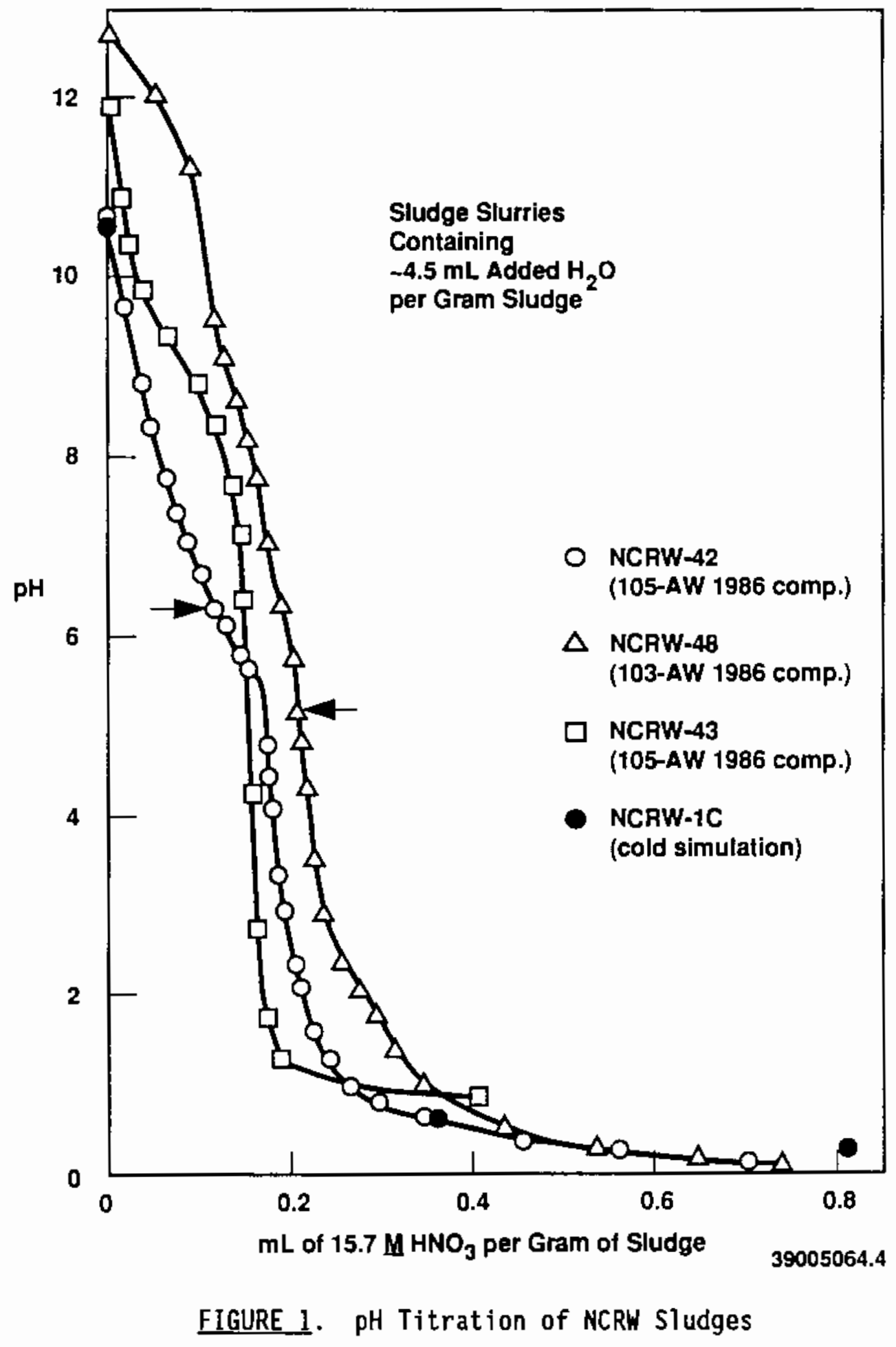


components (e.g.; $\mathrm{Zr}, \mathrm{Fe}$ ) and solubie sludge components (e.g.; Na, K, Al) that have been "acidified". In principle, it would seem that a distinction could be made between the contents of the non-hydrolyzable ions (e.g.; $\mathrm{Na}, \mathrm{K}$ ) and the hydrolyzable ions (e.g.; $\mathrm{Zr}, \mathrm{Fe}, \mathrm{Al}$ ) by comparing the volume of acid required to reach a $\mathrm{pH}$ value where the non-hydrolyzable ions have been neutralized but the hydrolyzable ions are still hydrolyzed, with the volume of acid required to proceed from that $\mathrm{pH}$ value to $\mathrm{pH}=1$. This approach worked reasonably we11 in NCRW-42; using $\mathrm{pH}=5.5$ (where the break in the curve occurred) as the dividing line between titration of non-hydrolyzable and hydrolyzable ions, the amount of acid needed to reach that point was $190 \%$ of that required to go from $\mathrm{pH}=5.5$ to $\mathrm{pH}=1$, which compares very we 11 with the $200 \%$ value calculated from the metal ion analysis of the final solution. However, the same approach did not work well in NCRW-48, where the quantity of acid required to reach $\mathrm{pH}=5.5$ was $150 \%$ of that required to go from $\mathrm{pH}=5.5$ to $\mathrm{pH}=1$, compared to the $240 \%$ value calculated from the metal ion analysis. More work on this approach appears to be indicated.

The preceding discussion applies to a batch dissolution procedure in which acid is added to the sludge slurry. Other dissolution approaches are being considered by WHC, including a "reverse strike" batch process in which the sludge slurry is added to acid, and a continuous process in which both components are added to a vesse] at rates that provide the necessary residence time. Both of these approaches have the advantage of smoothing out the gas evolution rate (it would be governed by the rate of sludge addition). However, proper sludge sampling and analysis might be more important to proper operation of these approaches than in the "direct strike" batch process used in this work.

\section{SEITLING STUDIES WITH UNDISSOLVED RESIDUES}

One of the questions of interest regarding the properties of the solids that remain undissolved after the sludge dissolution step is how well they settle. Accordingly, recent dissolution tests have been done in glass (instead of plastic) so that settling observations could be made. An important comparison was immediately evident; solids remaining from the 105 Aw (1986 composite) sludge floated at or near the surface of the dissolved 
sludge solution (which had a density of $-1.09 \mathrm{~g} / \mathrm{cm}^{3}$ ), while solids remaining from dissolution of the 103-AW sludge composites settled out of solutions having similar compositions. A sample of segment 5 from the 1986 sampling of 105-AW has been brought to the laboratory for use in a preliminary check into the possibility that the "floaty solids" originated in the tank heel, but that test has not yet been done.

Settling Studies In NCRW-42 (105-AW Sludge)

After the floaty solids obtained by dissolution of 105-AW (1986 composite) sludge experiment NCRW-42 had been recovered by filtration, and had been washed with water, they were resuspended in dilute $\mathrm{HNO}_{3}$ and settling observations were made at different $\mathrm{HNO}_{3}$ concentrations. The solids settled at $\mathrm{HNO}_{3}$ concentrations of $1.9 \mathrm{M}$ (density=1.06 $\mathrm{g} / \mathrm{cm}^{3}$ ) and below, but part of them floated in $2.4 \mathrm{M} \mathrm{HNO}_{3}$ (density=1.08 $\mathrm{g} / \mathrm{cm}^{3}$ ). This determination of the density required to float the solids is in good agreement with the observation that the solids floated in the dissolved sludge solution having a density of $-1.09 \mathrm{~g} / \mathrm{cm}^{3}$.

The solids were then concentrated by centrifugation (after adding water to lower the solution density) and resuspended in $0.33 \mathrm{H} \mathrm{HNO}_{3}$. Filtration of a portion of this suspension through a 5 - $\mathrm{m}$ plasic filter gave a clear filtrate. The remaining suspension was then used in a settling rate study, which did not give information of the desired type because no clear demarcation between settled solids and clear liquid was apparent (over a 2 hour period). Some settling did occur, but there was no way to measure a rate because of the lack of an "edge" to follow.

In a effort to obtain settling information of a different type, the solids were again suspended, then allowed to settle for -12 minutes, and a series of samples was removed from near the top of the solution so that concentrations of Pu+Am and of $\mathrm{Zr}$ could be measured in segments of the -12minute settled suspension. The results of these measurements, which are shown in Figure 2 along with those obtained in a similar experiment (described in the following section) with 103-AW solids are in accordance with the visual observations. While some rapid settling did occur, the concentrations of 

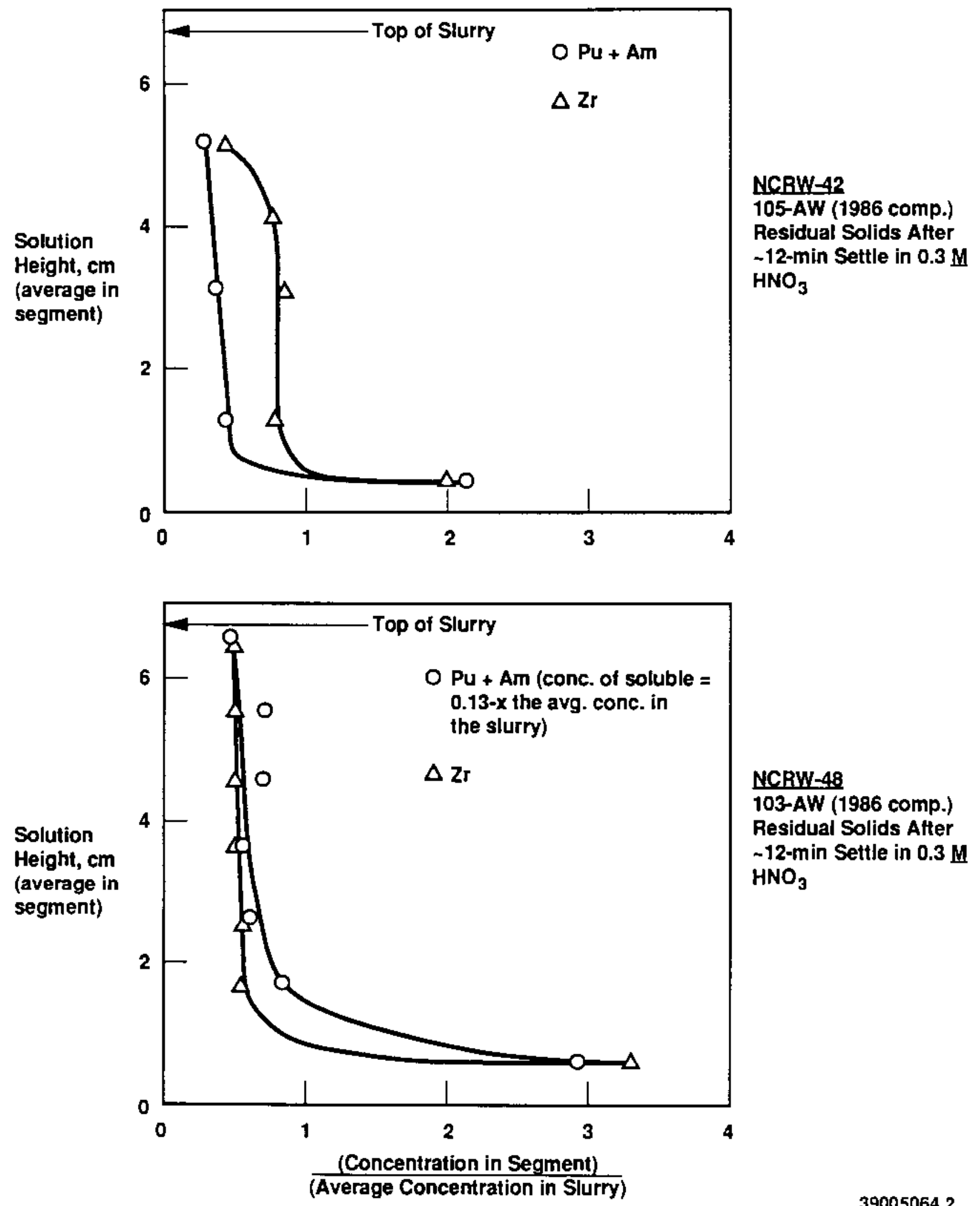

\section{NCRW-48}

103-AW (1986 comp.) Residual Solids After -12-min Settle in $0.3 \mathrm{M}$ $\mathrm{HNO}_{3}$

FIGURE 2. Distribution of (Pu+Am) and $\mathrm{Zr}$ in Settled Slurries 
suspended materials through the bulk of the suspension were fairly uniform and not much lower than the concentrations in the mixed suspension.

\section{Settling Studies In NCRW-48 (103-AW STudge)}

As was mentioned earlier, the residual solids from the dissolution of 103-AW (1986 composite) sludge did tend to settle out from the dissolved sludge solution; however, the settling was not very rapid. These solids were a] so collected by filtration and washed with water before being resuspended for settling tests in other solutions.

Visual observations indicated that these (103-AW) solids settled much better than the (105-AW) solids studied in NCRW-42. However, no clear demarcation between settled solids and clear liquid was evident in this case either, so again no settling rate value could be measured.

The results obtained by analyzing segments of the -12-minute settled suspension of these solids are presented in Figure 2, along with those measured in the 105-AW case discussed in the preceding section. These results are more complete than those of the 105-AW case, and appear to be reliable (material balances of $93 \%$ for Pu+Am and $101 \%$ for $\mathrm{Zr}$ were obtained). They show a fairly uniform suspension of solids (above the bottom segment) at a concentration that is roughly half that in the mixed suspension.

Settling Studies In NCRW-50 (103-AW Sludge)

The solids remaining after dissolution in this experiment, which used a portion of the 1989 103-AW composite, settled out of the dissolved sludge solution fairly well. A distinct edge of settled solids was apparent, although the liquid above the edge remained slightly murky. The edge was -0.9 $\mathrm{cm}$ below the liquid level after a 6-minute settling time and $-1.2 \mathrm{~cm}$ below the liquid level after a 12-minute settling time. The total height of the slurry was only $\sim 2.3 \mathrm{~cm}$, so "hindered settling" may have been occurring.

Settling Studies In NCRW-1C (Simulated Sludqe)

The solids remaining after dissolution of a portion of 4-week aged NCRWIC simulated sludge settled quite rapidiy out of the dissolved sludge solution; clear liquid became apparent at the top of the settling suspension 
at a rate of $-0.3 \mathrm{~cm} / \mathrm{min}$. This is much better settling behavior than was observed with any of the actual sludge samples, which indicates that the NCRW1C attempt at preparing a nonradioactive sludge having comparable properties to the actual sludges was not successfut.

\section{FILTRATION TESTS WITH UNDISSOLVED RESIDUES}

The undissolved residues from some dissolution tests were used to test the performance of some porous metal filters with these solids. The filters tested were obtained from Mott Metallurgical Corp.; they were made of 316 SS

and had an area of $2.2 \mathrm{~cm}^{2}\left(0.34 \mathrm{in}^{2}\right)$. Porosities of both $5 \mu \mathrm{m}$ and $0.5 \mu \mathrm{m}$ were tested with dissolved sludge slurries obtained from both 103-AW (1989 composite) and 105-AW (1986 composite).

Visually clear filtrates (indicating complete removal of solids) were obtained in both tests with $0.5-\mu \mathrm{m}$ filters and in the 103-AW (1989 composite)

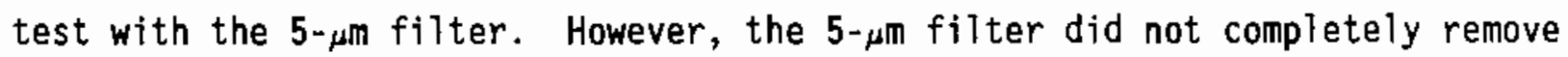
the residual solids in the 105-AW (1986 composite) slurry; collection and analysis (after dissolution) of the passed solids showed them to contain $-10 \%$ of the Pu+Am present in the solids fraction, which contained $-2 \%$ of Pu+Am present in the filtrate. No $\mathrm{Zr}$ data are yet available for this experiment.

The solids that passed the $5-\mu \mathrm{m}$ filter (but were retained by a $0.2-\mu \mathrm{m}$ filter) contained $\sim 2 \times 10^{4} \mathrm{nCi}$ of Pu+Am per gram of $\mathrm{Zr}+\mathrm{Al}+\mathrm{Na}$ in the solids. However, the quantity was so small that this amount of Pu+Am would add onty $-0.5 \mathrm{nCi} / \mathrm{mL}$ to the activity of the dissolved sludge solution. Thus, these solids (and their contained Pu+Am) could be included in the solvent extraction raffinate without affecting its status as low-leve1 waste. However, the effects of such solids on the operation of centrifugal contactors, which will likely be chosen for use, is not known, so a well-clarified feed appears to be a necessity. Solids such as this may well have less adverse effects in an (organic phase continuous) pulse column than in centrifugal contactors.

Filtration rate data obtained in these tests are shown in Figure 3. Comparison of the rates obtained with the slurries with that obtained in the absence of solids shows that filter pore plugging was extensive in all cases, although it was less severe with the $0.5-\mu \mathrm{m}$ filters than with the $5-\mu \mathrm{m}$ 


\section{Conditions}

- 5-mL slurry placed above filter and vacuum applied (vacuum of $\sim 23$ in. Hq)

- Filter area $\sim 2.2 \mathrm{~cm}^{2}$

- Filter porosity:

$$
\begin{aligned}
O & =5 \mu \mathrm{m} \\
\Delta & =0.5 \mu \mathrm{m}
\end{aligned}
$$

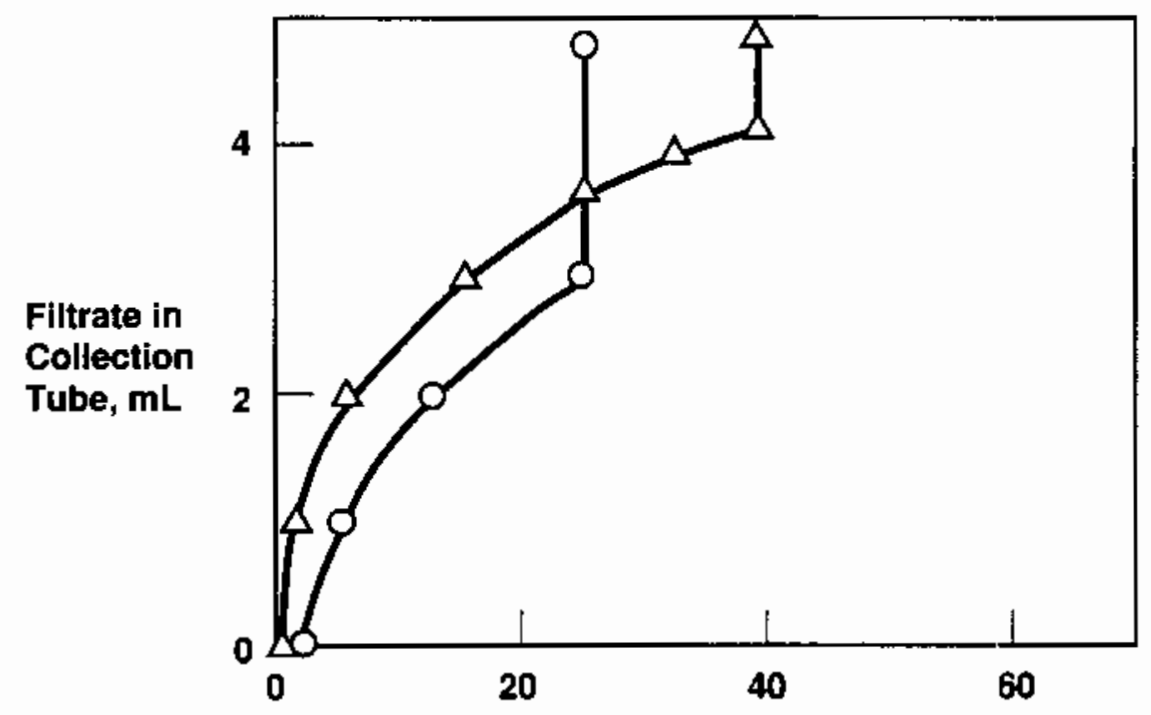

\section{NCRW-50 \\ 103-AW (1989 comp.)}

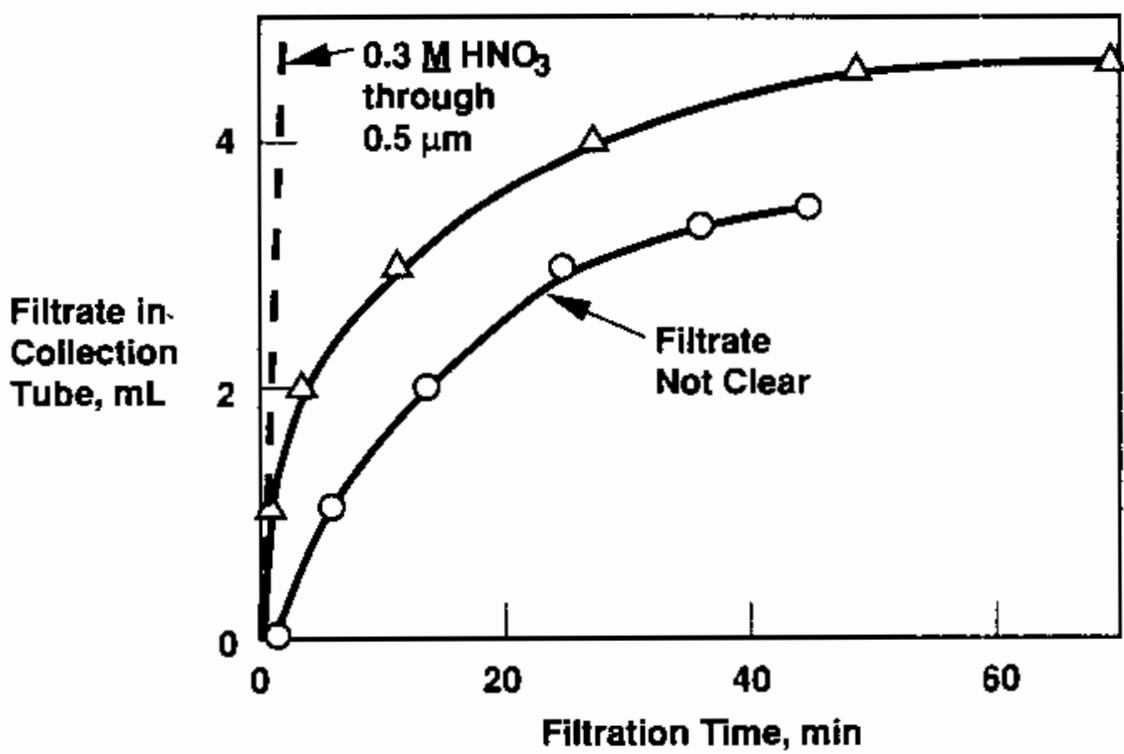

\section{NCRW-43}

105-AW (1986 comp.)

Filtrate in. Collection Fin

FIGURE 3. Filtration Rates of Dissolved S1udge Slurries Through Porous Metal Filters 
filters. The initial filtration rates were comparable with the two slurries, but sudden "spurts" were observed later with the 103-AW slurry. It is speculated that these spurts resulted when all of the 1 iquid had passed through the filter and a rush of air then swept filtered solution out of the line and into the collection tube. It is not known why the same behavior was not observed with the 105-AW slurry.

A related result was obtained in experiment NCRW-48, where a portion of the initiat sludge slurry (in water) was filtered through a plastic (supported acrylic copolymer) filter having a $5 \mu \mathrm{m}$ pore size. The filtrate was faintly murky, indicating that solids retention was not quite complete. Pore pluggage was very severe in this test, as indicated by the pressure that had to be applied to the syringe to force the liquid through the filter.

\section{PARTICLE SIZE DATA}

Particles from six different sources were examined by D. B. Bechtold of WHC with a Brinkman particle size analyzer. Three samples were of the waterinsoluble portion of the initial sludges (105-AW, 103-AW, and the laboratory simulation) and three were of the residues that remained undissolved after typical sludge dissolution steps. The particles in all samples were reported to be fairly regular in shape, with a large fraction being clear and coloriess when viewed under the video microscope. Size data were accumulated on all samples over the range 0.7 to $150-\mu \mathrm{m}$. The output of the analyzer is based on measured diameters; conversion to volumes was based on the assumption that the particles are spheres.

The particles size results were obtained in terms of both the percentage of the total number of particles in different diameter ranges and the percentage of the total particulate volume represented by particles in different diameter ranges. The volume fractions would also represent the weight fractions if all of the particles have the same density; however, this is not likely to be the case in a mixture of solids such as NCRW sludge (see section on SEM results).

Some comparative results of this study are summarized in Table 2 . The data based on the number of particles are comparable; essentially all of the 
TABLE 2. Summary of Particle Size Analyzer Results

\begin{tabular}{|c|c|c|c|c|c|c|}
\hline \multirow{3}{*}{$\begin{array}{l}\text { Particle } \\
\text { Dia,__m }\end{array}$} & \multicolumn{6}{|c|}{ Percentage of Total in Particles Smaller than Indicated } \\
\hline & \multicolumn{3}{|c|}{ Initial sludge } & \multicolumn{3}{|c|}{ Undissolved Residue } \\
\hline & 105-AW(a) & 103-AW(b) & Lab. (c) & $105-\mathrm{AW}^{(\mathrm{d})}$ & $103-$ AW $^{(B)}$ & Lab. (c) \\
\hline & \multicolumn{6}{|c|}{ Based on Number of Particles } \\
\hline 2 & 82 & 91 & 87 & 74 & 67 & 72 \\
\hline 10 & -100 & -100 & -100 & $\sim 100$ & -100 & -100 \\
\hline 50 & -100 & -100 & -100 & $\sim 100$ & -100 & -100 \\
\hline & \multicolumn{6}{|c|}{ Based on Particulate Volume } \\
\hline 2 & 10 & 25 & 4 & 3 & 3 & 8 \\
\hline 10 & 70 & 90 & 30 & 30 & 30 & 75 \\
\hline 50 & 95 & $>97$ & 90 & 80 & 60 & 85 \\
\hline
\end{tabular}

(a) From Experiment NCRW-43, with 1986 composite.

(b) From Experiment NCRW-48, with 1986 composite.

(c) From Experiment NCRW-1C.

(d) From Experiment NCRW-42, with 1986 composite.

particles had diameters $<10-\mu \mathrm{m}$ and 70 to $90 \%$ of the particles had diameters $<2-\mu \mathrm{m}$. However, variations among samples did occur in the particulate volume comparison. The laboratory-prepared initial sludge had a much smaller volume fraction in small particles than did the actual sludges. Also, the undissolved residue from the laboratory-prepared sludge had a larger volume fraction in small particles than did the residues from the actual sludges. This provides an apparent contradiction to the observation that the residue from the laboratory preparation settled from solution more rapidly than did those from the actual sludges; perhaps this apparent contradiction could be explainable based on different particle densities, but no such data are available. At any rate, this comparison points out again that this laboratory-prepared sludge did not behave like the actual sludges.

The high proportion of $\leq 2-\mu \mathrm{m}$ particles found in these samples increases the likelihood of plugging a filter having a pore size of comparable (or slightly larger) size; this is the case even though a reiatively small volume fraction of the particles is in that size range. This is consistent with the 
results of the filtration tests where, as was mentioned earlier, filter plugging was less of a problem with $0.5-\mu \mathrm{m}$ filters that with 5 - $\mu \mathrm{m}$ filters.

The particle size data for the six samples are presented graphically in Figure 4 through 9 . Care should be taken in making quick visual comparisons of these data because the computer-generated plots do not have consistent units on the ordinates and abscissas.

Figures 4 and 5 contain the data based on the number of particles. The presentation of number density (Figure 4) shows the great dominance (in all samples) of particles in the small size range and the cumulative number presentation (Figure 5) shows the percentage of particles that have diameters smaller than different sizes.

Figures 6 through 9 present the data based on particle volume instead of the number of particles. Figures 6 and 7 show the percentages of total particulate volume represented by particles in different diameter ranges (Figure 6 has a linear size scale, while Figure 7 has a logarithmic size scale). These figures provide a better (than Table 2) illustration of the fact that, in some of the cases examined, a substantial portion of the particulate volume was present in particles of 50 -to $100-\mu \mathrm{m}$ diameter, even though essentially $100 \%$ of all particles were $<10-\mu \mathrm{m}$ in diameter in all cases (remember that one $100-\mu \mathrm{m}$ particle occupies the same volume as $1,000,0001-\mu \mathrm{m}$ particles). Figures 8 and 9 are cumulative plots of the particle volume data (Figure 8 is a linear presentation of the percentage of the particulate volume that is occupied by particles having diameters smaller than different sizes and Figure 9 contains the same data in a log-normal presentation.)

\section{SCANNING ELECTION MICROSCOPE RESULTS}

Samples of the initial sludges and of the residual solids remaining after sludge dissolution were examined with PNL's scanning election microscope (SEM). Copies of some of the photomicrographs, and the highlight results obtained with the electron microprobe attachment, are presented here. Complete sets of glossy prints of the photomicrographs and the microprobe data have been provided to S. A. Barker of WHC. 

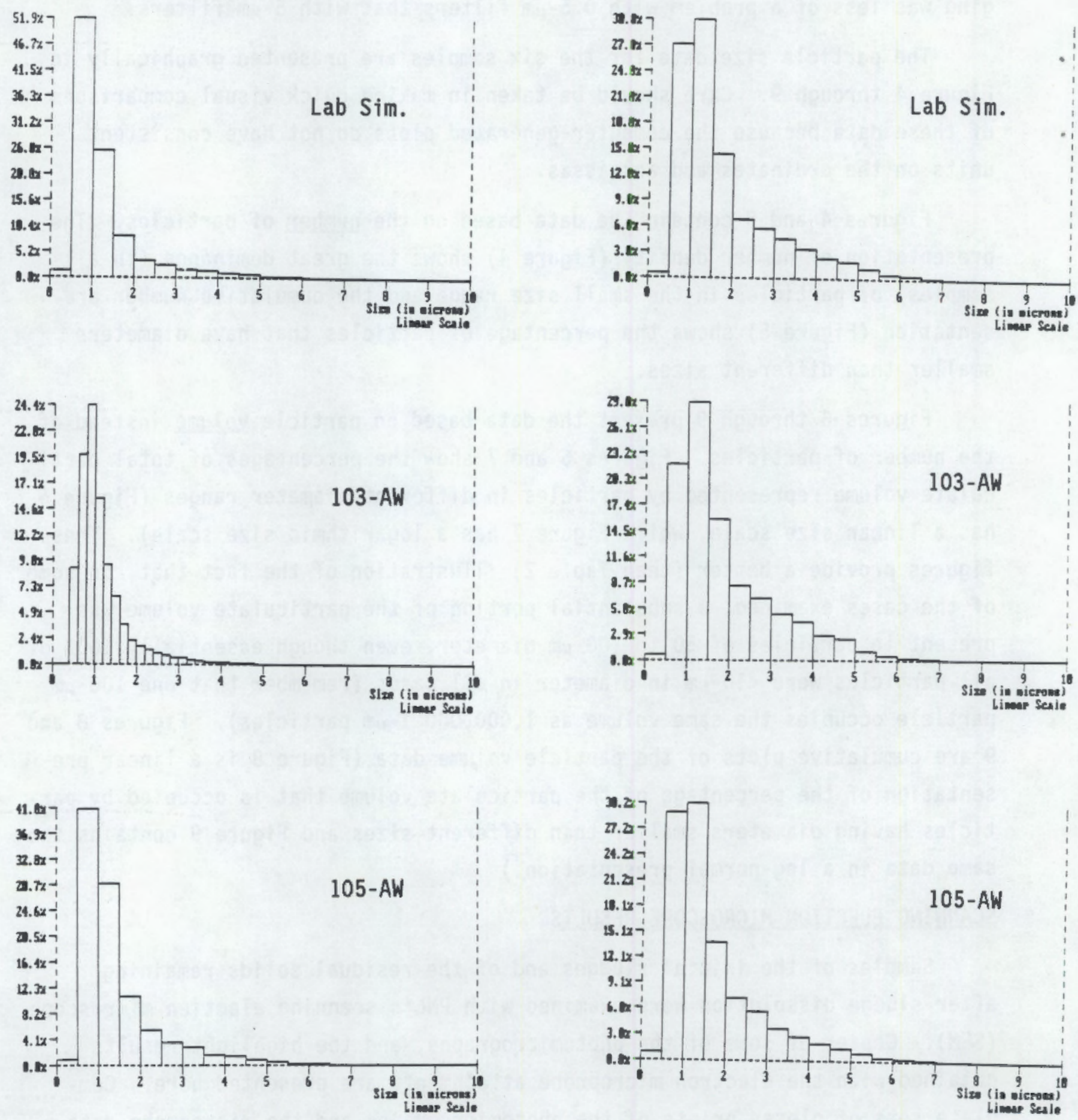

Initial Sludges

Undissolved Residues

FIGURE 4. Particle Size Data--Probability Number Density Graphs with Linear Scales 

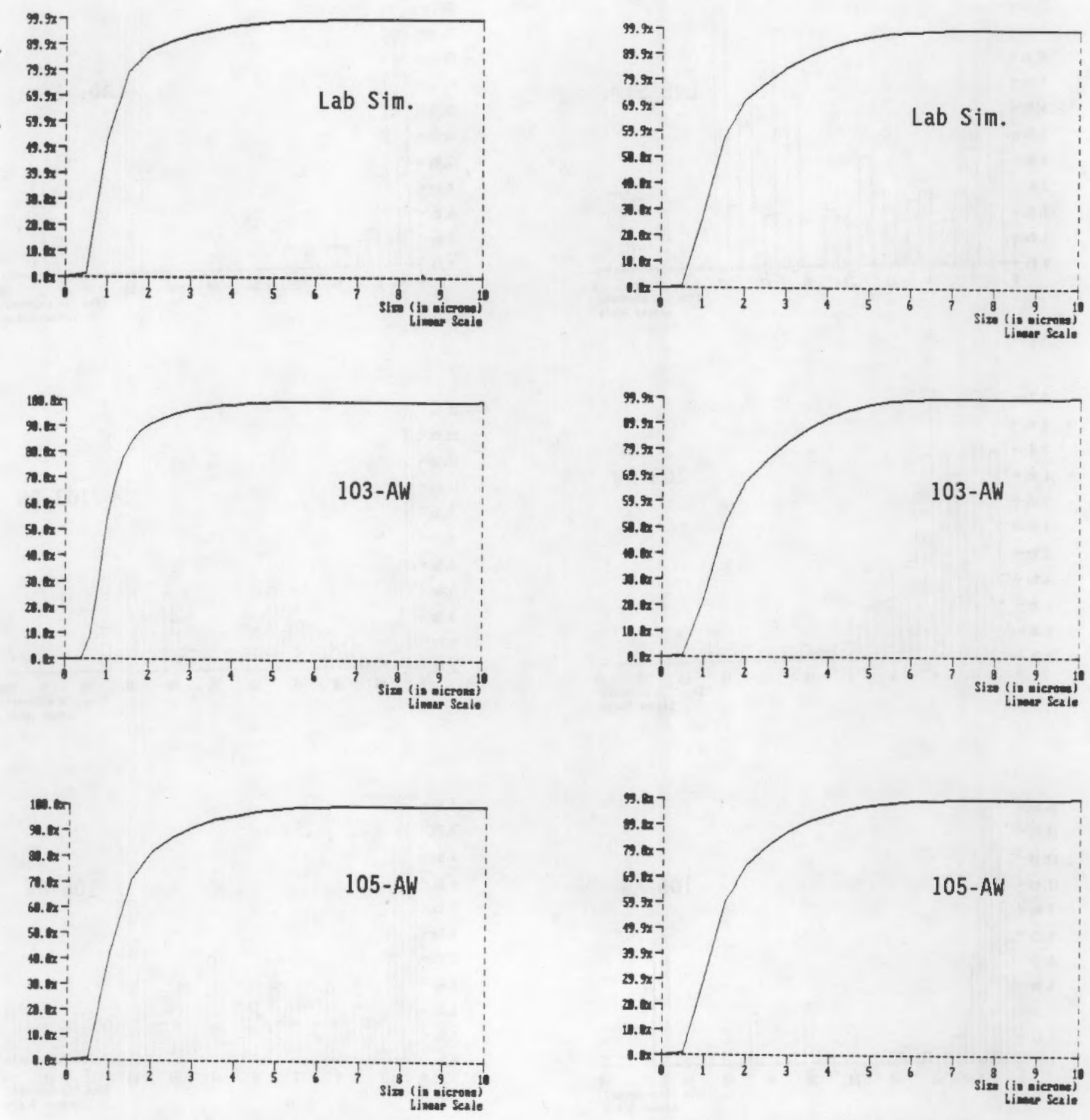

Initial Sludges

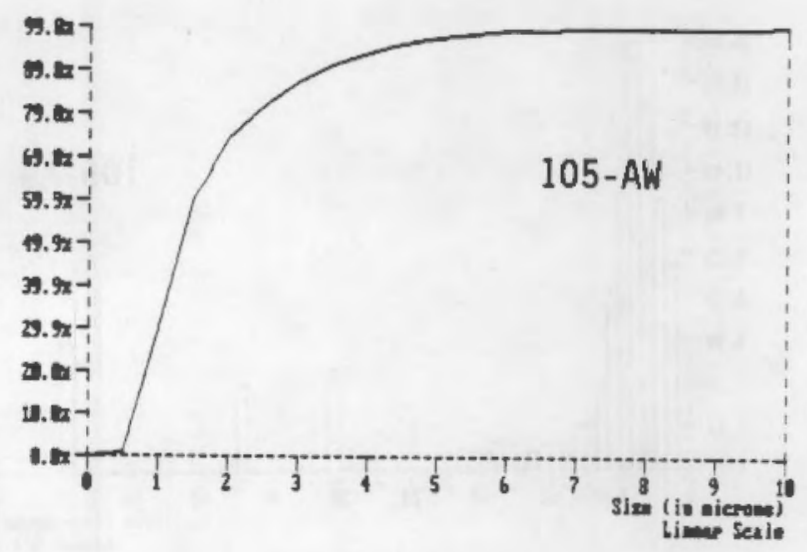

Undissolved Residues

FIGURE 5. Particle Size Data--Cumulative Number Distribution Graphs with Linear Scales 

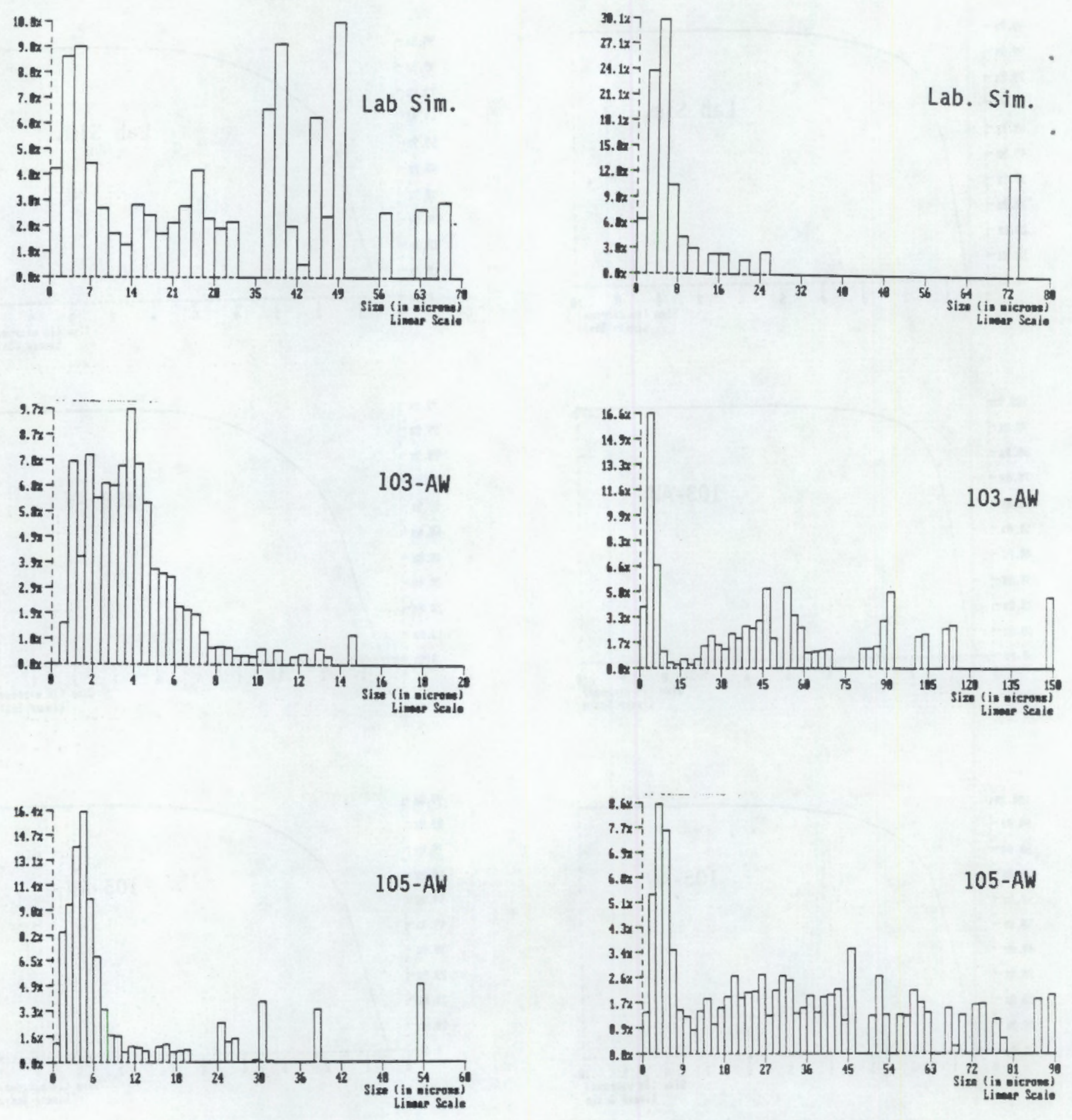

Initial Sludges Undissolved Residues

FIGURE 6. Particle Size Data--Probability Volume Density Graphs with Linear Scales 

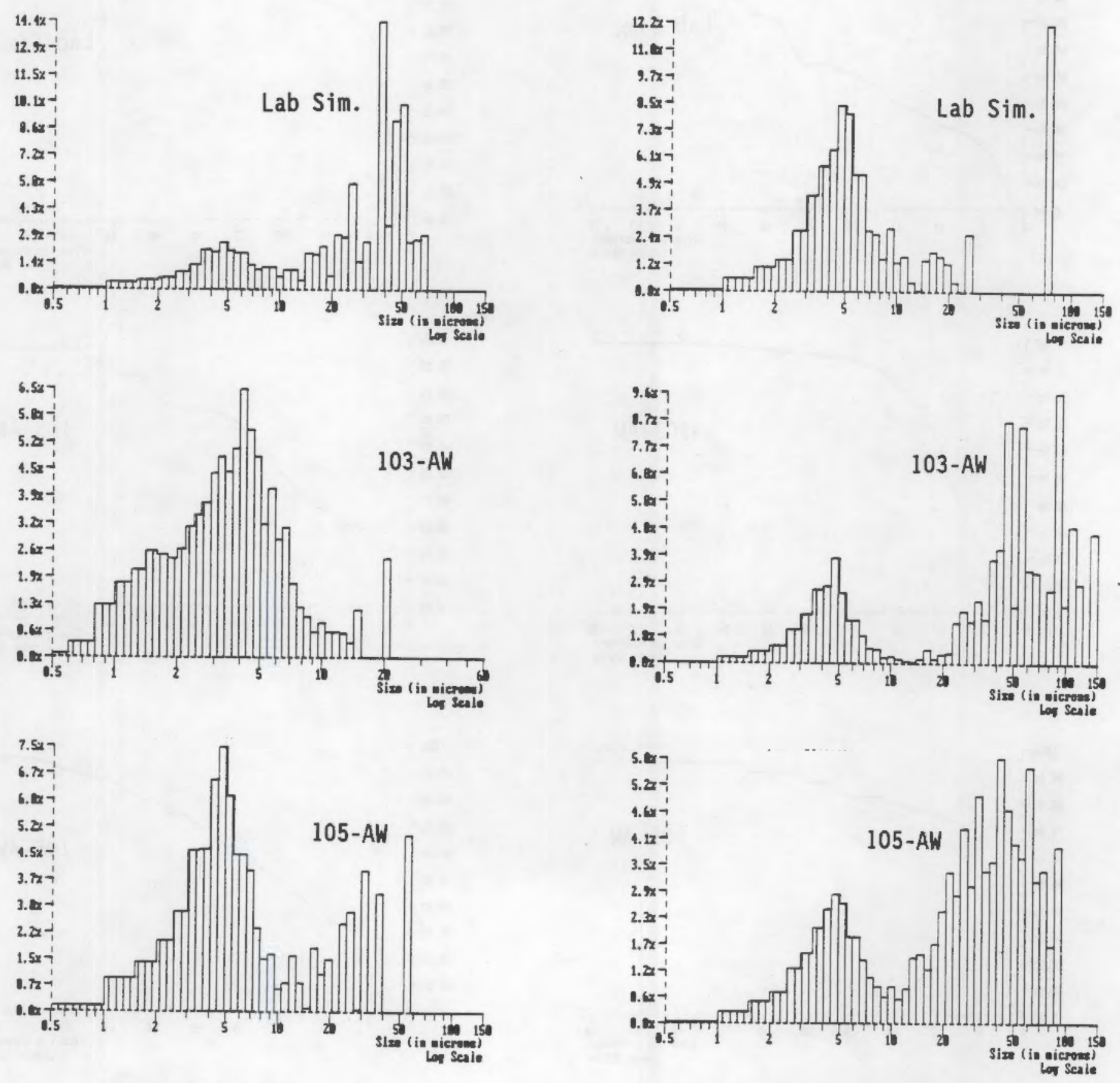

Initial Sludges

Undissolved Residues

FIGURE 7. Particle Size Data--Probability Volume Density Graphs with Log Scales 

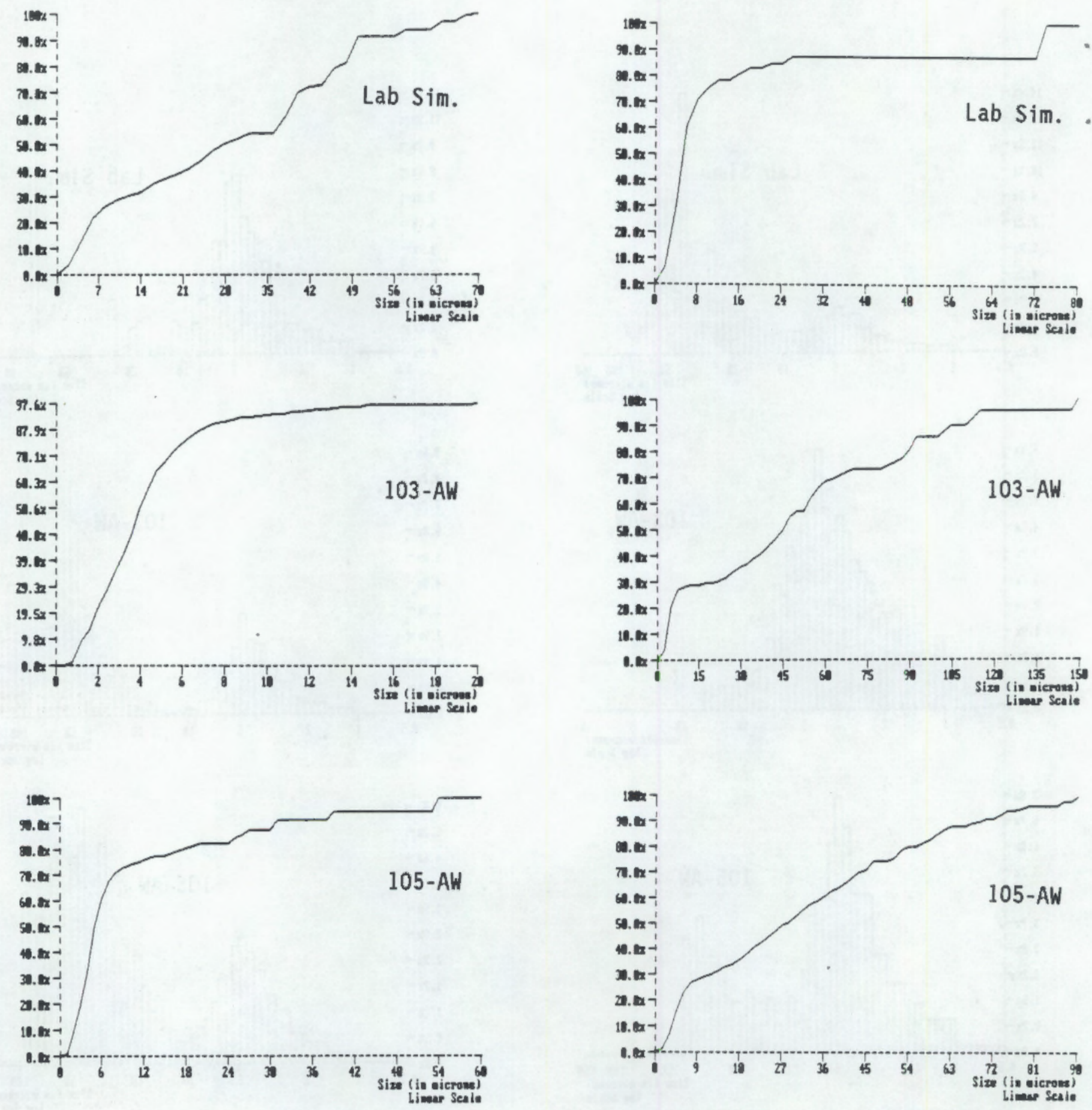

Initial Sludges

Undissolved Residues

FIGURE 8. Particle Size Data--Cumulative Volume Distribution Graphs with Linear Scales 

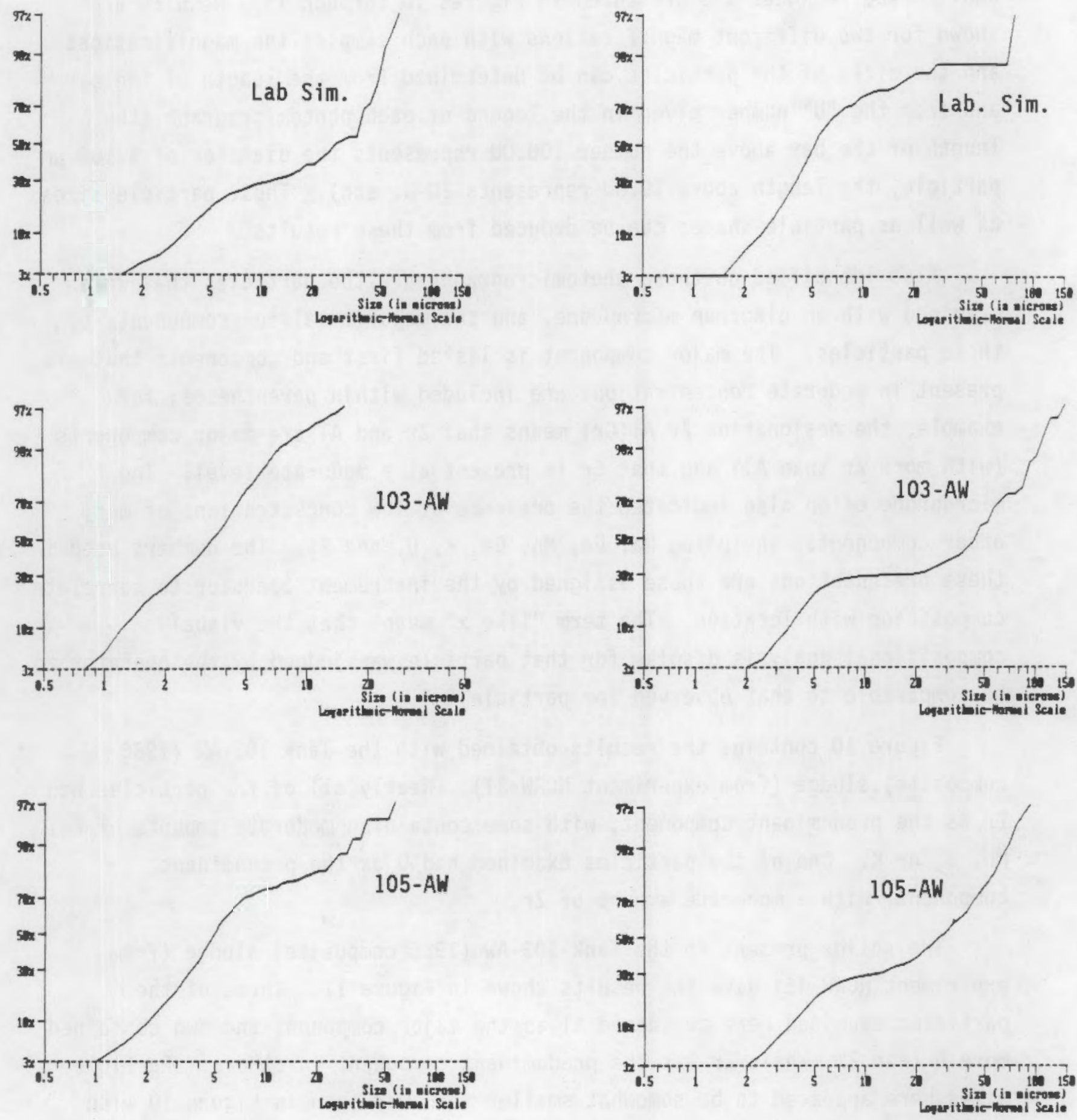

Initial Sludges

Undissolved Residues

FIGURE 9. Particle Size Data--Cumulative Volume Distribution Graphs with Log-Normal Scales 
Photomicrographs of particles from the initial sludges and from undissolved residues are presented in Figures 10 through 15. Results are shown for two different magnifications with each sample; the magnifications and the sizes of the particles can be determined from the length of the bar and from the "U" number given in the legend of each photomicrograph (the length of the bar above the number $100.0 \mathrm{U}$ represents the diameter of a $100-\mu \mathrm{m}$ particle, the length above $10.0 \mathrm{U}$ represents $10-\mu$, etc). Thus, particle sizes as well as particle shapes can be deduced from these results.

Also identified on these photomicrographs are the particles that were examined with an electron microprobe, and the major metal-ion components of those particles. The major component is listed first and components that are present in moderate concentrations are included within parentheses; for example, the designation $\mathrm{Zr}, \mathrm{Al}(\mathrm{Cr})$ means that $\mathrm{Zr}$ and $\mathrm{Al}$ are major components (with more $\mathrm{Zr}$ than $\mathrm{Al}$ ) and that $\mathrm{Cr}$ is present at a moderate level. The microprobe often also indicated the presence of low concentrations of many other components, including $\mathrm{Na}, \mathrm{Fe}, \mathrm{Mn}, \mathrm{Ca}, \mathrm{K}, \mathrm{U}$, and $\mathrm{Si}$. The numbers used in these presentations are those assigned by the instrument operator to correlate composition with location. The term "like $\mathrm{x}$ " means that the visual compositional analysis display for that particle was judged by the operator to be comparable to that observed for particle " $x$ ".

Figure 10 contains the results obtained with the Tank 105-AW (1986 composite) sludge (from experiment NCRW-31). Nearly all of the particles had $\mathrm{Zr}$ as the predominant component, with some containing moderate amounts of $\mathrm{Fe}$, $M n, U$, or $K$. One of the particles examined had $U$ as the predominant component, with a moderate amount of $\mathrm{Zr}$.

The solids present in the Tank 103-AW (1986 composite) sludge (from experiment NCRW-48) gave the results shown in Figure 11. Three of the particles examined here contained $\mathrm{Al}$ as the major component and two contained more $U$ than $\mathrm{Zr}$, while $\mathrm{Zr}$ was the predominant component in others. Particle sizes here appeared to be somewhat smaller than was seen in Figure 10 with solids from Tank 105-AW.

Figure 12 shows the results obtained with the solids from simulated sludge preparation NCRW-1C (note that these photographs are at tenfold greater 

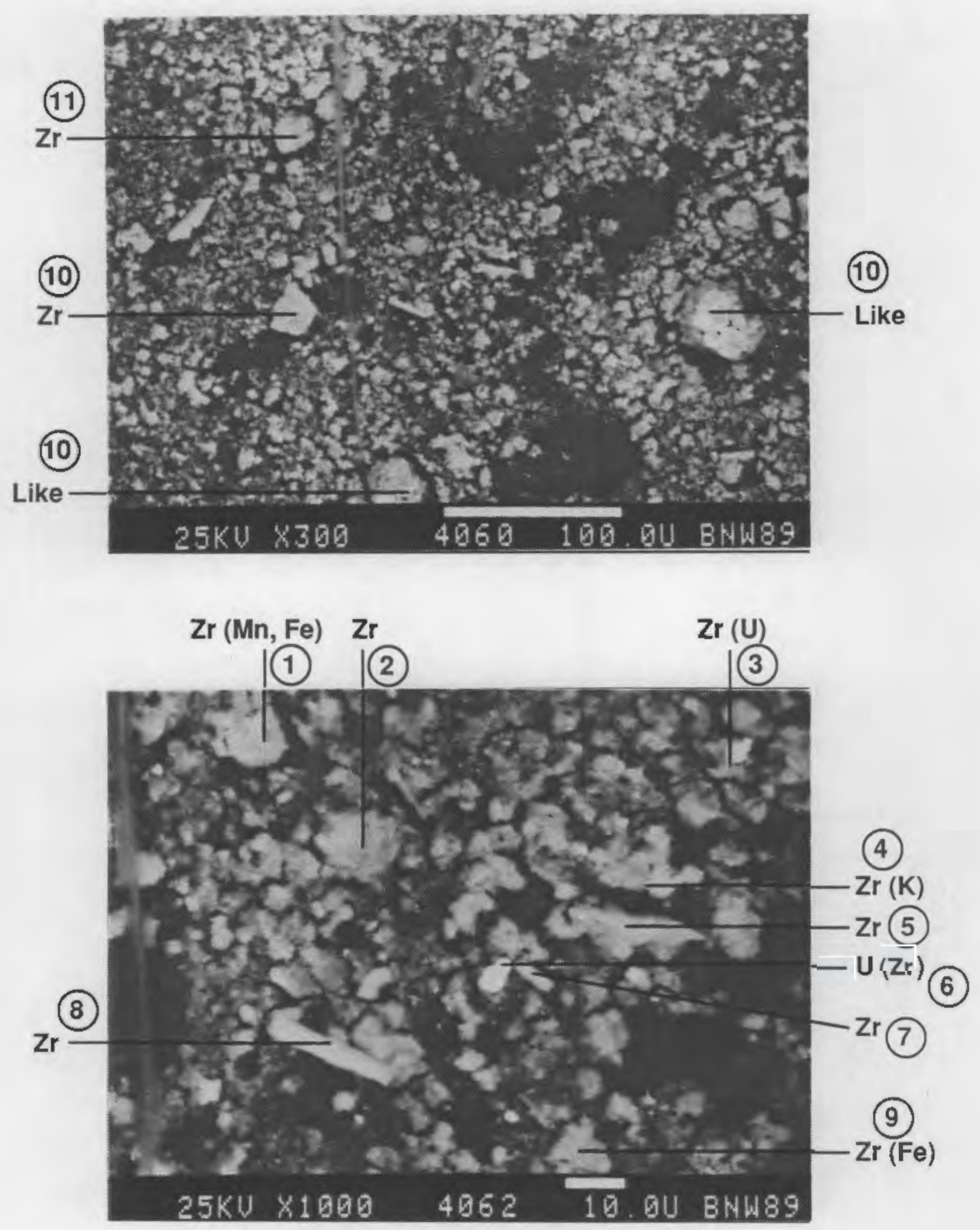

FIGURE 10. SEM Results - Initial S1udge from Tank 105-AW 

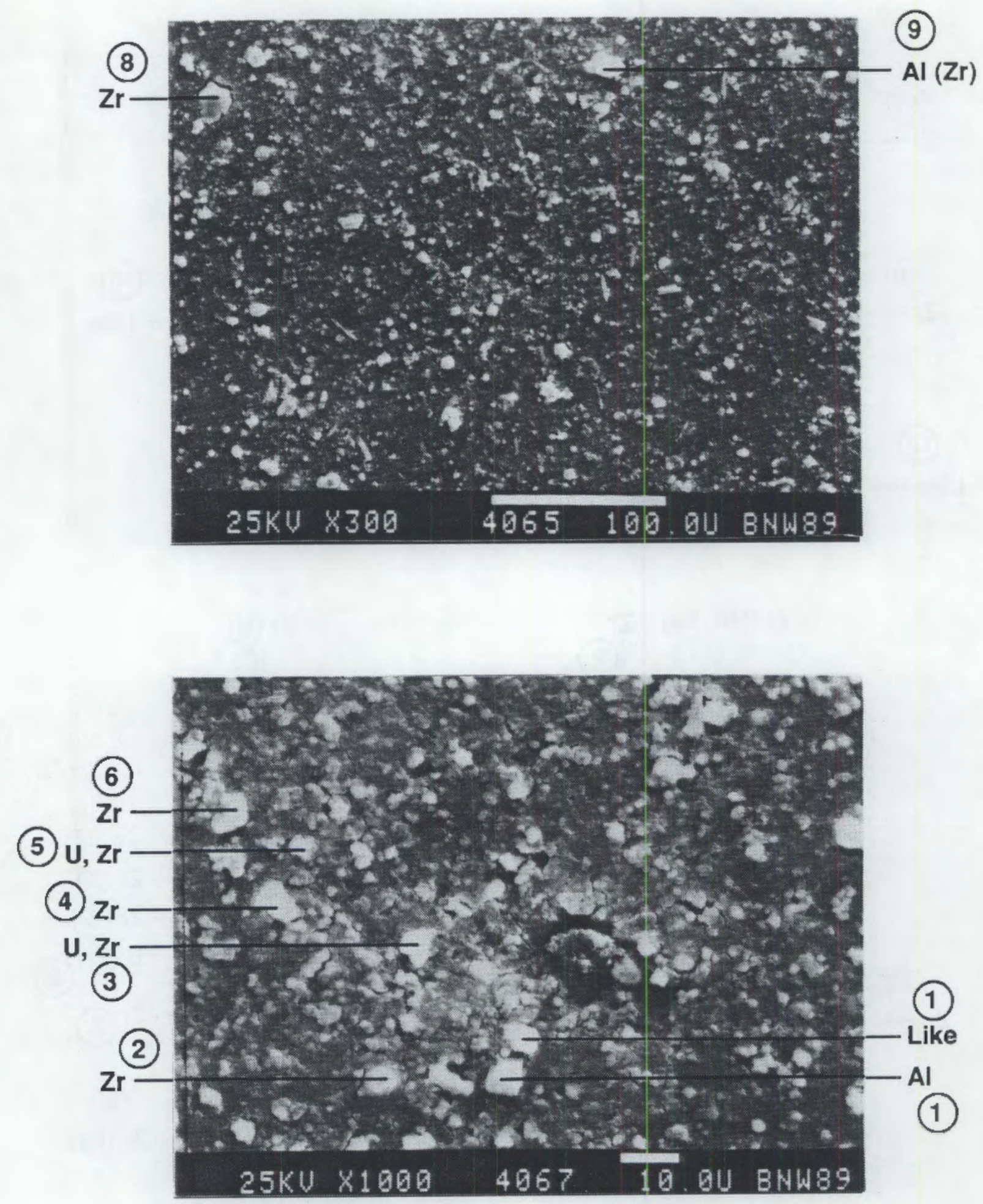

FIGURE 11. SEM Results - Initial Sludge from Tank 103-AW 


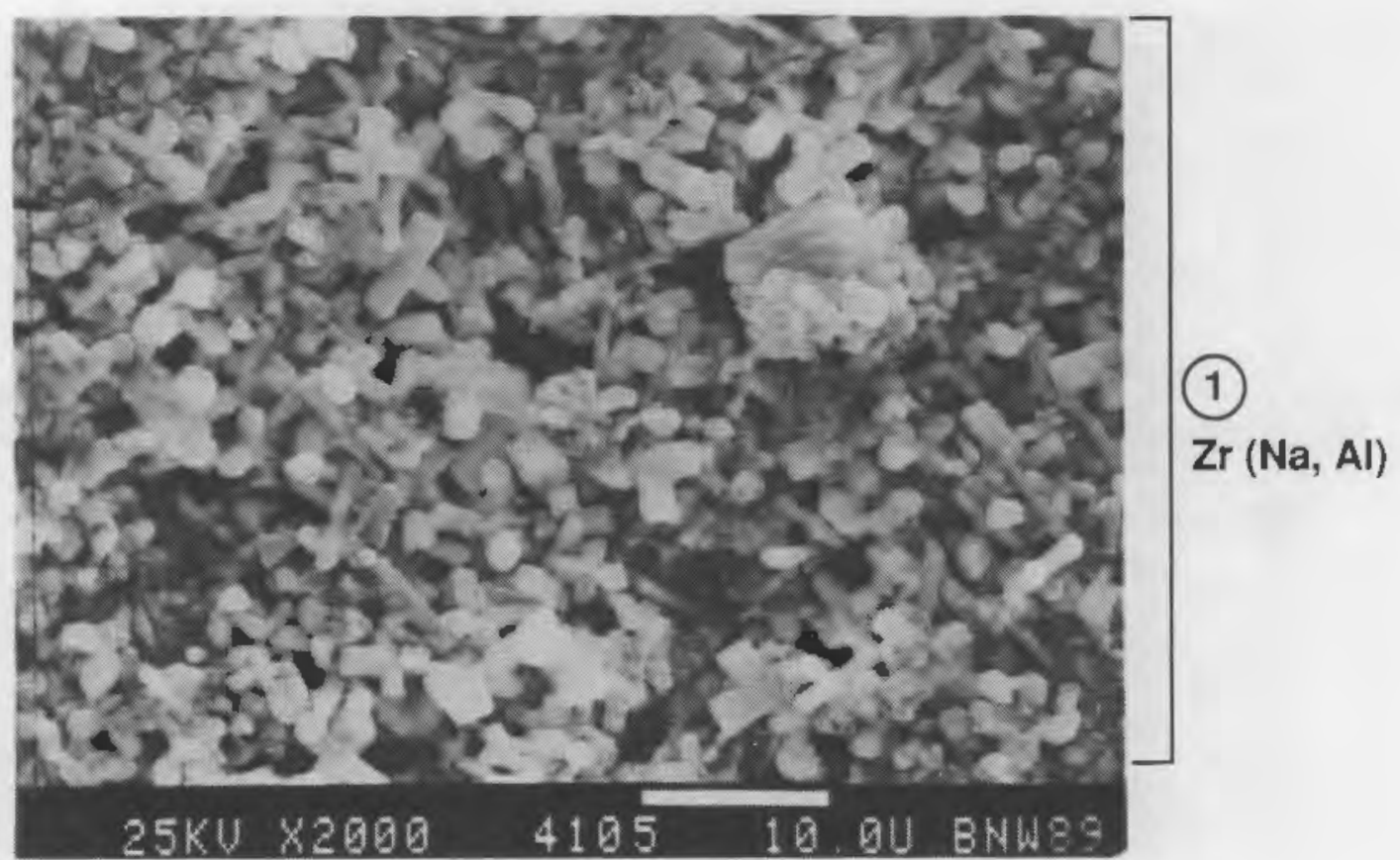

(2) (3)

$\mathrm{Zr}(\mathrm{Na}) \mathrm{Zr}(\mathrm{Na})$
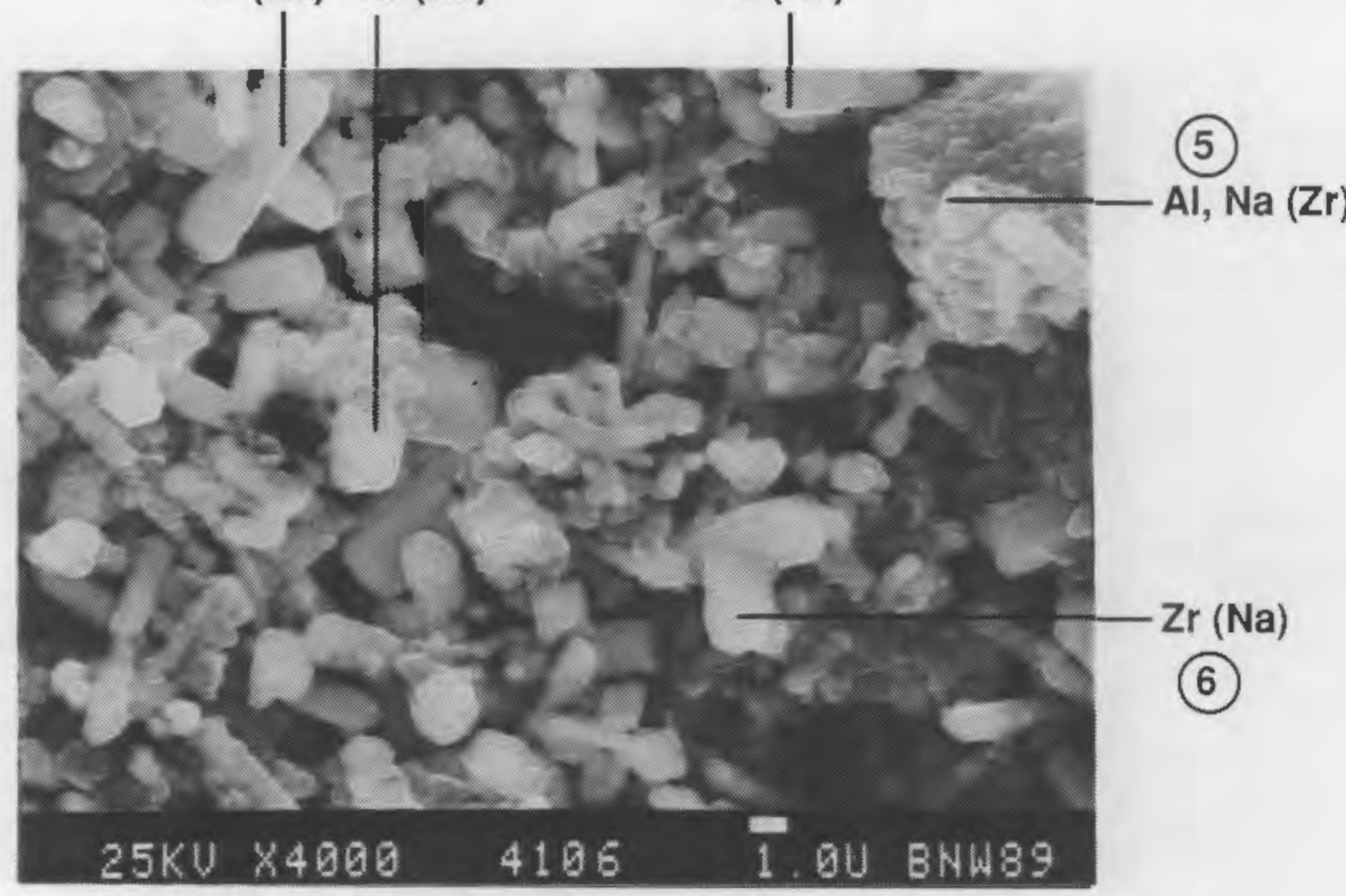

(6)

FIGURE 12. SEM Results - Initial Simulated Sludge 

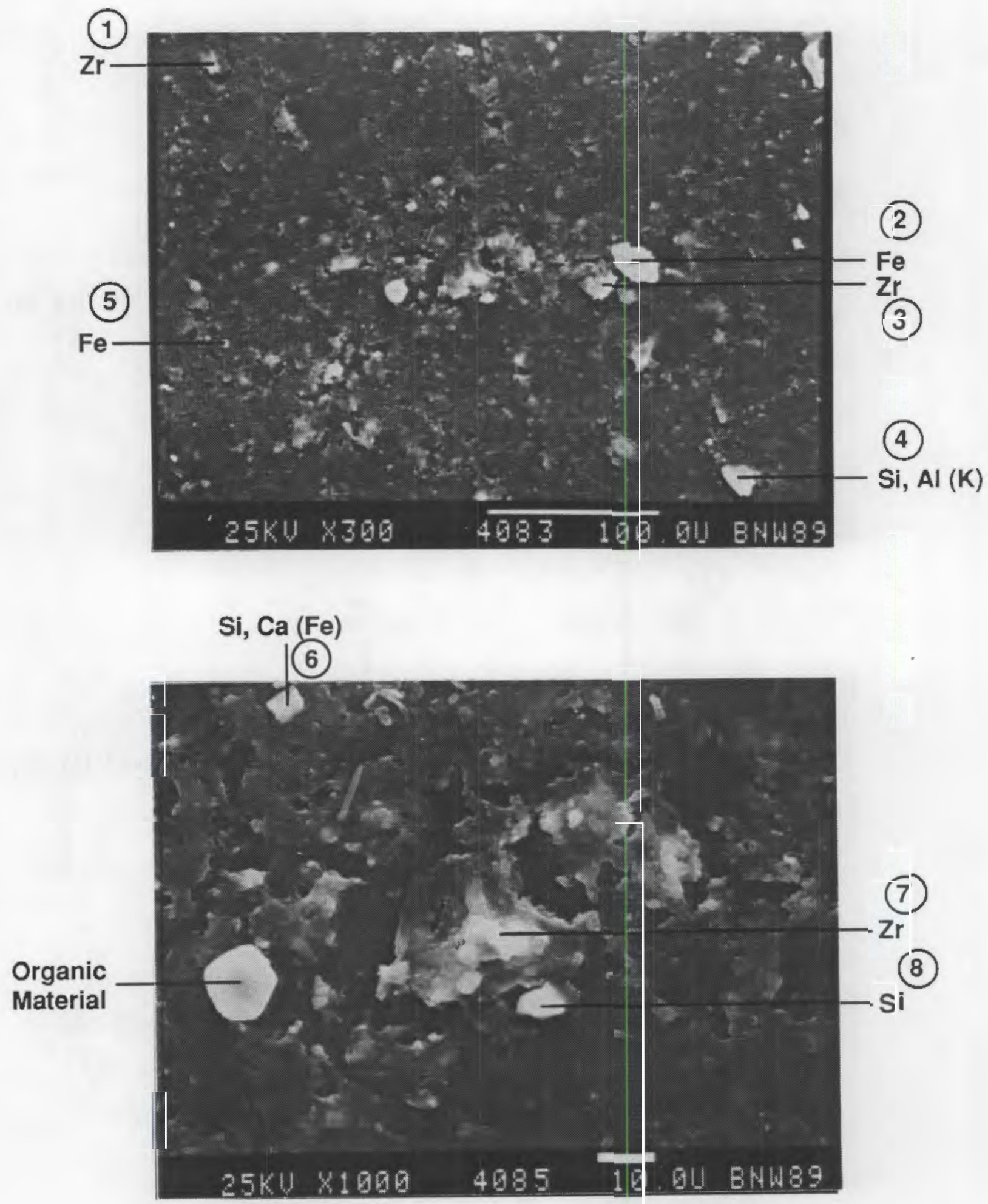

FIGURE 13. SEM Results - Tank 105-AW Dissolution Residue 

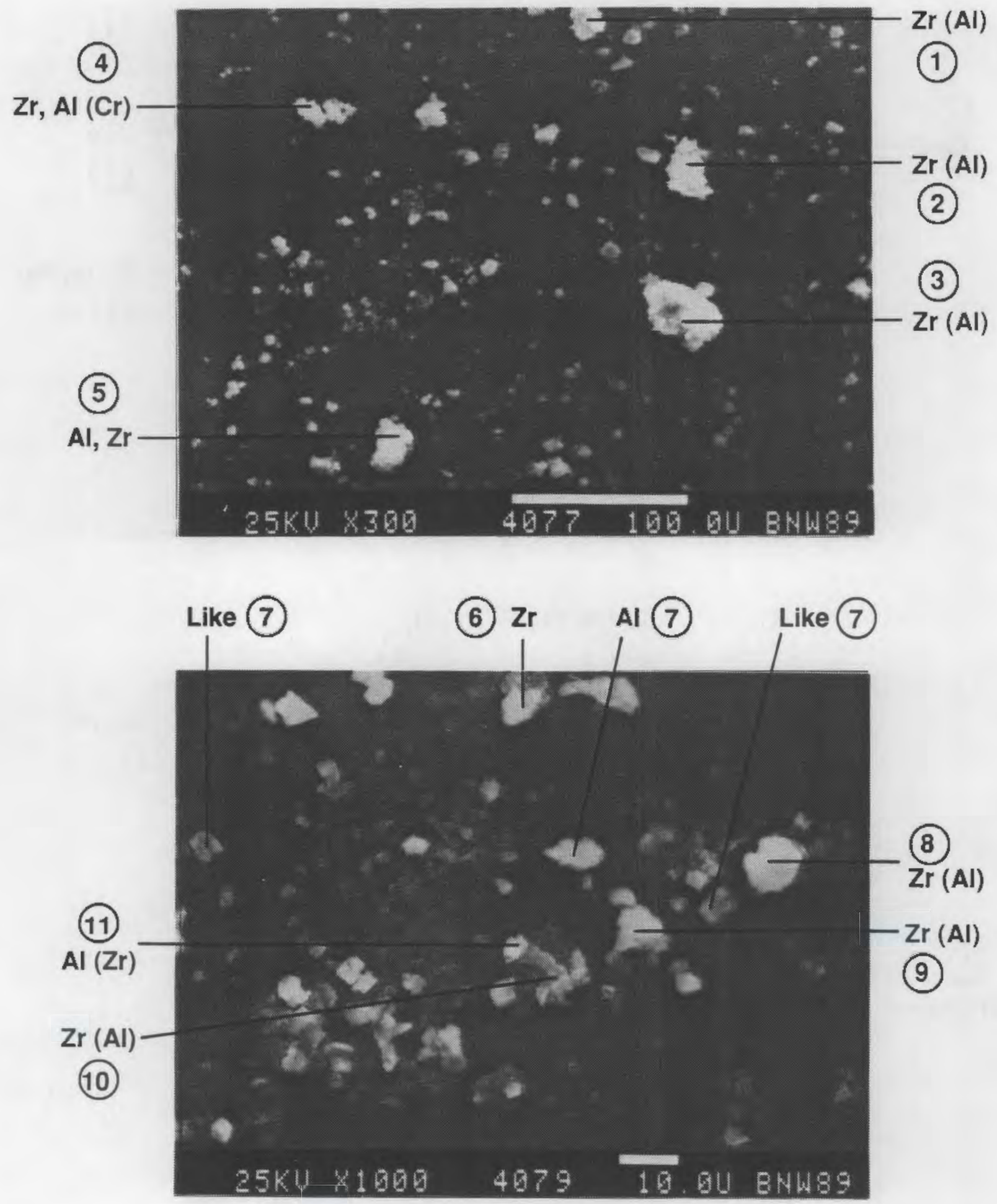

FIGURE 14. SEM Results - Tank 103-AW Dissolution Residue 

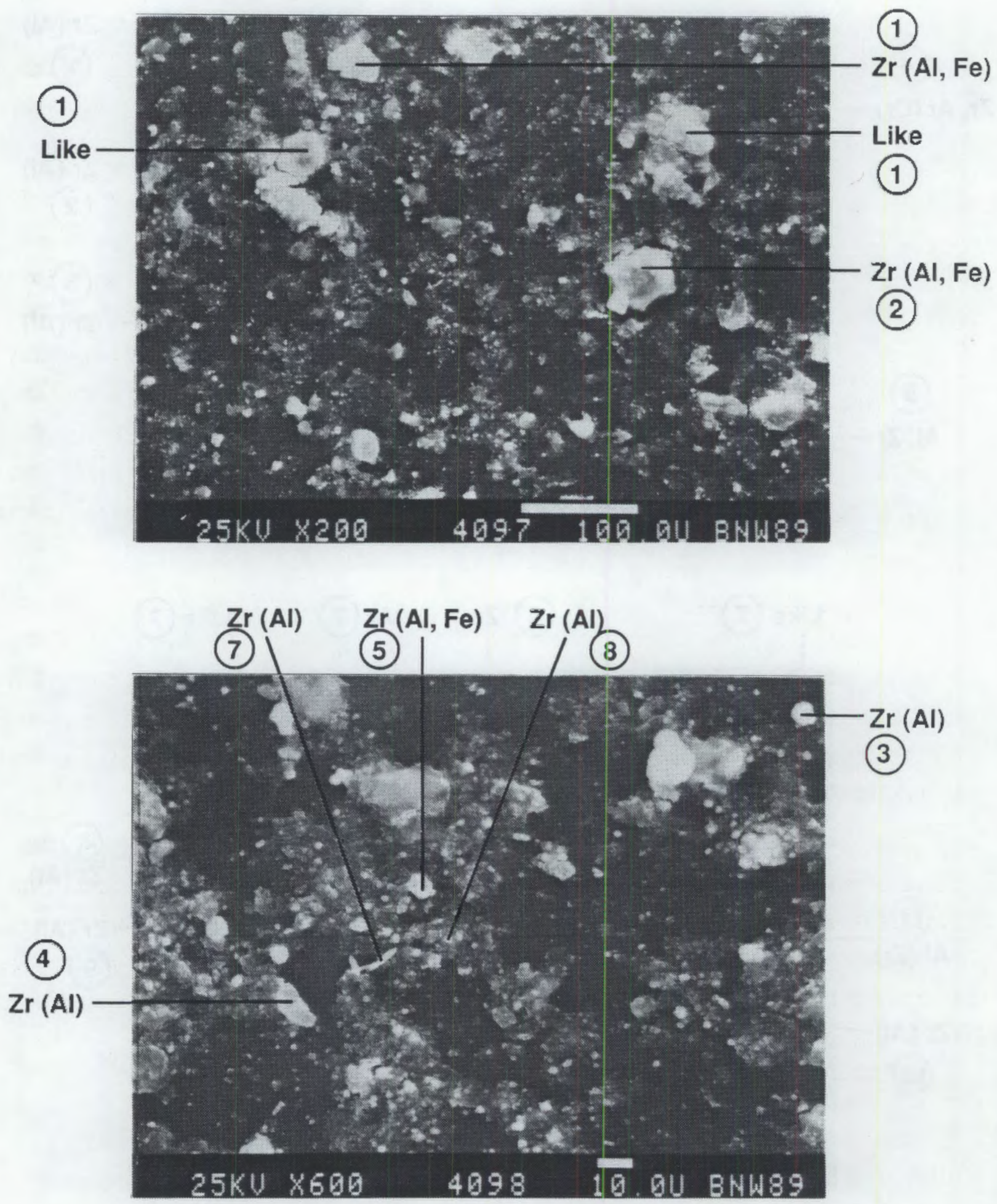

FIGURE 15. SEM Results - Dissolution Residue from Simulated Sludge 
magnifications than the corresponding ones in the preceding two figures). There appears to be a smaller fraction of small particles here, which is in agreement with the particle size data discussed in the preceding section. These particles contained more $\mathrm{Na}$ than did the particles in the actual sludge samples. One particle had both $\mathrm{Al}$ and $\mathrm{Na}$ as major components, along with a moderate amount of $\mathrm{Zr}$.

Particles of the residual solids after dissolution of the (bulk of the) sludge solids are featured in Figures 13 through 15 . Figure 13 shows those from an experiment (NCRW-42) with Tank 105-AW (1986 composite) sludge. Some particles contained predominantly $\mathrm{Zr}$, while others were predominantly $\mathrm{Fe}$ or Si. The high proportion of high Si-content particles observed here, but not with the residue from dissolution of Tank 103-AW sludge, may explain the "floaty solids" observed with Tank 105-AW composite sludge. Another interesting observation with this residual solid was apparent in a different sample of the same material; a small $(\sim 1-\mu \mathrm{m})$ particle that was high in Ag was observed.

Residual solids from dissolution of Tank 103-AW (1986 composite) siudge (in experiment NCRW-48) are pictured in Figure 14. The predominant metal ion components were solely $\mathrm{Zr}$ and $\mathrm{Al}$, with $\mathrm{Zr}$ being dominant in some particles and A1 being dominant in other particles. Although it was present to even a moderate degree in only one of the particles examined, $\mathrm{Cr}$ was present here at higher levels than in the other samples.

Figure 15 shows the residual solids remaining after dissolution of the simulated sludge. Zirconium was the major component in a1l cases and a high A1 content was again observed, although not to the extent observed with the 103-AW sludge. Iron was also observed in moderate amounts in some particles, but it was never the major component as it had been in some residual solid particles from the 105-AW sludge.

GAMMA-EMITTING RADIONUCLIDES IN UNDISSOLVED RESIDUES

As an additional characterization of the undissolved residues from sludge dissolutions, data were obtained on the fractions of gamma-emitting radionuclides that remained in the residues. Such data are of interest for 
completeness, even though the behavior of these materials is not critical to the operability of the process. It would probably be desirable to have $100 \%$ of these materials remain in the residues so that they would go to glass instead of to grout, but it is not reasonable to expect such a selective dissolution, and it has always been assumed that the bulk of the fission products would end up in the grout feed stream.

The fractions of gamma emitters found to remain in the undissolved residues from several experiments are summarized in Table 3, which also contains listings (from Appendix $\mathrm{C}$ ) of the compositions of the solutions resulting from the dissolutions and of the fractions of non-radioactive metal ions that remained in the residues. Table 3 also contains the total quantities of the gamma-emitters found in the dissolved sludge solutions plus the undissolved residues.

These data contain several surprises, foremost of which is the behavior of Cs-137 relative to that of other components. In many of the cases, the fraction of the Cs-137 that remained undissolved was not only higher than the fractions of the other fission products that remained undissolved, but was also higher than the fraction of sodium that remained undissolved. A simple explanation for this could be that a cesium-containing precipitate, which is not readily dissolved by acid, is present in the sludge; however, there is no independent evidence to support such an explanation.

Another surprising result is the high fraction of Sb-125 in the residue (along with a high fraction of zirconium) from the experiment (NCRW-46) in which the dissolved sludge solution was digested at $100^{\circ} \mathrm{C}$. While this is of interest, it is not of concern because such a digestion is not planned to be used in the process.

An important observation is that the fractions of the fission products that are present in the undissolved residues appear to be markedly lower in the cases where the terminal acidity was $>1 \underline{M}$. In those two cases, $\leq 2 \%$ of the fission products remained in the residues. 
IABLE 3. Ganma-Emitting Radionuclides In Undissolved Residues

$103-A W$
$(1986$ Composite) Sludge

Expt. \#

Diss. time, hrs.

Soln. Composition

$\begin{array}{lrrrrr}\mathrm{Na}, \mathrm{M} & 0.9 & 1.5 & 1.0 & 0.8 & 0.8 \\ \mathrm{Zr}, \mathrm{M} & 0.13 & 0.12 & 0.14 & 0.13 & 0.12 \\ \text { Acid, M } & 0.38 & 0.37 & 1.1 & 0.62 & 1.2\end{array}$

Total found in sludge, $\mathrm{nCi} / \mathrm{g}$ sludge

$\begin{array}{lrrrrr}\text { Cs }-137 & 74,000 & 72,000 & 76,000 & 45,000 & 36,000 \\ \text { Ru-106 } & 4,200 & 4,100 & 4,200 & 3,200 & 2,600 \\ \text { Sb-125 } & 4,500 & 2,900 & 4,500 & 4,500 & 4,200 \\ \text { Ce-144 } & 3,000 & 2,900 & 3,100 & 3,200 & 3,100 \\ \text { Eu-154 } & 90 & 80 & 100 & 580 & 570 \\ \text { Co-60 } & 150 & 150 & 160 & 210 & 160\end{array}$

$\%$ Undissolved

\begin{tabular}{|c|c|c|c|c|c|}
\hline $\begin{array}{l}\text { Cs }-137 \\
\text { Ru-106 } \\
\text { Sb-125 } \\
\text { Ce-144 } \\
\text { Eu-154 } \\
\text { Co-60 }\end{array}$ & $\begin{array}{r}7 \\
3 \\
3 \\
2 \\
<2 \\
14\end{array}$ & $\begin{array}{r}9 \\
1 \\
43 \\
2 \\
<4 \\
1\end{array}$ & $\begin{array}{r}1 \\
2 \\
0.4 \\
0.3 \\
<2 \\
2\end{array}$ & $\begin{array}{r}14 \\
6 \\
1 \\
2 \\
2 \\
4\end{array}$ & $\begin{array}{r}0.1 \\
(c)^{2} \\
(c) \\
(c) \\
1\end{array}$ \\
\hline $\begin{array}{l}\mathrm{Pu} \\
\mathrm{Am} \\
\mathrm{Zr} \\
\mathrm{Al} \\
\mathrm{Cr} \\
\mathrm{Fe} \\
\mathrm{Na}\end{array}$ & $\begin{array}{r}18 \\
7 \\
4 \\
28 \\
29 \\
15 \\
0\end{array}$ & $\begin{array}{r}8 \\
2 \\
45 \\
0 \\
2 \\
7 \\
1\end{array}$ & $\begin{array}{l}\text { (b) } \\
\text { (b) } \\
\text { (b) } \\
\text { (b) } \\
\text { (b) } \\
\text { (b) } \\
\text { (b) }\end{array}$ & $\begin{array}{r}4 \\
1 \\
2 \\
28 \\
4 \\
5 \\
0\end{array}$ & $\begin{array}{l}\text { (b) } \\
\text { (b) } \\
\text { (b) } \\
\text { (b) } \\
\text { (b) } \\
\text { (b) } \\
\text { (b) }\end{array}$ \\
\hline
\end{tabular}

\footnotetext{
(a) Digested at $100^{\circ} \mathrm{C}$ for $4 \mathrm{hrs}$ following addition of acid.

(b) Data not available.

(c) Concentration below the detection limit.
}

NON-METAL-ION COMPONENTS OF UNDISSOLVED RESIDUES

Tests were also run to determine the amounts of some non-metal-ion components that are present in the undissolved residues remaining from the 
sludge dissolution step. The components of interest were those that might cause problems in the vitrification step, either in equipment corrosion, in melter operation, or in the quality of the glass produced. Data were obtained for sulfate, fluoride, carbon, and chloride; these results were then compared with reference glass plant feed specifications on a "per mole $\mathrm{Zr}$ " basis. These calculated limits are 0.05 mole sulfate/mole $\mathrm{Zr}, 0.4 \mathrm{~mole}$ fluoride/mole $\mathrm{Zr}, 1.0 \mathrm{~mole}$ total organic carbon/mole $\mathrm{Zr}$, and 0.05 mole chloride/mole $\mathrm{Zr}$.

To obtain solutions to be analyzed for these components, portions of the undissolved residues from the sludge dissolution steps were dissolved using more severe conditions. One portion was dissolved for sulfate and carbon measurements by heating in $2 \underline{M} \mathrm{HCl}+0.2 \underline{\mathrm{M} \mathrm{HF}}$ and another portion was dissolved for fluoride and chloride measurements by heating in $3 \underline{M} \mathrm{HNO}_{3}+0.25 \underline{M}$ $\mathrm{H}_{2} \mathrm{C}_{2} \mathrm{O}_{4}$.

\section{Sulfate in Undissolved Residues}

The sulfate concentration in the undissolved residues was investigated in two experiments; NCRW-42, which used 105-AW (1986 composite) sludge, and NCRW-48, which used 103-AW (1986 composite) sludge. The results from NCRW-48 are more straightforward and will be discussed first.

The undissolved residues from NCRW-48 were recovered (after being washed well with water) from the filter and were first added to water. The water was then removed and $0.3 \mathrm{M} \mathrm{HNO}_{3}$ was added to perform some settling studies before the solids were dissolved for analysis. The sulfate concentrations found in the water and $0.3 \mathrm{M} \mathrm{HNO}_{3}$ soak solutions ( 1.3 and $1.5 \mathrm{ppm}$ ) were both very close to those measured in blanks ( 1.0 and $2.4 \mathrm{ppm}$, respectively), so it appears to be safe to say that little if any sulfate leached from the solids into the soak solutions. Half of the solids were then dissolved in $2 \mathrm{M} \mathrm{HCl}+0.2 \mathrm{M} \mathrm{HF}$; this solution was analyzed to contain $28 \mathrm{ppm}$ sulfate, but a blank containing the same concentrations of $\mathrm{HCl}$ and $\mathrm{HF}$ showed $25 \mathrm{ppm}$ sulfate. Based on this highly uncertain difference of $3 \mathrm{ppm}$ sulfate, and assuming that $5 \%$ of the initial $\mathrm{Zr}$ remained in the undissolved residue as indicated by the previous work (Appendix $C$ ), the mole ratio of sulfate to $\mathrm{Zr}$ in the residue was $\sim 0.004$. While this value is very uncertain, it is also very comforting because it is an order-of-magnitude lower than the "limit" calculated as discussed above. 
The calculated limit would not be exceeded even if none of the sulfate found had been introduced with the $\mathrm{HCl}$ and/or HF used to dissolve the residue.

The sulfate results obtained in NCRW-42, with 105-AW sludge, were not straightforward. Following settling studies at different $\mathrm{HNO}_{3}$ concentration in this experiment, the solution was diluted to $0.6 \mathrm{M} \mathrm{HNO}$ and the solids were

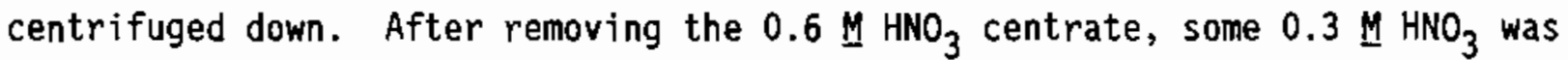
added to the solids and the settling study was performed. The solids were then dissolved and the samples were analyzed. However, the initial analytical results did not look reasonable (for one thing, the $0.6 \mathrm{M} \mathrm{HNO}_{3}$ solution was reported to contain the identical concentration of sulfate as did the solution of the dissolved residue), so the samples were submitted again (after some necessary dilutions). The second set of data gave much lower sulfate concentrations throughout; in fact, the solution of the dissolved residue was reported to contain less sulfate than the blank. Thus, no sulfate-to-Zr ratio can be given for this experiment.

If the high initial analytical results for the NCRW-42 samples are accepted, which is not thought to be appropriate, the sulfate-to-zr mole ratio in the residue was 0.35 including the amounts reported for the dilute acid soak solutions but only 0.06 if those amounts are excluded. Another experiment should probably be done to verify this feeling, but it is thought to be highly likely that the sulfate concentration in the undissolved residues from 105-AW sludge is also below the limit derived from the reference glass plant specifications.

\section{Fluoride In Undissolved Residues}

The total fluoride concentrations found in the washed residual solids from NCRH-42, with 105-AW (1986 composite) sludge, and from NCRW-48, with 103AW (1986 composite) sludge amounted to $2 \times 10^{-5}$ and $4 \times 10^{-5} \mathrm{~g} F$ /initial g sludge, respectively. Assuming that these residual solids contained $5 \%$ of the $\mathrm{Zr}$ initially present in the sludge, as indicated by the previous work (Appendix C), these amounts correspond to. 0.02 and 0.04 mole $\mathrm{F} / \mathrm{mole} \mathrm{Zr}$ in the residual solids, respectively. These values are both well below the allowed level of 0.4 mole $\mathrm{F} / \mathrm{mole} \mathrm{Zr}$ in the feed to the glass plant. 


\section{Carbon In Undissolved Residues}

The total carbon concentrations found in the washed residual solids from NCRW-42, with 105-AW (1986 composite) sludge, and from NCRW-48, with 103-AW (1986 composite) sludge amounted to $4.7 \times 10^{-4}$ and $6.6 \times 10^{-5} \mathrm{~g} \mathrm{C} /$ initial $\mathrm{g}$ sludge, respectively. Assuming that these residual soljds contained $5 \%$ of the Zr initially present in the sludge, as indicated by the previous work (Appendix C), these amounts correspond to 0.9 and 0.1 mole $\mathrm{C} /$ mole $\mathrm{Zr}$ in the residual solids, respectively. These values are both below the allowed level of 1 mole $\mathrm{C} /$ mole $\mathrm{Zr}$ in the feed to the glass plant, although the value with 105-AW sludge is uncomfortably close. Most $(-80 \%)$ of the carbon attributed to the residue in that experiment was found in the first acid soak solution, which is surprising. Another experiment may be in order to address this question, also.

A point to be remembered is that the carbon content of the undissolved residue might need to be very low so that the amount of carbon allowed in the melter feed will not be surpassed by that present as entrained solvent in the Pu+Am stream from the TRUEX operation.

Chloride In Undissolved Residues

No precipitate was observed when silver ion was added to the dissolved (in nitric + oxalic acids) residue from the primary sludge dissolutions step in experiments NCRH-42 and -48. Thus, the level of chloride in these residues is below the detection limit and should be of no concern in the vitrification step.

\section{SOLVENT EXTRACTION STUDIES}

Solvent extraction studies have not been pursued extensively since the last report because of the higher priority assigned to the other areas of study. However, some observations of interest have been made.

Interfacial crud was not observed in extraction contacts with three recently prepared dissolved sludge solutions, although some precipitate appeared to form in the aqueous phase with one of the solutions. These solutions all had higher free acid concentrations than those reported earlier, 
which may (or may not) have helped avoid the crud formation. This is an area that definitely needs more work.

Another test investigated the possible effect of sulfate (the reaction product of sulfamic acid, which might be used to minimize $\mathrm{NO}_{x}$ releases) in the extraction step. The presence of $0.05 \mathrm{M} \mathrm{H}_{2} \mathrm{SO}_{4}$ in the dissolved sludge solution from NCRW-43 did not suppress the extraction of either Pu or Am (the extraction of Am appeared to be markedly higher, but more data are needed before a positive statement can be made).

Recent experiments regarding scrubbing of the organic extract of the dissolved sludge solution have centered around the desire to find a way to scrub zirconium without using oxalate-containing solutions (which work very well, but which have the possibility of leading to precipitate formation during the process, which is undesirable). The use of HEDPA instead of oxal ic acid as a complexant (in $1.5 \underline{\mathrm{M} \mathrm{HNO}} 3+0.05 \underline{\mathrm{M}}$ complexant) gave a much worse precipitation problem than had been obtained with oxalate. Another complexant that reportedly (E. P. Horwitz of Argonne) forms highly soluble $\mathrm{Zr}$ complexes has been obtained, but not yet tested; this complexant is tetrahydrofurantetracarboxylic acid. The lack of precipitate formation in the extraction test with sulfate suggests that sulfate might also be tested as a scrubbing agent.

Addition of fluoride to enhance $\mathrm{Zr}$ scrubbing was found to be quite effective. Three scrub contacts with $0.5 \mathrm{M} \mathrm{HNO}_{3}+0.1 \mathrm{M} \mathrm{HF}$ and $0 / \mathrm{A}=3$ decreased the $Z r$ content of an organic extract of NCRW- 42 by a factor of -100 , from $0.026 \underline{M}$ (11\% of the $Z r$ in the dissolved sludge solution) to $2.2 \times 10^{-4} \underline{M}$. In a similar experiment (NCRW-41) with no fluoride in the scrub solution, the $\mathrm{Zr}$ content of the extract was decreased by a factor of only -3 . The fluoride added to the scrub in NCRW-42 amounted to only $-6 \%$ of that al ready present in the feed; that increase is felt to be inconsequential. However, use of a fluoride-containing scrub solution would also require use of additional scrub stages to remove fluoride from the solvent unless some other process is employed to separate the fluoride from the Pu and Am feed to the vitrification process. 
$+$ 


\section{DISTRIBUTION}

No. of

Copies

2 DOE/Office of Scientific and Technical Information

12 Westinghouse Hanford Company

J. N. Appel, R2-07

S. A. Barker (3), R2-07

W. B. Barton, S6-70

M. A. Cahill, R3-46

M. J. Horhota, S1-53

J. R. Jewett, I6-50

S. S. Lowe, R2-07

D. J. Newl and, $\mathrm{Nl}-35$

R. M. Orme, R2-07

D. E. Place, S6-70

1 DOE Richland Operations office

M. Dev, A5-21
No. of

Copies

34 Pacific Northwest Laboratory

L. M. G. Ballou, P7-18

G. H. Bryan, P7-25

J. M. Deal, P7-25

R. E. Einziger, P7-14

B. M. Johnson, K5-02

D. E. Kurath, P7-43

W. W. Laity, K2-15

G. J. Lumetta, P7-25

K. H. Pool, P8-44

R. D. Scheele, P7-25

P. A. Scott, P7-43

L. J. Sealock, K2-10

J. L. Swanson (15), P7-25

M. J. Wagner, P7-25

Publishing Coordination

Technical Report Files (5) 
